\title{
Republic of Moldova: Poverty Reduction Strategy Annual Evaluation Report 2005
}

Poverty Reduction Strategy Papers (PRSPs) are prepared by member countries in broad consultation with stakeholders and development partners, including the staffs of the World Bank and the IMF. Updated every three years with annual progress reports, they describe the country's macroeconomic, structural, and social policies in support of growth and poverty reduction, as well as associated external financing needs and major sources of financing. This country document for the Republic of Moldova, dated 2006, is being made available on the IMF Website by agreement with the member country as a service to users of the IMF website.

To assist the IMF in evaluating the publication policy, reader comments are invited and may be sent by e-mail to publicationpolicy@imf.org.

Copies of this report are available to the public from

International Monetary Fund • Publication Services

$70019^{\text {th }}$ Street, N.W. • Washington, D.C. 20431

Telephone: (202) 623-7430 • Telefax: (202) 623-7201

E-mail: publications@imf.org•Internet: http://www.imf.org

Price: $\$ 15.00$ a copy

\section{International Monetary Fund \\ Washington, D.C.}



GOVERNMENT OF THE REPUBLIC OF MOLDOVA

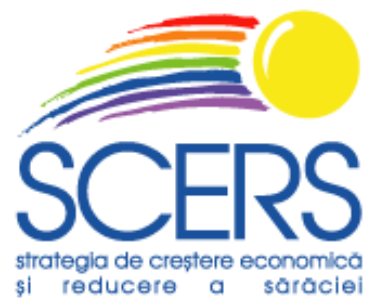

ANNUAL EVALUATION REPORT

ON THE IMPLEMENTATION OF THE ECONOMIC GROWTH AND POVERTY REDUCTION STRATEGY

2005

Chisinau, 2006 


\section{LIST OF ACRONYMS}

\begin{tabular}{|c|c|}
\hline CPAR & Central Public Administration Reform \\
\hline CIS & Commonwealth of Independent States \\
\hline DFID & $\begin{array}{l}\text { Department for International } \\
\text { Development }\end{array}$ \\
\hline EBRD & $\begin{array}{l}\text { European Bank for Reconstruction and } \\
\text { Development }\end{array}$ \\
\hline EFA & Education for All \\
\hline EGPRS & $\begin{array}{l}\text { Economic Growth and Poverty Reduction } \\
\text { Strategy }\end{array}$ \\
\hline FSAP & Financial Sector Assessment Program \\
\hline EU & European Union \\
\hline GDP & Gross Domestic Product \\
\hline GVA & Gross Value Added \\
\hline HBS & Household Budget Survey \\
\hline HIV/AIDS & $\begin{array}{l}\text { Human Immunodeficiency Virus/ } \\
\text { Acquired Immunodeficiency Syndrome }\end{array}$ \\
\hline ILO & International Labour Office \\
\hline IDA & International Development Agency \\
\hline MDG & Millennium Development Goals \\
\hline MET & Ministry of Economy and Trade \\
\hline
\end{tabular}

MEYS Ministry of Education, Youth and Sports MTEF Medium Term Expenditure Framework MMIF Mandatory Medical Insurance Fund NGO Non Governmental Organization

NBM National Bank of Moldova

NBS National Bureau of Statistics

PAR Public Administration Reform

PC Participation Council

PPP Purchasing Power Parity

SDC Swiss Agency for Development and Cooperation

SS State Securities

SSIB State Social Insurance Budget

TAU Territorial Administrative Unit

TB Tuberculosis

VAT Value Added Tax

UNICEF United Nations Children's Fund

UNDP United Nations Development Program

USSR Union of Soviet Socialist Republics 


\section{TABLE OF CONTENTS}

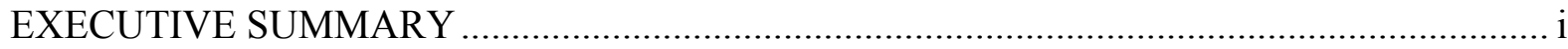

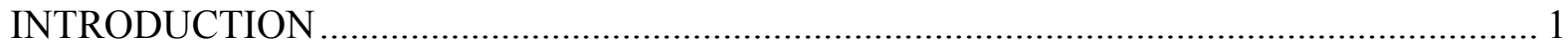

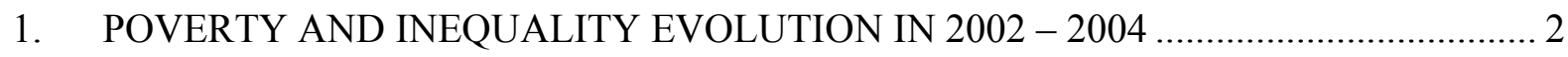

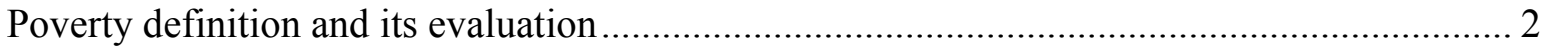

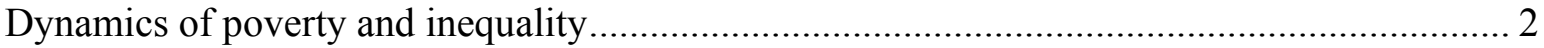

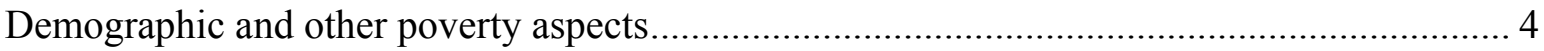

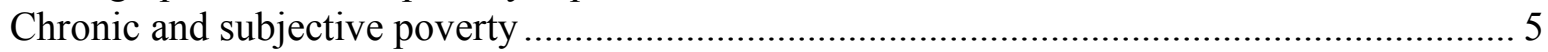

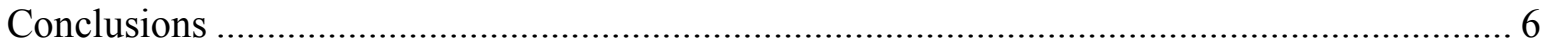

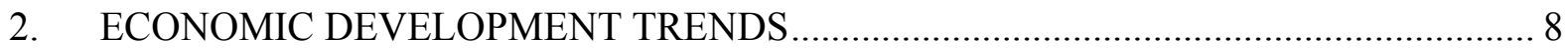

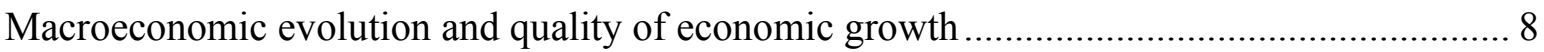

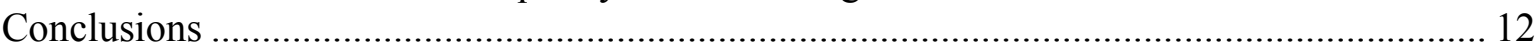

The evolution of revenues and expenditures. Public finance management............................ 13

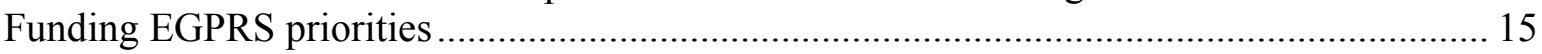

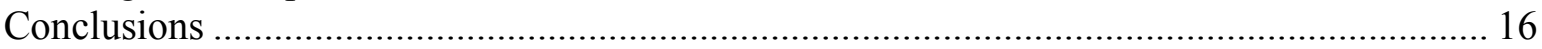

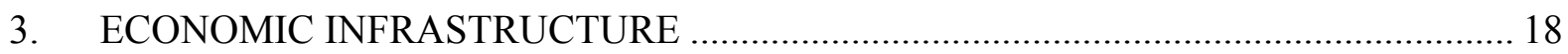

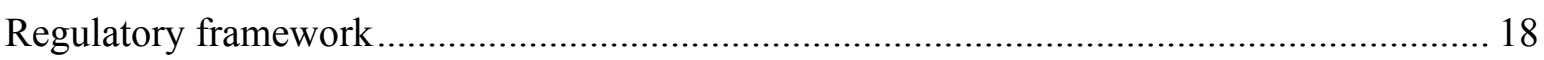

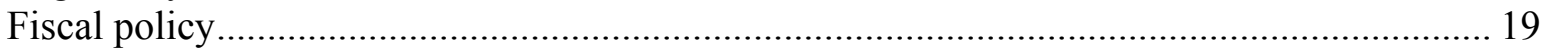

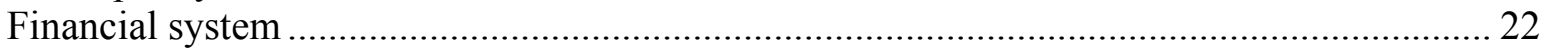

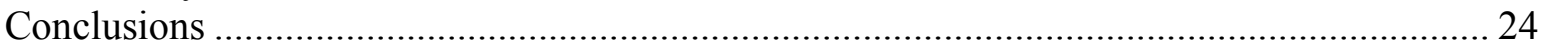

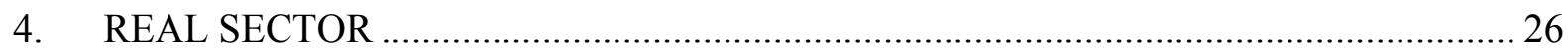

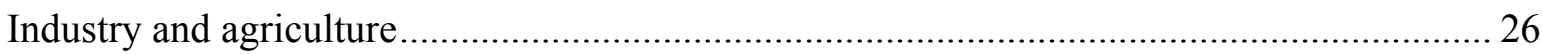

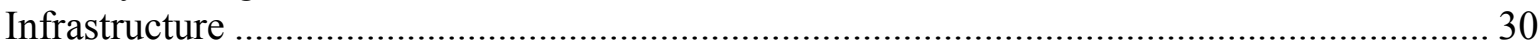

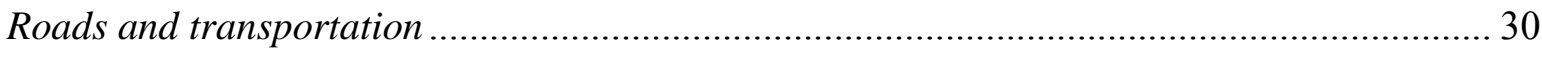

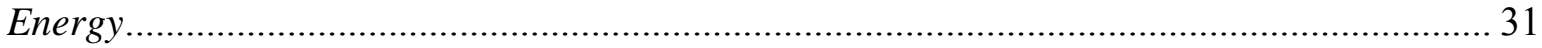

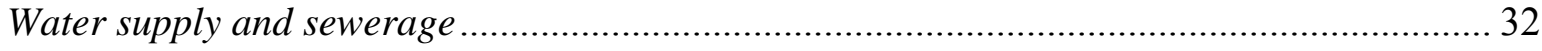

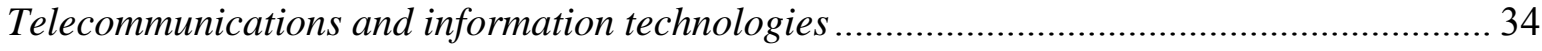

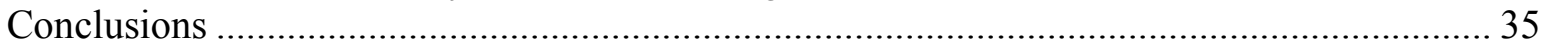

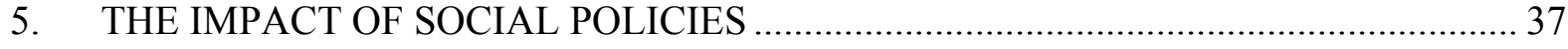

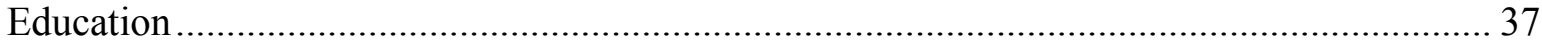

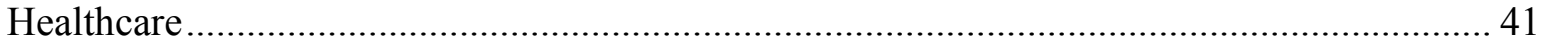

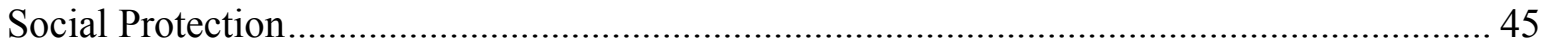

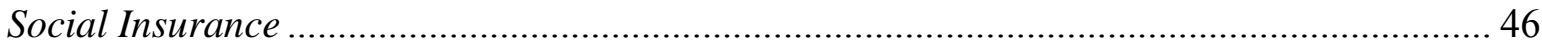

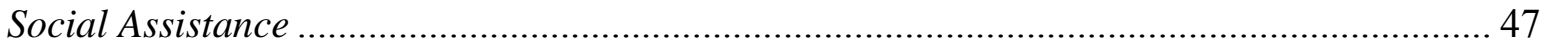

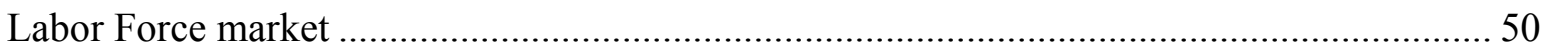

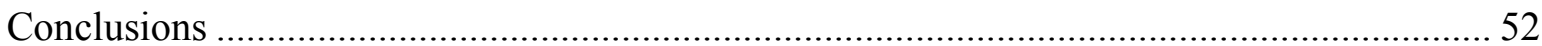

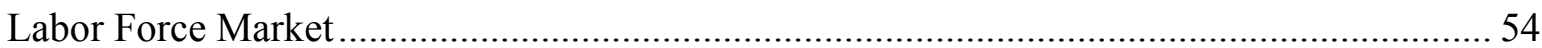

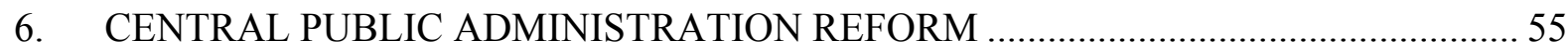

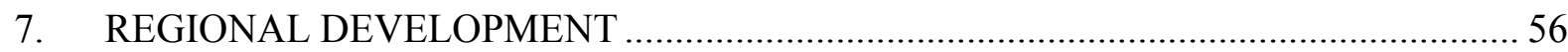

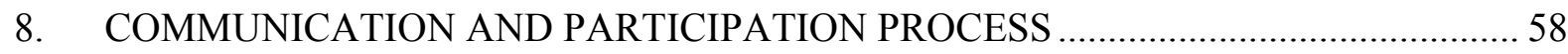

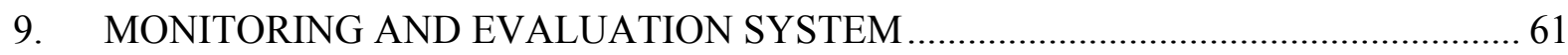

\section{List of tables}

1. Distribution of consumption expenditures between $2000-2004$

2. Accomplishment of MDG poverty indicators

3. Persistent poverty by area of residence, 2001-2004

4. GDP by categories of resources

5. GDP by categories of use 


\section{List of figures}

1. Dynamics of poverty rate between $1998-2004$

2. Relationship Final Consumption - Remittances

3. Relationship Final Consumption - Net Export

4. Inflation rate at the beginning of the year

5. Exchange rate evolution

6. Cash availability

7. Direct net foreign investments dynamics

8. Evolution of public revenues and expenditures

9. Credits granted to economy

10. Industrial growth

11. Net rate of enrolment by educational levels, 2000-2004

\section{Annexes}

- Annex A1: Data and methodology for poverty measurement

- Annex A2: Statistical annexes on poverty

- Annex A3: Government Decision on establishing the Poverty Monitoring System, no. 851, dated 15 August 2005

- Annex B: EGPRS monitoring indicators

- Annex C: Draft Guidelines for EGPRS monitoring and evaluation 


\section{EXECUTIVE SUMMARY}

1. Economic growth and income redistribution policies promoted in the context of Economic Growth and Poverty Reduction Strategy (EGPRS) implementation contributed to higher incomes and improved access of population to social services, which led to higher living standards and poverty reduction. During 2002 - 2004, poverty rates decreased by 14.5 percentage points (p.p.). By 2004, only $26.5 \%$ of the population of the Republic of Moldova was poor, i.e. their welfare was below the absolute poverty line (as compared to $40 \%$ in 2002). The most essential decrease (by 11.4 p.p.) took place in 2002-2003. In this period, extreme poverty decreased considerably (by 11.2 p.p.). However, in 2004 the pace of poverty reduction slowed down.

2. Together with poverty rate, inequality level also reduced. This trend is reflected by the Gini coefficient that measures inequality at country level and income and consumption distribution by quintiles. As a result, in the period of $2000-2004$ the Gini coefficient decreased from 0.38 to 0.36 . However, the downward trend was not so clear and stable, as in the case of poverty rate, inequality remaining at a relatively high level. In 2004 , the richest $20 \%$ of households had over $40 \%$ of the total consumption, while the poorest $40 \%$ benefited from less than $20 \%$ of the total consumption.

3. Economic growth is a pre-condition for higher living standards and poverty reduction. Between 2003 and 2004, the estimated average poverty elasticity to average consumption growth was $2.1 \%$. That means that with each percent of growth, the poverty rate reduces by $2.1 \%$. In 2002-2004, two thirds of reduction of poverty rates (which was empirically decomposed into growth of household consumption and redistribution of consumption between households) can be attributed to consumption growth, and one third is due to inequality reduction, i.e. redistribution among households.

4. Under these circumstances, at this stage Moldova manages to achieve the intermediary targets for poverty reduction identified in the Millennium Development Goals, whereas the slowdown of the poverty reduction pace raises concern.

5. The statistical results relating to the socio-economic development revealed a number of increasing trends in most sectors of the national economy in 2005. The GDP increased by $7.1 \%$ as compared to the previous year versus $5 \%$ provided in the EGPRS. Consequently, starting with the year 2000 the GDP increased by over $43 \%$. In 2005, the GDP per capita exceeded US $\$ 860$. However, the structure of growth has not improved and some challenging trends in the country's macroeconomic development were not overcome. Economic and investment growth took place in the context of slow restructuring of the national economy, reduction of the growth rate in industry and agriculture. The accelerated growth of import led to higher share of net production and import duties in GDP, while the share of the gross value added in the GDP decreased.

6. An encouraging trend in 2005 was the increase of gross capital formation (by $11 \%$ ), which exceeded both the final consumption growth (by 9.5\%) and the GDP growth as a whole (by 7.1\%). At the same time, the impact of this indicator on the GDP growth increased from 2.4 to $2.9 \%$, while the input of the final consumption increased from 2.2 to $9.9 \%$. The increased demand, which was primarily generated by the increased inflow of monetary income from abroad as well as by increased domestic income, in the context of insufficient domestic production in terms of quantity and structure, led to increased imports. Given that exports increased less than imports, and the rate of growth of revenues of Moldovan citizens working 
abroad decreased (by $29 \%$ vs. $45 \%$ in 2004), the current account deficit increased considerably (from $2.7 \%$ in 2004 to $9.8 \%$ in 2005).

7. The high level of remittances (30\% of GDP), import growth (77.5\% of GDP), trade balance deficit (39\% of GDP) and the current account deficit ( $9.8 \%$ of GDP) testify to a higher dependency of economic growth and the overall economic situation on external factors. Under these circumstances, and given the deficient economic reform and low level of investments, the country's external vulnerability increases, and the perspective of sustainable economic growth and poverty reduction can become uncertain unless immediate actions are taken in order to improve the current situation.

8. In December 2005, the inflation rate was $10 \%$ as compared to December 2004, showing a decrease by 2.5 p.p., as compared to the same period of 2004 . The reduction of the overall inflation rate was caused by the reduction of the food price growth rate by 4.4 p.p. and tariffs for services - by 5.2 p.p. At the same time, the non-food price growth rate increased by 3 p.p.

9. Another element of macroeconomic stability is the implementation of a fiscal and budget policy that ensures a balance between budget revenues and expenditures. The efforts of improving mid-term financial planning, tax administration, and financial discipline created premises to execute the budget for 2005 at $100.6 \%$ for revenues and $92.7 \%$ for expenditures. In revenues formation, direct taxes constituted $35.9 \%$, whereas indirect taxes $-44.1 \%$. In the structure of indirect taxes, VAT represents the highest share of $71.3 \%$, of which VAT for the imported goods is $88 \%$. Thus, consumption and import taxes still represent the main base for public revenues, and this cannot be considered as a budget sustainability element.

10. Improvement and extension of MTEF contributed to a better resource allocation. In 2005 social sectors still had the highest share in public expenditures - $63.2 \%$, of which social insurance and assistance $-30.3 \%$, education $-19.4 \%$, health care $-11.3 \%$. About $14.1 \%$ of the public expenditures were made by economic sectors. Despite these developments, the expenditure framework for some sectors was not totally adjusted to the EGPRS priorities. Thus, expenditures for public investments and economic services, that could facilitate economic growth, remained limited.

11. In Moldova, economic growth is still dependent on the consumption growth. Consumption is mainly satisfied by imports and is mainly financed from remittances. Respectively, the maintenance and acceleration of the current growth rates can be ensured by changes in its structure in terms of transforming the productivity factor into the driving force of growth. Consequently, the increased productivity and competitiveness of the national economy, have to be ensured by continued and enhanced structural reforms, and namely by: (a) further simplification and optimization of the regulatory framework; (b) ensuring stability of the legislative and fiscal frameworks; (c) rehabilitating infrastructure, by promoting the publicprivate partnership, and by increasing public investments, (e) divestiture and efficient use of assets, which are still in public property, (d) improving access to finance.

12. The State Regulatory Reform, initiated by the Government in 2004 and continued throughout 2005, aims at creating an open, flexible and cost-effective business environment, which will facilitate investments and innovations in business. In the period 2004-2005, a number of actions were undertaken to: (a) simplify and centralize the licensing procedure, (b) optimize the registration procedure, (c) reduce conflicts of interest between the role of inspections and the role of testing the control agents. The Law on revising and optimizing the regulatory framework for the entrepreneurial activity (regulatory guillotine) was developed and 
implemented. This allowed for a significant reduction in the number of normative acts that regulate the entrepreneurial activity and reduced the cost of authorization documents.

13. The experience of the first phase of the regulatory reform, as well as the experience of other countries in this field, testifies to the need to transform the regulatory reform into a continued, comprehensive and systematic effort, which will cover the entire Government, and which will be supplemented with sector-specific reforms. A successful implementation of this complex reform depends to a great extend on the level of commitment of different local and central public institutions, some of which show lack of will to ease the regulatory burden or to give away additional income earned under the current system.

14. In order to diminish the tax burden on the business environment and identify those who are acting in the shadow economy, the share of income tax for legal entities was reduced from $18 \%$ in 2005 to $15 \%$ in 2006 . Starting with 2006 , agricultural producers are exempted from a number of taxes for a period of five years and have to pay only the land tax (the amount of the annual share is maintained), the VAT (if the turnover exceeds the amount of MDL 200 thou. per year) and the contributions to the state social insurance budget. Overall, the fiscal pressure as the share of fiscal revenues in GDP for 5 years evolved as follows: in $2000-24.6 \%$; in $2001-$ $24.2 \%$; in $2002-25.6 \%$; in $2003-27.3 \%$; in $2004-29.5 \%$; in $2005-31.9 \%$. The tax burden in Moldova is relatively low as compared that of the countries in the region. At the same time, given that the process of defining the fiscal system has not been finalized, a sufficient level of stability cannot be ensured.

15. The absolute indicators relating to the operation of the banking system are compliant with the economic development of the country in 2005 and this creates, in principle, relevant monetary conditions. Given that the nominal GDP increased by $14.7 \%$, the total assets of the banking system increased by $35.4 \%$, the monetary mass in MDL (M2) increased by $36.7 \%$, credit allocations - by $35 \%$, and deposits - by $40 \%$. As a result, the ratio of assets in the banking system to GDP went up from $42 \%$ in 2004 to $49 \%$ in 2005 . The economy monetization level also increased.

16. At the same time, some of the qualitative characteristics of the banking activity deteriorated and the economy crediting level remained low. Assets return rate as well as banking activity efficiency decreased. The dynamic of interest rates for credits does not fully meet the objective to considerably increase investments and does not lead to increasing the crediting level to the desired extent and for longer terms. The share of bank credits in the total investments in fixed capital has decreased from $4.8 \%$ in 2004 to $2.7 \%$ in 2005 . In this situation, without accelerating economic reforms and diversifying the banking system, the reduction of interest rate can lead to the reduction of the rate of return of the banking activity. At the same time, a bigger diversity of the banking products and lower interest rates can be ensured by a more serious competition among banks.

17. Industrial sector has a special role in ensuring the sustainable economic growth. In the last five years, the cumulative industrial growth was $67.5 \%$. Nevertheless, the growth rates in $2004-2005$ went down, amounting to 8.2 and $6.3 \%$ respectively, while the share of this sector in GDP remained at a relatively lower level $-17 \%$. The limited progress of the industrial sector, under the relevant EGPRS objective, accounts for the low performance of exports, which are treated as an „engine" of the sustainable economic development. Both the growth and the structure of industry determine the dynamics and the diversity of exports.

18. The performance of imports is closely related to the development of the real sector of the national economy, and especially the industry. First of all, Moldova inherited a structure from 
the previous economic system that is $70 \%$ dependant on imports. The structural reforms that were implemented from the declaration of independence up to present were not sufficient to change the situation. Thus, more than a half of goods imported to date, especially those that are indispensable for the economic development, cannot be substituted. On the other hand, there is a growth of imports of current consumption goods, such as: chemicals, textiles, foodstuff, drinks and tobacco, plastics, vegetal products, etc. As a result, domestic producers benefit very little from the increased demand, which stimulates economic growth in general. To a great extent, the advantages of this growth are in favour of foreign economies. This testifies to major problems faced in the organization of enterprise activity.

19. The main factors that determine the low performance of domestic enterprises are as follows: deficient corporative management, inadequate productive structures, outdated production capacities and limited access to financial resources. Both legal entities with some state-owned shares and the completely private ones face problems in terms of assets decapitalization.

20. In order to improve the situation, the Government initiated a number of actions to improve the public patrimony management and denationalization. The concept of the Law on management and denationalization of the public patrimony was developed. It identifies the following priorities: enhancement of the public patrimony accounting, optimization of dimensions, structures and methods for the management of public property, especially by introducing corporative management principles. Also, the draft law on amending the law on state enterprises, which is aimed at implementing the corporate management principles in the relevant enterprises.

21. In the same context, the agricultural growth remains to be modest. The agricultural output in 2001-2005 increased by only 16\%. In 2005, the agricultural output increased by only $1 \%$ (in comparable prices) as compared to the previous year. Agriculture is still characterized by the lowest productivity and remuneration level. It represents almost $18 \%$ of GDP and provides jobs to $45 \%$ of the total labour force. However, low productivity and small growth in agricultural sector diminished the perspectives for the rest of the economy. Moreover, agriculture has an important role in the context of poverty reduction, as it represents the core activity for many people who are concentrated close to poverty line.

22. Creation of a favourable environment for economic growth in line with the market economy principles depends, to a great extent, on the infrastructure recovery and development, and namely the road network, water supply system, heating system, energy sector, and telecommunications. Following the declaration of independence, public investments in infrastructure were limited and most of them were provided from external resources.

23. Recovery and maintenance of infrastructure implies high costs, which cannot be fully covered by the national public budget. At the same time, delays in the recovery of infrastructure, on the one hand, is dangerous for the economic and social development, and on the other hand, leads to higher recovery costs in the future. In this situation, efforts should be made to increase public investments, especially in those areas where the private sector is not interested to make investments, as well as to develop alternative financing mechanisms such as private-public partnership.

24. The country's transport network infrastructure was considerably depreciated in the transition period and the current efforts to maintain, recover and build roads are insufficient to upgrade the road network. 
25. Achieving the objective related to ensuring energy security is still a serious challenge. The increase in price for energy resources is directly affecting the low competitiveness of domestic production as well as the population's welfare in general. In the electric energy sector, efforts to increase energy generation capacities failed, the local power stations were not upgraded and the new energy generation capacities were not developed. The heating system, which is the main debtor for gas consumption, is in a more critical situation. In most localities, the heating system faces financial problems, low level of collection, and lack of investments.

26. Water supply and sewerage system reform is being implemented under EGPRS and MDG commitments that envisage "halving the number of people with no sustainable access to potable water by 2015 ", which implies that the share of population with access to sustainable water sources should be increased from $38 \%$ in 2002 up to $47.7 \%$ in 2006 and $68.5 \%$ in 2015 . Actions undertaken to date are not sufficient, and the achievement of objectives in this area is still a challenge.

27. Access to education has been slightly improved during the last few years. The enrolment rates have been stable except for the enrolment in primary school from the rural areas (NBS data). Children from poor households and from rural households go to school at a later age and leave earlier than children from other households. These children start their school career already with a lag when entering primary school as they missed pre-school. .. The main reasons for not going to school in case of 3-16 year-old children are the schools that are not functioning (33\%) and financial difficulties (27\%). Poverty analysis shows that the education level is directly related to the living standards of the individual. Households headed by people without secondary education face a considerably higher poverty risk. As a result, poor children that do not have the possibility to obtain a higher level of education than the mandatory one have all the chances to be poor also in future. In this regard, provision of food to children within education institutions is an effective tool to attract children from poor families in the education system.

28. Moldova made progress in achieving MDG objectives in the health sector. Mortality rate for both infants and children under 5 years decreased both in rural and urban areas. Infant mortality rate reduced from 18.3 per 1000 newborn in 2000 to 12.2 in 2005 , while the underfive mortality rate reduced respectively, from 23.3 per 1000 newborn in 2000 to 15.3 in 2004 . Immunization coverage of children under two amounted to $99.2 \%$ in 2004 . The maternal mortality rate reduced to 23.5 per 100,000 live births in 2004 up to 18.6 in 2005. So far, no considerable progress in decreasing TB-associated mortality rate was noted. Furthermore, the increased HIV/AIDS prevalence is a special concern. An important problem is non-contagious disease prevention, which is the main cause of morbidity, disability and premature death in Moldova.

29. Pension system reform is implemented slowly and the financial stability of the Social Insurance Budget raises concern. Slowdown in the implementation of Individual Records system and lack of motivation system for both the employers and employees does not contribute to improving the situation.

30. The average old-age pension in 2005 was adjusted by $18.2 \%$. The amount of the old-age pension (adjusted to the consumption price index) was 300.9 MDL, and represented an increase by $39 \%$.

31. The social assistance programs have the highest share in the total public expenditures. In the period 2000-2005, the share of transfers to the population in the total discretionary expenditures increased from $28.9 \%$ to $31.6 \%$, and their share in GDP increased from $8.7 \%$ to $10.4 \%$. The performance of social assistance programs was still low over the last years because 
of inadequate targeting of resources. The poverty profile shows that the poverty rate among households, whose main income is obtained from social transfers, is higher than the average poverty rate. $36 \%$ of population that live in such households is poor and $20 \%$ - extremely poor. The households headed by pensioners have a higher poverty risk (31\%).

32. Despite the importance and relevance of regional policies in the context of promotion of sustainable economic growth, the progress achieved in this respect is insufficient. So far, no regional development policy was defined. With the support of the development partners, a study was carried out and a main draft law was developed for a further legal framework in this field. In this context, it is suggested to specify the main functions of different central administrative bodies in the field of regional development. 


\section{INTRODUCTION}

33. This report is the first annual report evaluating the EGPRS implementation since its approval by the Parliament on December 2, 2004. The main purpose of the report is the evaluation of progress made in achieving the set objectives, as well as assessing the trends in economic and social development of the country in general.

34. Besides estimating the degree of completion by the assigned institutions of policies and activities provided in the Strategy, the Report intended to evaluate the relevance, efficiency, effectiveness, sustainability and the impact of these on the development of social and economic indicators. At the same time, the analysis of policies impact is a difficult task. The outcome of most of the policies/activities undertaken can be observed after a period of time that can last several years. In the situation when only a year has passed after the Strategy's approval, it is difficult to obtain measurable results for all the undertaken actions. Accordingly, the report does not consider strictly the period since the approval of the document. It analyses the development in the last two years and for certain phenomena identifies trends for the last five years - the period of economic recovery.

35. Moreover, the Report evaluates, on a selective basis, the fulfilment of the EGPRS commitments. Taking into account the multitude and complexity of the objectives provided in the Strategy, it was not possible to have in this report an in-depth evaluation of all these objectives. The areas were chosen considering the seven priorities identified within EGPRS, as well as considering the importance/relevance of certain areas of activities for achieving the poverty reduction and economic growth objectives in the existent situation. Thus, since poverty analysis shows that two thirds of poverty reduction is due to economic growth, whereas one third - due to redistribution policies, priority was given to the analysis of policies and activities that have a direct impact on economic growth and redistribution between the households.

36. It is necessary to mention, that the current report represents the position of the Government of the Republic of Moldova. However, the evaluations and findings of the report are based on different studies and analysis in the areas covered by the Strategy carried out by development partners, civil society and academia. Also, the report was developed with the support of the UNDP/UNICEF/SDC Joint Programme "Support to Strategic Policy Formulation, Monitoring and Evaluation".

37. The draft Report was presented at the EGPRS National Forum organized on March 23, 2006 with the participation of all interested stakeholders: Parliament, Presidency, central and local public administration, civil society, business community, and Moldova's development partners. The Report was finalized taking into consideration the comments expressed during and after the Forum. 


\section{POVERTY AND INEQUALITY EVOLUTION IN $2002-2004^{1}$}

\section{Poverty definition and its evaluation}

38. The living standard of a household is determined both by the monetary aspect ${ }^{2}$, as well as by the non-monetary factor ${ }^{3}$. In order to measure poverty, two poverty lines have been defined: extreme and absolute poverty lines, identifying poor and the very poor households (Annex A1). Extreme poverty line is based on the minimum ratio of calories per day, and the absolute poverty line makes a supplement for the non-food goods and services to the extreme poverty line. Poverty analysis uses the data from HBS, implemented by the National Bureau of Statistics (NBS). The methodological principles for the evaluation of the absolute poverty line have been identified in the EGPRS.

\section{Dynamics of poverty and inequality}

39. Poverty in Moldova is strongly correlated with economic growth. The evolution of the absolute poverty incidence over time shows that poverty increased sharply from 1998-1999 (Figure 1). Seventy one percent of the Moldovan population was poor in 1999 based on the absolute poverty line. The extremely high poverty incidence in 1999 reflects the serious impact of the Russian financial crisis on Moldova. Since 2000 poverty rates have decreased constantly and by the year 2004, only $26.5 \%$ of the Moldovan population was poor, i.e. their well-being was below the absolute poverty line. The most important decrease has taken place between 2002 - 2003. In this period of time the rate of extreme poverty has also decreased significantly (11.2 p.p.).

40. Other poverty indicators have illustrated similar trends.

Figure 1

Poverty rate dynamics, $1998-2004$ Surse: MEC, based on HBB

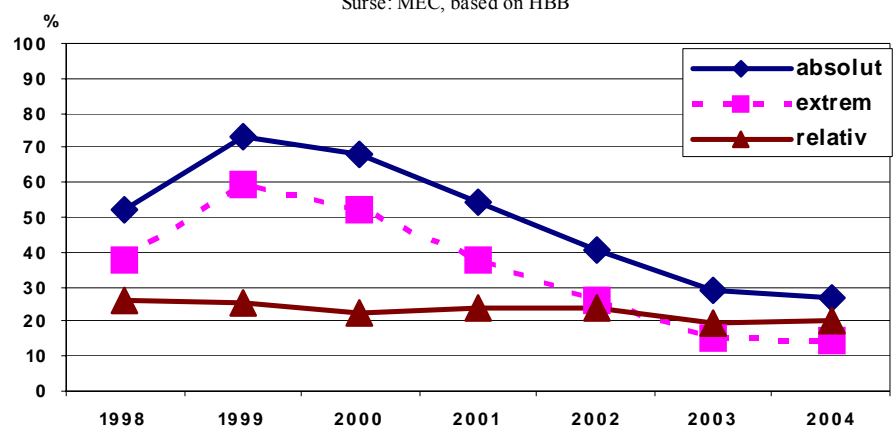

Poverty became deeper and more severe in the period of the economic crisis, but after the economic recovery, the poverty gap (the average gap between expenditures of the poor and the poverty line) and poverty severity (measuring the distance of the poor from the poverty line) started to decrease again (Annex A2).

41. Parallel with declining poverty rates, the level of inequality has been decreasing as well. This trend is reflected in the developments of the Gini coefficient, which is a measure for the level of inequality in the country, and the distribution of income and consumption across quintiles. Thus, between 2000 - 2004, the Gini coefficient has decreased from 0.38 to 0.36 (Table 1). However, inequality remains at a high level in Moldova compared to other countries

\footnotetext{
${ }^{1}$ Poverty evolution is thoroughly analysed in the MET "Poverty and Policy Impact Report" (published on www.mec.md and www.scers.md).

${ }^{2}$ Income and consumption are examples of monetary indicators of poverty.

${ }^{3}$ Examples for non-monetary indicators of poverty are: access to education and medical services, availability, and/or quality of living space.
} 
in the region. ${ }^{4}$ The downward trend is not as explicit and steady as with the poverty rates. The problem of inequality is aggravated by the fact that poor people receive part of their income in kind. Consequently, the access of poor people to goods and services becomes limited. Thus in 2004 , the richest $20 \%$ of households had more than $40 \%$ of the total consumption, and the poorest $40 \%$ of households had less than $20 \%$ of the total consumption. Overt time, the distribution remained quite stable.

Table 1. Distribution of consumption expenditures between $2000-2004^{1}$

\begin{tabular}{|l|c|c|c|c|c|c|}
\hline & $\mathbf{2 0 0 0}$ & $\mathbf{2 0 0 1}$ & $\mathbf{2 0 0 2}$ & $\mathbf{2 0 0 3}$ & $\mathbf{2 0 0 4}$ \\
\hline Share of consumption expenditures by groups of quintiles (20\%) of population: \\
\hline TOTAL & 100 & 100 & 100 & 100 & 100 \\
\hline I Quintile & 6.8 & 6.5 & 6.8 & 7.5 & 7.2 \\
\hline II Quintile & 11.2 & 10.7 & 11.1 & 11.6 & 11.6 \\
\hline III Quintile & 15.3 & 15.0 & 15.6 & 15.7 & 15.7 \\
\hline IV Quintile & 21.5 & 21.6 & 22.2 & 21.6 & 21.5 \\
\hline V Quintile & 45.2 & 46.2 & 44.3 & 43.6 & 43.9 \\
\hline \multicolumn{7}{|l|}{} \\
\hline Gini by consumption expenditures per capita & 0.380 & 0.388 & 0.372 & 0.356 & 0.361 \\
\hline $\begin{array}{l}\text { 90/10 distribution, mean of consumption } \\
\text { expenditures by adult equivalent }\end{array}$ & 10.45 & 10.85 & 9.40 & 8.39 & 9.10 \\
\hline
\end{tabular}

Source: MET, on the basis of HBS

Note: $1 \backslash$ The figures are weighted and representative at the national level

42. There is a close link between the economic growth, inequality and poverty reduction. Between 2002 - 2004, the economic situation of the Republic of Moldova has improved, and poverty has decreased. Economic growth represents the main condition for increasing living standards and achieving poverty reduction. Without economic growth, poverty reduction is extremely difficult. In such situation, just the redistribution of income from richer households to the poorer can result in lower poverty rates.

43. The estimated average elasticity of poverty with respect to growth in average consumption was -2.1 over 2003 and 2004. This means, for each one percent increase in growth, poverty rates fall by $2.1 \%$. This is slightly less than the -2.9 estimated by the World Bank for the period 2000 to $2002 .^{5}$ However, the level of elasticity is comparable with other countries, such as Romania (average of -2 between 1999 and 2001). ${ }^{6}$

44. Between 2002 and 2004, poverty rates (empirically decomposed into growth of household consumption and redistribution of consumption between households) decreased with 14.5 p.p. Two third of this decrease can be attributed to growth in consumption and one third of the poverty reduction is due to lower inequality, i.e. redistribution between households. The greatest poverty reduction occurred in small towns, 18.6 p.p., and is largely due to the increase in the population's consumption $(17.2 \%)$. One sixth of the reduction is due to decrease in inequality. In 2003 - 2004, poverty reduction slowed down and the 2.5 p.p. change from 2003 to 2004 is determined by the decrease in inequality.

45. The Millennium Development Goals for Moldova aim at halving the poverty rate until 2015 , using the international poverty line of 2.15 USD PPP per capita per day. Initially, in order to monitor this objective poverty has been defined in terms of income. Based on the income

\footnotetext{
${ }^{4}$ Gini coefficients for selected other countries: Albania 0.28 (2002), Armenia 0.28 (2001), Romania 0.29 (2002), Georgia 0.36 (2001), Tajikistan 0.33 (2203) (World Bank, 2004: p. 9).

${ }^{5}$ The World Bank (2004), Recession, Recovery and Poverty in Moldova, Report No. 28024-MD, Washington DC: p. 4.

${ }^{6}$ Ibid.
} 
definition, the poverty rates accounted for $27.8 \%$ in 2004 compared with the target of $28 \%$ set for the 2006. However, due to the unreliability of income data collected in the HBS, poverty should be assessed using consumption expenditures. Data on expenditures collected with the HBS represent a more reliable estimate of the welfare level of the population and are preferred for the poverty rates calculation, including for the purpose of monitoring MDG. The table 2 shows the evolution of poverty rates considering both approaches. A preliminary conclusion for this subject is that for the moment Moldova manages to achieve the intermediate targets of poverty reduction, but the slow down of the poverty decrease raises concerns.

Table 2. Poverty Reduction MDG achievement

\begin{tabular}{|l|r|r|r|r|r|}
\hline & $\mathbf{2 0 0 0}$ & $\mathbf{2 0 0 1}$ & $\mathbf{2 0 0 2}$ & $\mathbf{2 0 0 3}$ & $\mathbf{2 0 0 4}$ \\
\hline $\begin{array}{l}\text { International poverty line of 2.15 US dollars PPP per capita } \\
\text { /day (MDL/per capita /month) }\end{array}$ & 167.5 & 183.9 & 193.7 & 216.2 & 239.5 \\
\hline Poverty rate (income per capita ) & 64.5 & 52.4 & 29.9 & 28.9 & 27.8 \\
\hline Poverty rate (expenditures per capita) & 63.5 & 50 & 25.6 & 25.1 & 23.9 \\
\hline Source: MET on the basis of HBS
\end{tabular}

Source: MET on the basis of HBS

\section{Demographic and other poverty aspects}

46. Area of residence, source of income, household composition and the characteristics of the household head are important when determining poverty risk of a household. Considering the area of residence, there are significant differences between the urban and rural areas. The most essential poverty reduction has been registered in the big cities. Poverty risk in the big cities, Chisinau and Balti, is about five times smaller than in small cities and rural areas. Just $7 \%$ of the population of big cities was considered poor in 2004 , compared to one third in the other regions. The consumption level of the households in the big cities is estimated to be $30 \%$ higher than in the rural areas.

47. Households living in small cities are in a less favourable situation. The living conditions in these localities are more difficult, and as a result, each third person was living in absolute poverty in 2004. At the same time, the positive trends in the economic development had a positive impact on the poverty depth, which approached the level of poverty depth in rural areas in 2004.

48. In the rural areas, poverty reduction has stagnated in 2004. Rural residents earn the main income from the agricultural activity and social transfers. Widespread rural poverty is associated with the fact that a considerable share of rural population is involved in the agricultural sector, which is characterized by low labour productivity and reduced incomes. The farmers and the employees in the agricultural sector represent $40 \%$ and $18 \%$ accordingly out of the total poor population in the rural area. Given that in Moldova the majority of the rural households, and about $66 \%$ of the households of small towns, have land plots, the draught from 2003 and the deterioration of the material situation of the rural households in 2004 has generated an increase of extreme poverty ${ }^{7}$.

49. Individuals over 75 years and children have the highest risk of living in poverty. Children living in rural areas face a 2.6 times higher poverty risk than those living in urban areas. Large households and those with many children are also confronted with an increased risk of living in poverty. The poverty rates increase with the number of children present in a household. Forty percent of the households with 3 or more children are considered poor. The

\footnotetext{
${ }^{7}$ The increased prices for fuel also contribute to production expenditures increase, as they constitute the biggest part out of the total expenditures of the agricultural producers.
} 
risk associated with the presence of children in the household is much higher in the rural area than in the urban area.

50. Education represents another factor that influences the level of poverty. Individuals with a higher level of education have a better position in the labour market and frequently earn more than those with lower education. Most of the poor individuals (41\%) are living in households with a head with incomplete secondary or primary education.

51. Employment does not ensure an adequate protection against poverty. Sixty eight percent of the poor live in households whose heads are employed. Persons from households, whose heads are employed in agricultural activities, especially as agricultural workers, are exposed to the highest risk of poverty. Usually, these are unskilled workers whose income is much lower than that of the other socio-economic groups. The poverty risk in the households, in which the social benefits represent the main source of income, is the biggest. More than $36 \%$ of these households are poor.

\section{Chronic and subjective poverty}

52. Based on the analysis of the panel data of the HBS, approximately one third of the sampled households have been chronically poor, and two fifths were occasionally poor in the period of 2001-2004 ${ }^{8}$ (Table 3 ).

53. Chronic poverty is a serious problem, especially in small towns. Over a half of households were chronically poor in the period between 2001-2004. Temporary poverty is a bigger problem in the rural areas. As a result of the research we can observe that $43 \%$ of households were considered poor at least once in four years, even though their average consumption over the period was above the poverty line. Volatility of incomes in the households that are involved in agriculture represents the main factor that explains the relatively high share of temporarily poor households.

Table 3. Persistent poverty by area of residence, 2001-2004, \%

\begin{tabular}{|c|c|c|c|c|c|c|c|}
\hline & \multirow{2}{*}{$\begin{array}{c}\begin{array}{c}\text { Total } \\
\text { households }\end{array} \\
\text { Structure }\end{array}$} & \multicolumn{2}{|c|}{ Chronic Poverty } & \multicolumn{2}{|c|}{ Temporary poverty } & \multicolumn{2}{|c|}{ Non-poor } \\
\hline & & Structure & Incidence & Structure & Incidence & Structure & Incidence \\
\hline Big cities & 13.7 & 5.9 & 13.5 & 10.8 & 31.1 & 26.1 & 55.5 \\
\hline Small cities & 17.5 & 28.8 & 51.7 & 14.9 & 33.8 & 8.7 & 14.6 \\
\hline Rural & 68.8 & 65.3 & 29.7 & 74.3 & 42.6 & 65.2 & 27.7 \\
\hline Total & 100.0 & 100.0 & 31.3 & 100.0 & 39.5 & 100 & 29.2 \\
\hline
\end{tabular}

Source: MET, on the basis of HBS panel data

54. The chronic poverty risk increases with the number of children in the household. About 6 out of 10 households with 3 or more children lived in chronic poverty during the research period. Households of this kind are about two times more exposed to chronic poverty, than those who have one child or no children at all. The biggest temporary poverty incidence rate is for households with two children and households with no children. About $44 \%$ out of the households with 2 children, had on average consumption expenditures level higher than the poverty line, but were at least once poor in 4 years.

55. In order to provide a comprehensive assessment of poverty in the Republic of Moldova, the subjective perception of the population has been evaluated as well. Approximately $46 \%$ of

\footnotetext{
${ }^{8}$ In order to differentiate chronic poverty from the temporary poverty, we have used the categories described by Hulme and Sheperd (2003). Chronically poor households are households that have been poor in every year (persistently poor) and households whose average consumption level over the four years has been below the average poverty line (usually poor). Temporarily poor households (transient poverty) have been poor at least once during the four-year period, but have an average consumption level higher than the poverty line.
} 
the interviewed households were considering themselves poor in 2004. In rural areas more households consider themselves poor (48\%) than in the urban area (43\%), confirming the results of the quantitative analysis. Nevertheless, the difference is much smaller in the context of the subjective method.

56. Subjective poverty rates are higher than those based on monetary evaluation of poverty. Seventy five percent of the households that consider themselves poor are not poor according to the monetary indicator. Twenty nine percent of the households, that consider themselves not poor, are objectively poor. Clearly, the subjective perception of the living standard is a relative concept that depends also on other factors besides the monetary welfare.

57. For the majority of respondents the notion of poverty, regardless of the place of residence or if they are considering themselves as poor or not, is associated with low income (78\%). Bad health, insufficient nutrition, bad living conditions, low educational level and economic security, are other aspects related with the subjective perception of poverty.

\section{Conclusions}

58. Economic growth policies and income redistribution undertaken in the context of EGPRS implementation have contributed to the increase in income and improved access of population to the social services.

59. The overall trend of decreasing poverty and inequality continued in 2004. Twenty seven percent of the population lived in absolute poverty in 2004, with a level of welfare of less than MDL 328 per month per adult. Each seventh citizen (15\%) can be considered to be extremely poor, which means that his/her consumption was below the extreme poverty line of MDL 257 per month. Inequality rates have reduced, but to a smaller extent and not as constant as the poverty rates. As for the moment, Moldova is accomplishing the intermediary targets of poverty reduction set in MDGs, but the slowdown of poverty reduction pace in 2004 raises concerns.

60. Poverty is strongly correlated with economic growth. Over the period of $2002-2004$, poverty rates decreased with 14.5 percentage points. About two third of the decrease in poverty rates can be attributed to economic growth, and one third to redistribution between households. The redistribution from wealthier to poor households also contributed to the reduction of poverty, especially in rural areas, while economic growth was more important in small towns for the decrease in poverty.

61. The poverty profile of Moldova is characterized by large differences between urban and rural areas. Poverty reduction in rural areas stagnated in 2004. It even slightly increased. The slowdown of poverty reduction in rural areas as observed in 2004 can be mainly attributed to negative growth of household consumption. The drought in 2003 had a detrimental impact on farming households and is most probably the main factor underlying the disappointing poverty developments in rural areas. The poverty risk in the two main cities, Chisinau and Balti, is almost five times less than in small towns and rural areas. Only seven percent of the population living in the big cities was poor in 2004, compared to one third in the other regions.

62. Children and the very old people $(75+)$ are the most vulnerable groups. They have a higher poverty risk than the rest of the population. Especially vulnerable are infants living in rural areas. This needs to be taken into account when promoting social protection policies targeted to the poor.

63. One third of the population was chronically poor between 2001 and 2004. Forty percent could be considered to live in transitory poverty, which means that they have been poor at least 
once during one year. In small towns, more than half of the population is chronically poor, and one fourth was chronically living below the extreme poverty line. This applies only to $13 \%$ of the population in the two major cities.

64. Poverty is not deep and most of the households are concentrated close to the poverty line. Accordingly, promotion of certain efficient policies targeted towards the poor people can have a significant impact in achieving the poverty reduction objectives. 


\section{ECONOMIC DEVELOPMENT TRENDS}

\section{Macroeconomic evolution and quality of economic growth}

65. Statistics with regard to socio-economic development show the maintenance of economic upward trends in most sectors of national economy in 2005. The base case scenario of the forecast set out in the EGPRS suggested a 5\% increase of the Gross Domestic Product (GDP) in 2005. In reality GDP reached MDL 36.7 billion, 7.1\% more (in comparable prices) compared to the previous year. Starting with 2000, GDP growth exceeded $43 \%$, while during 1992-1999 it decreased by almost 60\%. In 2005, the GDP per capita exceeded US\$860 ${ }^{8}$.

66. In 2005, gross value added (GVA), i.e. GDP production component, increased by $4.5 \%$, while taxes on products and imports increased by $22.5 \%$ (Table 4). Import taxes accounted for the largest share. The value added in the area of goods production increased by $2.9 \%$, and by $5.1 \%$ in services rendering area.

Table 4. Gross Domestic Product by categories of resources

\begin{tabular}{|c|c|c|c|c|c|c|c|c|c|c|c|c|}
\hline & \multicolumn{6}{|c|}{ Growth } & \multicolumn{6}{|c|}{ Structure } \\
\hline & 2000 & 2001 & 2002 & 2003 & 2004 & 2005 & 2000 & 2001 & 2002 & 2003 & 2004 & 2005 \\
\hline Gross value added & 100.3 & 105.8 & 106.5 & 104.2 & 108.3 & 104.5 & 87.5 & 88.0 & 87.3 & 85.2 & 85.9 & 83.6 \\
\hline Goods - total & 105.8 & 107.2 & 102.7 & 101.2 & 114.0 & 102.9 & 41.7 & 41.1 & 38.3 & 35.9 & 34.7 & 31.2 \\
\hline Agriculture & 102.3 & 107.4 & 105.1 & 89.1 & 120.4 & 101.8 & 25.4 & 22.4 & 21.0 & 18.3 & 17.6 & 14.3 \\
\hline Industry- total & 110.8 & 107.0 & 99.8 & 116.0 & 107.4 & 104.1 & 16.3 & 18.7 & 17.3 & 17.6 & 17.1 & 17.0 \\
\hline Processing industry & 115.9 & 105.5 & 102.9 & 117.8 & 107.8 & 102.2 & 14.2 & 15.8 & 14.9 & 15.4 & 14.5 & 14.5 \\
\hline Electricity, gas, water & 93.6 & 117.0 & 80.5 & 103.0 & 100.9 & 115.4 & 1.9 & 2.7 & 2.2 & 1.9 & 2.2 & 2.1 \\
\hline Services - total & 90.2 & 104.8 & 109.4 & 107.1 & 104.0 & 105.1 & 48.2 & 49.2 & 51.0 & 51.6 & 53.5 & 54.4 \\
\hline Construction & 69.7 & 124.5 & 105.7 & 116.7 & 127.4 & 101.0 & 2.7 & 3.1 & 2.9 & 2.9 & 3.4 & 3.5 \\
\hline Trade & 76.1 & 100.9 & 103.4 & 106.4 & 95.9 & 102.1 & 12.5 & 12.0 & 11.0 & 10.7 & 10.6 & 10.6 \\
\hline Transportation and communications & 121.4 & 109.1 & 109.4 & 109.0 & 105.2 & 106.8 & 9.5 & 10.4 & 10.0 & 10.8 & 11.8 & 12.1 \\
\hline Financial intermidearies services & 46.4 & 110.2 & 101.2 & 122.7 & 102.9 & 91.8 & -2.4 & -2.3 & -2.1 & -2.3 & -2.3 & -2.0 \\
\hline Net taxes on products and imports & 117.2 & 108.6 & 117.7 & 123.4 & 102.1 & 122.5 & 12.5 & 12.0 & 12.7 & 14.8 & 14.1 & 16.4 \\
\hline GROSS DOMESTIC PRODUCT & 102.1 & 106.1 & 107.8 & 106.6 & 107.4 & 107.1 & 100.0 & 100.0 & 100.0 & 100.0 & 100.0 & 100.0 \\
\hline
\end{tabular}

67. GVA growth in agriculture decreased from $20.4 \%$ in 2004 to $1.8 \%$ in 2005 and that of industry decreased from $7.4 \%$ down to $4.1 \%$. In electricity, gas and water supply sectors, GVA increased by 14.5 , transportation and communications sectors registered a $6.8 \%$ increase, and processing industry, agriculture and constructions increased by $2.2 \%, 1.8 \%$ and $1 \%$ respectively.

68. The irregular evolution of GDP components led to changes in its structure. Due to an increase of $16.4 \%$ of taxes weight in GDP, the share of production sector reduced from $88 \%$ in 2000 to $83.6 \%$ in 2005 , of which the share of goods production shrank from 42 to $31 \%$, whereas the share of services increased from 48 up to $54 \%$.

69. A positive trend is the growth of gross capital formation (11\%), which exceeded both final consumption growth (9.5\%) and the increase of GDP (7.1\%). At the same time, the impact of this indicator on GDP growth increased from 2.4 up to $2.9 \%$, i.e. by 0.5 p.p., while the contribution of final consumption increased from 2.2 to $9.9 \%$, i.e. by 7.7 p.p. The absolute growth of final consumption exceeded GDP growth by $40 \%$, while domestic demand (final consumption and gross capital formation) increased almost twofold. From 2000 until present,

\footnotetext{
${ }^{8}$ The revised figure of population according to census data from 2004 was used for calculations in the report.
} 
the growth of final consumption and domestic demand exceeded the GDP growth on average by $12 \%$ and $13 \%$ respectively (Table 5 ).

70. While the growth of public and private administration final consumption is largely due to the introduction of the medical insurance system, the increase of final household consumption was largely due to money transfers from Moldovan citizens working abroad and, to a smaller extent,

\begin{tabular}{|l|r|r|r|r|r|r|}
\hline \multicolumn{7}{|c|}{ Table 5. Gross Domestic Product growth by categories of use } \\
\hline & $\mathbf{2 0 0 0}$ & $\mathbf{2 0 0 1}$ & $\mathbf{2 0 0 2}$ & $\mathbf{2 0 0 3}$ & $\mathbf{2 0 0 4}$ & $\mathbf{2 0 0 5}$ \\
\hline Total final consumption & $\mathbf{1 1 7 . 2}$ & $\mathbf{1 0 4 . 4}$ & $\mathbf{1 0 9 . 7}$ & $\mathbf{1 1 5 . 4}$ & $\mathbf{1 0 2 . 0}$ & $\mathbf{1 0 9 . 5}$ \\
Final household consumption & 120.7 & 106.1 & 105.9 & 118.5 & 106.2 & 110.1 \\
Final consumption of public & & & & & & \\
and private administration & 100.4 & 94.2 & 131.4 & 103.2 & 83.8 & 106.3 \\
Gross capital formation & $\mathbf{1 1 1 . 9}$ & $\mathbf{1 0 5 . 2}$ & $\mathbf{1 0 1 . 1}$ & $\mathbf{1 1 3 . 5}$ & $\mathbf{1 1 0 . 5}$ & $\mathbf{1 1 1 . 0}$ \\
Gross fixed capital formation & 91.3 & 117.3 & 105.7 & 118.6 & 108.2 & 110.2 \\
Net export & $\mathbf{2 2 4 . 6}$ & $\mathbf{9 8 . 5}$ & $\mathbf{1 0 9 . 1}$ & $\mathbf{1 4 8 . 8}$ & $\mathbf{9 1 . 8}$ & $\mathbf{1 1 8 . 8}$ \\
$\quad$ Export & 109.5 & 117.2 & 119.0 & 119.2 & 111.0 & 117.6 \\
$\quad$ Import & 132.3 & 110.6 & 115.7 & 128.7 & 103.6 & 118.1 \\
\hline GROSS DOMESTIC & & & & & \\
PRODUCT & $\mathbf{1 0 2 . 1}$ & $\mathbf{1 0 6 . 1}$ & $\mathbf{1 0 7 . 8}$ & $\mathbf{1 0 6 . 6}$ & $\mathbf{1 0 7 . 4}$ & $\mathbf{1 0 7 . 1}$ \\
\hline
\end{tabular}
due to a $20 \%$ increase in the average wage (Figure 2). According to preliminary data of the balance of payments for 2005, remittances of citizens working abroad made up US\$890 million ( $30 \%$ of GDP versus $27 \%$ in the previous year), which is a $29 \%$ increase or US $\$ 188$ million more than the previous year level.

71. The increasing demand that was largely due to the intensification of inflow of remittances from abroad, coupled with insufficient domestic production in terms of volume and structure, resulted in an increase of imports. In the upshot, over $82 \%$ of the increase in the domestic demand is satisfied by growing imports. On the other hand, in 2005 , the amount of domestic and aggregate growth increased to 138 and $191 \%$ of GDP, compared to 130 and $182 \%$ in 2004 . This was only possible due to the increase of Figure 2. Relationship Final consumption -

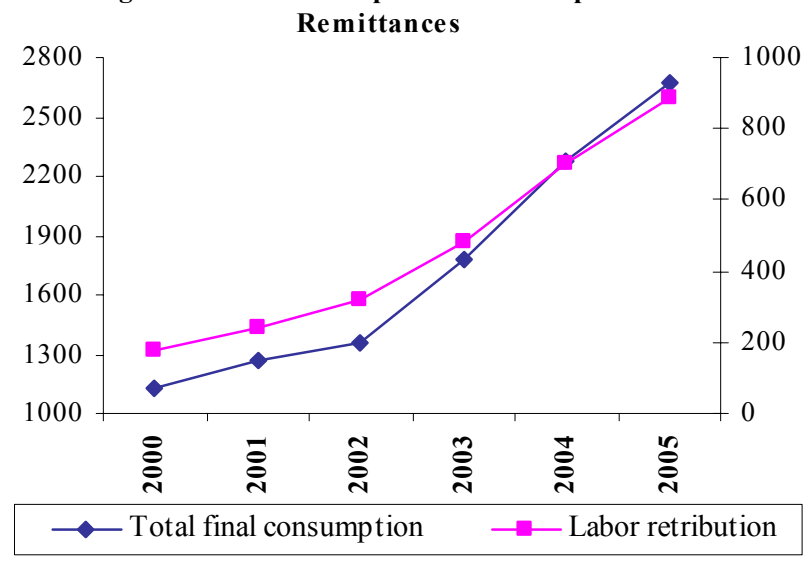
imports, which led to a raise in the negative balance of net exports (Figure 3). During the previous year, the amount of imports in current prices grew by $30 \%$ and increased virtually twice, compared to the GDP growth, while exports increased only by $19 \%$.

72. According to the 2005 balance of payments data, the level of imports of goods and services coverage by exports decreased from $62 \%$ in 2000 and $57 \%$ in 2004 and down to $50 \%$ in 2005 . At the same time, the ratio of trade deficit in the GDP increased from $23 \%$ to $29 \%$ and to $39 \%$ respectively.

73. The modest performance of exports was caused also by difficulties in traditional export markets, like the emergence of additional problems regarding the export of alcoholic beverages to the Russian Federation, i.e. introduction of new excise stamps as well as hold up of agricultural

Figure 3. Ralationship Final consumption - Net export

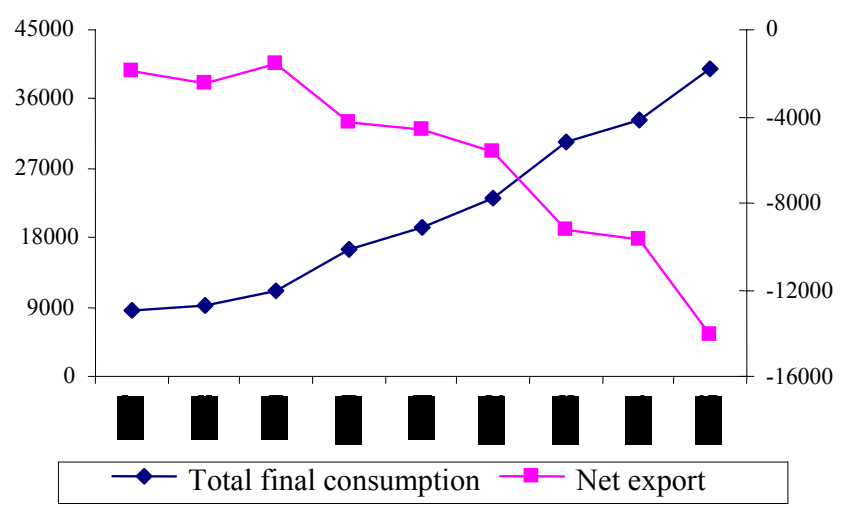


products imports from Moldova. Alongside, high sanitary and phytosanitary norms in European Union countries are an impediment to the export of animal origin products to these countries and Romania. Generally, even though in 2005, exports to European Union countries and to Central and Eastern Europe increased by 9.5 and $15 \%$ respectively, the non-compliance of the national quality system with European standards, a more advanced preferences system and structural funds granted to countries with an advanced level of integration, results in a reduction of Moldovan products competitiveness, both on external and domestic markets.

74. Another factor that on the one hand, contributed to the increase of import value and on the other to the decrease of export competitiveness was the rise in fuel prices. The amount of mineral products (fuel, electricity, etc.) imported in 2005 increased by $31.3 \%$ and accounted for $22 \%$ of total imports. Generally, besides energy sources, the following categories prevail in the structure of imports: automobiles and devices, electric appliances and parts thereof $(13.9 \%)$, products of the chemical industry $(10.1 \%)$, textile items and products $(7.8 \%)$ and common metals (7.0\%). Most of these goods are non-substitutable. However, the large and growing amount of imports has also an objective explanation, as Moldova inherited an economic structure that is dependable on imports in amount of $70 \%$.

75. Another medium term objective is the decrease of inflation aimed at ensuring favorable conditions for free initiative and investment activities, as well as for the protection of population's real incomes. Ensuring a relatively stable price level is a compulsory prerequisite for a sustained economic growth.

76. In April 2005, inflation was 5.5\% higher compared to December 2004 (Figure 4) and exceeded 14\% compared to April 2004. The problem was that from November 2004 until January 2005, inclusively, the NBM purchased more than US\$85 million, increasing the money supply by more than MDL 1 billion. During the first two months of the previous year, money supply increased by $1 \%$ (MDL 117 million) and bank reserves grew by $44 \%$ (MDL 710 million). In this case, there was a great risk of targeting the huge liquidity flow into channels of monetary circulation, thus speeding up the inflationary process.

77. By applying sterilization market tools (issuance of NBM certificates and

Figure 4. Inflation rate at the beginning of the year

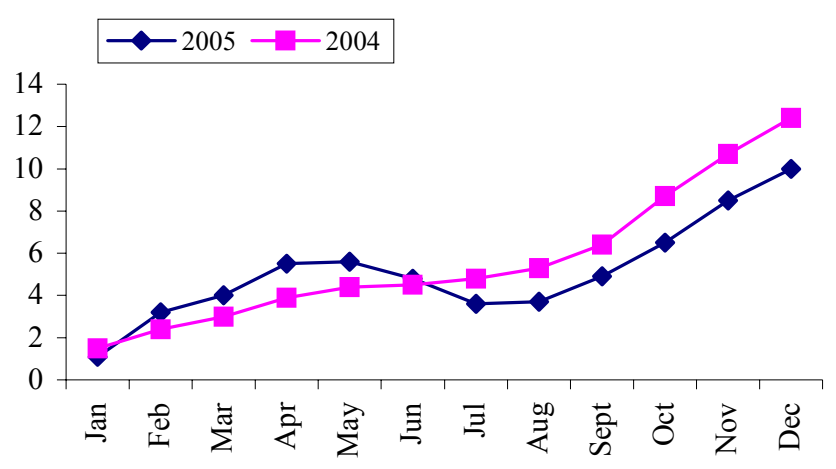
deposit auctions), by June 2005, NBM reduced the currency base and bank reserves by 2 and by $10 \%$ respectively, compared to the beginning of year level. The average monthly amount of financial means attracted in 2005, exceeded MDL 700 million, while throughout the previous year, attracted financial means made up MDL 230 million, including operations with state securities. As a result, inflation climbed down, while the seasonal summer decrease of prices for fruits and vegetables actually created deflation.

78. In December 2005, the inflation rate was $10 \%$ compared to December 2004, registering a 2.5 p.p. decrease compared to the respective period of 2004 . The reduction of the general level of inflation was influenced by a decrease in the growth rate of food products by 4.4 p.p. and that of tariffs for services by 5.2 p.p. Concurrently, the prices for non-food items grew by 3 p.p. 
79. The national currency exchange rate policy is another important factor that defines country's macroeconomic stability. The exchange rate dynamics, which defines the external aspect of national currency stability, is essential, both for economic agents, natural persons and overall economy.

80. NBM policy concerning MDL exchange rate is targeted to the lessening and nonadmission of sudden fluctuations of MDL exchange rate by using indirect tools for the management of monetary liquidity. As mentioned above, the sudden increase of liquidities at beginning of the year caused grave risks with regard to the intensification of inflationary and depreciation processes. An important factor of liquidity growth was the flow of remittances of Moldovan citizens working abroad - a trend that has been in place for a number of years.

81. Although the inflow of foreign exchange during the current year increased, not only was NBM able to control the monetary factors of inflation but it prevented an excessive appreciation of MDL through the purchase of surplus currency. This also helped avoid sudden changes of MDL exchange rate (Figure 5). It was largely due to the use of above mentioned sterilization tools.

82. Throughout the year, NBM purchased more than US\$170 million on the foreign exchange market and issued over MDL 2.2 billion. With all that, in 2005 , the monetary base increased by $31.8 \%$, money supply M2 by $36.7 \%$ and Figure 5. Exchange rate (end of period) the money supply M3 by $35 \%$. At the same time, the national currency depreciated by 3\%. Official foreign exchange reserves at the end of 2005 were at US\$597.4 million covering 2.7 months of imports.

83. Meanwhile, the analysis of the structure and factors of economic growth in Moldova in 2005 shows a large dependence of country's economy on external economic factors. This highlights the particular importance of balance of payments situation and the trends in relations with "the rest of the world". The trade deficit grew by $51 \%$ versus $21 \%$ in 2004 and reached the level of US\$1.1 billion. Consequently, its ratio to GDP increased from 29 to 39\%. If in 2004, the growth of the trade deficit was to a large extent funded on the expense of increasing current incomes and transfers, resulting in a decrease of the current account deficit, the situation changed in 2005. If in 2004 the amount of remittances grew by US\$217 million and the trade balance deficit by US\$131 million, in 2005 the growth was US\$188 and 386 million, respectively. As a result, the current account deficit increased more than twice and amounted to US\$213 million with its ratio in the GDP increasing from 2.7 to $9.8 \%$.

84. In these circumstances, two tendencies occurred in 2005. Firstly, the pace of remittances growth decreased; in

Figure 6. Foreign currency availability

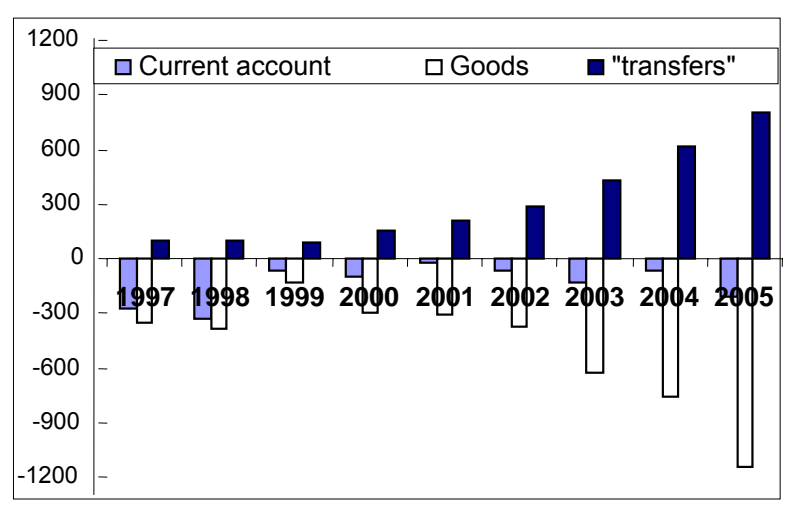


2004. The smaller rate of transfers' growth did not allow covering the increase of imports. Secondly, the incomes of Moldovan citizens working abroad and the increase in labor retribution and other incomes are enough however to fund consumption imports (Figure 6). Meanwhile, another component of imports and namely imports of investment goods and raw materials exceeds the capacities of the domestic economy, as the currency revenues from exports and remittances are not sufficient to pay for it. A part of investment imports and raw materials is funded on the expense of credits, which leads to the increase of country's external debt.

85. Thus, while the state debt decreased by $12 \%$, private debt increased by $19 \%$, causing a $5 \%$ growth of external debt. In the structure of private debt, commercial loans grew by $29 \%$, long-term loans grew by $11 \%$ and direct investments credited by the parent firm increased in the amount of $50 \%$. Out of the total growth of private external debt in amount of US\$192 million, US\$50 million account for commercial loans, US\$28 million account for long-term loans and US\$92 million are direct investments, credited by the head firm. Therefore, the increase of imports and trade deficit occurs not only on the expense of increasing consumption demand fuelled by remittances but also as a result of an increased demand for investment goods and raw materials, which in turn are funded from loans (respectively an increased debt). This is the reason for the essential increase of the current account deficit.

86. Investments have an important role in ensuring a sustainable economic growth. Relatively high interest rates for loans and reduced lending terms grant an even greater role to direct foreign investments. In 2005, the value of direct foreign investments increased by $44 \%$ of which investments in economy grew by $41 \%$. It should be mentioned however that investments in social capital decreased from US\$116 million in 2004 to US\$65 million in 2005 (44\%). Generally, investment growth was mainly caused by an increase of investments in other capital (loans from parent firms) from "minus" US\$16 to 84 million, as well as the increase of re-invested revenue by $15 \%$ up to US $\$ 53$ million.

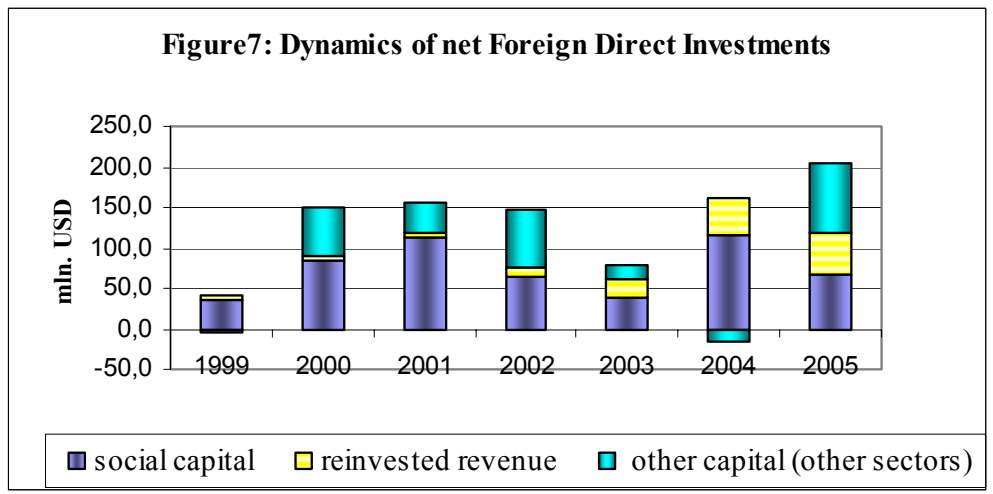

87. The analysis of foreign direct investment dynamics during the last 7 years shows that a serious growth of investment in social capital takes place especially in the context of privatization through capital increase at the time of purchase and later at the time of accomplishing investment commitments (Figure 7). During a passive privatization process, foreign investments in social capital remain rather modest.

\section{Conclusions}

88. Despite the fact that in 2005, GDP growth exceeded EGPRS parameters, the attempts to improve growth quality and reverse some alarming macroeconomic trends have failed. Economic and investment growth occurred on the background of a slow economic restructuring, decrease of industrial growth rate, especially in the processing industry. Imports grew faster than the GDP determining an increase in the share of net taxes on products and imports.

89. Gross capital formation increased by $11 \%$, which exceeds GDP growth and is slightly greater than final consumption growth. On the other hand, the growth of households' final 
consumption is virtually equal to the increase of investments in fixed capital. The growth of final consumption and the gross capital formation is defined to a large extent by the flow of remittances from abroad and partially from wage growth. Domestic and aggregate demand is largely satisfied by imports. As a result, any measures to limit imports may lead to GDP decrease and a reduction of final consumption and investments. In this case, there is need for rational policy to stimulate the export of goods and services, especially based on extending current industries oriented to exports and creation of new industries of this type.

90. The import of investment goods and raw materials is funded from export revenues and partially on the account of an increased external debt. At the same time, the increase of the trade deficit is not fully offset by the increase of other components of the current account (balance of services, incomes and current transfers), which led to a significant increase of the current account deficit.

91. Exports to eastern markets are affected by the emergence of new barriers, especially in the case of exports to Russia. Meanwhile, Moldovan products competitiveness, both on the European and domestic markets is reduced because of the non-compliance of the national quality system with Europeans standards, as well as the differences in the system of preferences and structural funds to countries that are at a more advanced level of integration.

92. The higher growth of imports versus exports has an objective explanation, since Moldova inherited an economic structure that is dependable on imports in amount of $70 \%$. Generally, in 2005, the structure of imports continues to be dominated by the following categories: $22 \%$ energy sources, automobiles and devices, electric appliances and parts thereof $(13.9 \%)$, products of the chemical industry $(10.1 \%)$, and common metals $(7.0 \%)$. Most of these goods are non-substitutable.

93. The big flow of remittances (30\% of the GDP), imports increase (77.5\% of GDP), deficit of trade balance (39\% of the GDP) and the deficit of the current account ( $9.8 \%$ of GDP) highlights an increased dependence of economic growth and overall economic situation on external factors. In these circumstances and in case of insufficient restructuring of economy, and a low level of investments, country's external vulnerability is growing, therefore the prospect of economic growth sustainability and poverty reduction may become uncertain if there is no immediate action for recovery. These actions are as follows: real optimization of business climate, creating conditions that would favor the funding by financial institutions, including commercial banks but also direct foreign investments of prospective investments projects, improving the management of state assets, promotion of public and private partnerships in the creation of production infrastructure etc.

\section{The evolution of revenues and expenditures. Public finance management}

94. During this period, budgetary policy was focused on continuing the efforts to introduce elements of medium term financial planning, as well as the extension of program budgeting. The budgetary and fiscal legislation reform continued. The link between the budgetary process and regulatory reform was ensured providing for the reduction of paid services, rendered by state bodies funded from special means earmarked in the national public budget.

95. The Medium Term Expenditures Framework (MTEF) for 2006-2008 is characterized by development and improvement, extending the application of elements of analysis and strategic planning of public expenditures. The agricultural sector was additionally included in the MTEF (2006-2008) by drafting the respective technical note. MTEF started at the local level by involving the strategic analysis of three pilot rayons - Orhei, Ungheni and Glodeni. 
96. In view of consolidating financial discipline, efforts continued for the development of the treasury system in 2005, and enhancement of budget execution procedures. During 2005, a Public Financial Management Project was under preparation. The loan agreement with IDA was ratified by the Parliament in November 2005. The concept paper regarding the new information system integrated with public financial management, the modernization plan, as well as the design of the future system was developed within the framework of the project. The mechanism of executing the revenues of the state social insurance budget through the treasury system was developed in cooperation with the National Social Insurance House. Starring with January $1^{\text {st }}$, 2006 these revenues are being managed through the treasury system.

97. During the current year, the Ministry of Finance started the process of adjusting the budgetary classification to GFS 2001 standards of the International Monetary Fund. Concurrently, the adjustment of Methodological norms regarding the accounting in the public system to international standards was initiated. During the previous year, the draft Law on public debt and state guarantees, and draft Law on audit were developed.

98. In the context of an efficient use of public expenditures through monitoring of performance indicators, the annual Report on budget execution for 2004 included an analysis, which describes programs execution through the prism of performance indicators. A quarterly financial report was created in 2005, regarding the execution of program budgets and currently published on Government's web page.

99. In 2005, as a result of these actions, the national public budget accumulated revenues in amount of MDL 14.7 billion, which is 3.3 billion or $28.8 \%$ more than in 2004 . The state budget collected revenues in amount of MDL 9.1 billion, which is $37.9 \%$ more than compared to the respective period of the previous year. The main revenues made up MDL 7.8 billion, exceeding by $40 \%$ the level of collections from 2004. The revenue part of ATUs budgets in 2005, increased by MDL 843 million or by $28.7 \%$ compared to 2004 .

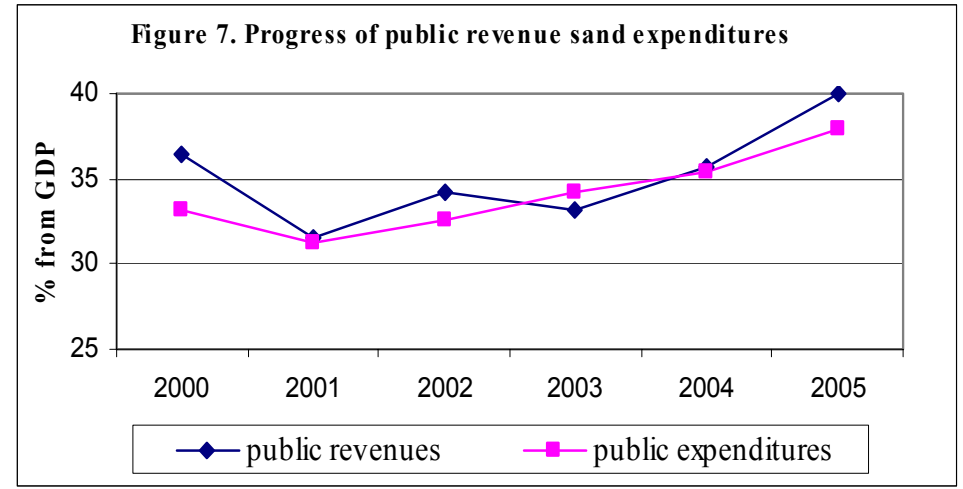

100. According to preliminary estimates, total public expenditures grew from MDL 11.3 billion in 2004 to MDL 13.9 billion in 2005, with a concurrent increase of all elements of the global expenditures framework.

101. The structure of budgetary revenues did not suffer any significant change. The main part of fiscal payments was created by indirect taxes and fees on external trade transactions, followed by contributions for medical and social insurance. Contributions to the social insurance and medical budget are similar to taxes but are not identical from the point of view of tax legislation, since the first ones become onerous, in case if payment of insurance is required: illness, child birth etc. and therefore are different from taxes and fees.

102. Direct taxes made up MDL 5,272.1 million or 35.9\% in the total amount of national budget revenues. Indirect taxes accounted for MDL 6,475. 9 million (44.1\%) and were collected at a level of $100.4 \%$ compared to annual reviewed provisions. Throughout the reporting year, other revenues (including revenues from special means and funds, grants, proceeds from privatization and sale of public goods) were collected at a level of $102 \%$ as compared to budget 
provisions, from the account of reducing the amount of special means (paid services) in the context of the regulatory reform. At the same time, the share of above-mentioned revenues within the national budget made up $20 \%$ (by $2.4 \%$ more than in 2004).

103. The major share in the structure of indirect taxes, and namely $71.4 \%$ relate to VAT, which makes up MDL 4,623.2 million of which VAT on goods and services rendered in Moldova - MDL 1,577.6 million, VAT on imported goods - MDL 4,051.8 million (87.6\%); VAT refunds on goods and services exported and delivered at decreased rates - MDL 1,006.2 million (22\%). During the reported year, excises made up MDL 1,171.96 million or $18.1 \%$ from the total amount and taxes on external trade and operations $-10.6 \%$ from total indirect taxes.

104. Thus, taxes on consumption and import continue to represent the basis for the creation of budget revenues - a fact that cannot be viewed as an element of fiscal sustainability. The medium term forecast for 2006-2008 indicates that the structure of national budget revenues will not change. The share of taxes in the GDP will be maintained at the level of $35 \%-36 \%$. Just as in 2005, taxes on consumption and import will prevail.

105. In 2005, public expenditures did not achieve the forecasted amount of $7.3 \%$. The analysis of the structure of public expenditures in the reporting period shows that almost $63.3 \%$ from public expenditures account for socio-cultural expenses of which for social assistance and insurance $-30.4 \%$, education $-19.3 \%$, health protection $11.3 \%$. Approximately $14.1 \%$ of public expenditures account for expenditures related to economy sectors. Compared to 2004, public expenditures in the socio-cultural area registered an increase of $24.9 \%$, and public expenditures for economic development increased by $45.4 \%$, compared to the general growth of $23.8 \%$ of national public budget.

106. In 2005, MDL 616.6 million from budget expenditures were used to finance capital investments, by 2.8 times more than in 2004, concurrently their share in the total amount of main expenditures of the state budget increased (from $4.1 \%$ in 2004 to $8.9 \%$ in 2005). However, expenditures for public investments and economic services remained compressed. Given the unsatisfactory and deteriorated state of public infrastructure this low level of expenditures inhibits the prospects for an economic growth in the future.

107. Public debt decreased from $73 \%$ of GDP in 2000 to $33.2 \%$ in 2005 , while the external public debt - from $60 \%$ of GDP to $23 \%$ during the same period. In 2005 state debt made up a total of MDL 12.2 billion, increasing by MDL 262 million compared to the beginning of the year as a result of increased internal debt and exchange rate fluctuations. In 2005, US\$ 52.4 million were used to service the external debt. Concurrently, a special account was opened in order to pay off the debt to the Paris Club. At the end of the year, almost MDL 100 million were deposited on this account, with another MDL 100 million planned to be collected this year.

\section{Funding EGPRS priorities}

108. Monitoring the funding of EGPRS actions and measures is an important element of the monitoring and evaluation system. MTEF that was developed as a tool to plan public financial resources for a medium term should define the allocation of funds for the strategy goals within real budgetary and fiscal limits.

109. It is difficult to track the allocation of financial resources for EGPRS priorities for two reasons: (i) costs of actions and programs set out in the EGPRS are rather approximate, since public institutions have reduced capacities for medium term budget formulation and (ii) current budget classification does not allow tracking the allocations separately by actions. Moreover, 
within the previous MTEF, some public institutions formulated other priorities than those agreed in the EGPRS.

110. Despite these limitations, the Ministry of Finance was able to present an estimation of the general distribution of resources by areas included in the strategy. The total allocated amount for the areas included in EGPRS was MDL 2,042.7 million of which 1,392 million were allocated in 2005. At the same time, only a part of these resources may be tracked for specific actions of EGPRS and namely:

- for private sector development, MDL 104.8 million allocated versus MDL 83.8 million as provided by the strategy. Most of the funds were allocated for the optimization of customs procedures, creation of the informational climate in the customs sector and creation of the real estate cadastre.

- for the public administration reform, out of MDL 26.3 million set out in the strategy, MDL 17.7 million were allocated. Public finance management and legal system enhancement were prioritized.

- for the development of infrastructure, industry and agriculture - MDL 910.4 million versus MDL 610.6 million as provided in the strategy

- for environment protection, MDL 54.6 million versus MDL 108.5 million

- for education, health protection, social protection, labor market development and youth policy - MDL 256 million versus MDL 314.9 million were allocated.

Within the framework of the strategy, actions related to tax administration enhancement and financial sector development received funding. In this sense, MDL 4 million compared to forecasted amounts of MDL 4.1 million were allocated.

111. Generally, actions set out in the EGPRS were funded both from the national public budget and from external sources, subject to priority areas/actions. This was possible as a result of changes made to the format of the national budget and inclusion of financial means from loans and grants.

112. The monitoring of financial coverage of priority actions provided in the EGPRS highlighted the need to specify the cost of priority actions, taking into account all funding sources and the need to enhance the current system of planning and budget forecasting. To a certain extent, social area represents an exception.

113. The problem of enhancing strategic methods used while planning public revenues and expenditures is subject to improvement during 2006-2007 and will be carried out by the Ministry of Finance with the support of the World Bank. Concurrently, at present, a better collaboration at the level of relevant public institutions is needed, in order to ensure a better quantification of EGPRS costs and a better adjustment of MTEF priorities to those of EGPRS. This will allow the state bodies to reason the policy promoted and measures of accomplishment, whereas the Ministry of Finance and other bodies will be able to correlate the mandates (qualitative and quantitative indicators) of respective bodies with the funding.

\section{Conclusions}

114. Efforts aimed at improving medium term financial planning, enhancement of tax administration, consolidation of financial discipline, allowed the budget execution at a level of $100.6 \%$ for the revenues part and $92.7 \%$ for the expenditures part. Direct taxes made up $35.9 \%$ and indirect taxes- $44.1 \%$. The major share in the structure of indirect taxes, and namely $71.4 \%$ 
is VAT, which makes up MDL 4,623.2 million of which VAT on imported goods - $(87.6 \%)$. For the reporting year, excises accounted for $18.1 \%$ of the total amount and taxes on external trade and external operations $-10.6 \%$ from total indirect taxes. Hence, taxes on consumption and imports continue to represent the basis for the creation of budget revenues - a fact that cannot be considered as an element of tax sustainability.

115. MTEF improvement and broadening allowed for a better allocation of resources. Social sectors continued to account for most of public expenditures $-63.3 \%$ of which insurance and social assistance accounted for $30.4 \%$, education $-19.4 \%$, health protection $-11.3 \%$. Approximately, $14.1 \%$ of public expenditures account for expenditures for economic sectors. Compared to 2004, they registered a growth of $45.4 \%$ versus the general $23.8 \%$ growth of public budget expenditures.

116. Despite these progresses, expenditures framework was not fully adjusted to EGPRS priorities. Moreover, the increase of allocations within MTEF is not necessarily followed by a real progress related to the improving the efficiency of funds use. MTEF for 2006-2008, and the budget for 2006 continue to be socially oriented, ensuring a reasonable coverage of EGPRS priorities in social sectors including the funding of social infrastructure. Meanwhile, expenditures for public investments that could favor economic growth remain to be compressed. Given the unsatisfactory and deteriorated state of public infrastructure in Moldova, this low level of expenditures inhibits the prospects for a future economic growth.

117. During the process of EGPRS elaboration for 2007-2009, a more serious dialogue between relevant institutions was initiated with regard to the need of a better reflection of EGPRS and MTEF priorities. To this end, modifications in the action plan for MTEF development were introduced for a better synchronization with the process of monitoring and assessment of EGPRS implementation, which would allow for better information at the level of setting the sector ceilings for public expenditures and distribution of priorities within sectors. 


\section{ECONOMIC INFRASTRUCTURE}

118. Findings and conclusions of the previous chapter indicate very clearly that currently, consumption, which is mainly satisfied from imports and is funded largely from remittances, represents a major source of GDP growth. The huge deficit of trade balance and that of the current account would not be sustained in the future, unless measures are taken to define the answer of domestic supply. Supporting and speeding up current growth pace might be ensured only by influencing its structure in view of transforming productivity in a driving force of growth. Productivity growth and that of national economy competitiveness will be ensured through continuing and amplifying structural reforms, namely: (a) further simplification and optimization of the regulatory framework; (b) ensuring the stability of the legal and fiscal framework; (c) infrastructure rehabilitation, including through promotion of public and private partnerships, but also through increase of public investments, (d) ensuring the consolidation of the innovative dimension of the development, (e) divesture of state property and improving the management of state assets, and (f) improving access to financing.

\section{Regulatory framework}

119. The state regulatory reform, initiated by the Government in 2004 and continued throughout 2005 is aimed at creating an open, flexible and cost reduced business climate that would facilitate investments and innovations in business. Only this type of environment will help Moldova adjust rapidly to new market risks and opportunities, and ensure the competitiveness of domestic production.

120. This reform, which represents a complex and long-term effort, envisages two major stages: (i) deregulation and simplification, and (ii) consolidation of the capacity of good regulation within Government institutions. During 2004-2005, a number of actions were taken within the first stage and namely (a) simplification and centralization of licensing procedure, (b) optimization of the registration procedure, (c) reduction of conflicts of interest between the role of inspections and the testing role of control agencies. The Law on reviewing and optimizing the legal framework regarding the regulation of business activities (regulatory guillotine) was drafted, allowing for a significant reduction of the number of normative acts that regulate business activity, and decreased the cost of authorization documents.

121. In view of ensuring a better transparency of the regulatory framework, the List of authorizations, permits and certificates issued for business activities was approved. It was created as a practical guide comprising authorizations, certificates and permits for entrepreneurs. For each of these, the issuing agency is expressly indicated, as well as the validity term and their cost (if they are no free charge), thus excluding the levying and collection by public administration authorities of illegal payments for authorizations. The list comprises 125 authorization documents of which 82 are issued free of charge. As a result of these actions, the number of licensed activities decreased to 37. The number of authorizations and licensing permission was reduced from 360 to 49. The validity term for 7 types of authorizations was increased from 1 to 3-5 years. Concurrently, the term of issuing the documents was reduced from 30 to 10 days at most (except for those for which respective laws, agreements and international conventions provide otherwise).

122. The experience gathered during the first stage of regulatory reform, as well as the experience of other countries in transition, points out the need to transform the regulatory reform in an ongoing, comprehensive and systematic effort of the entire Government, that could be supplemented by specific sector reforms. To this end, the Concept of regulatory reform based on the regulatory guillotine was developed representing the road map of the long term reform. 
At present, the draft of the national Strategy with regard to the regulatory reform is being finalized and together with the implementation action plan will be proposed for discussion to counterparts in the first half of the current year. In compliance with the Concept, the second stage of the regulatory guillotine will start following a Parliament approval of the Law on basic principles and mechanisms of regulating the business activity, and will be completed by the end of 2007. This law will ensure the review and simplification of the legal framework (primary) that regulates the business activity.

123. The concept, presupposes as well capacity building in the area of good regulation, including through the creation of the regulatory management system for the control of the quality of laws and regulations, improvement of transparency, laws and regulations enforcement. An important element of reforms is the creation and institutionalization of the system of assessment of the regulatory impact, which is an activity that will be initiated during the current year.

124. The successful implementation of this complex reform depends to a great extent on the level of involvement of various public institutions of which some appear unwilling to ease the burden of regulations or renounce on the additional income they receive within the current system. The experience of the first stage of accomplishing the regulatory reform shows that the fight against inefficient and excessive regulations is difficult to implement, since public administration continues to introduce new regulations that are sometimes contradictory with previous decisions.

125. Studies carried out during the analyzed period clearly point out that though licensing procedures were reformed and consolidated within the Licensing Chamber; there are many reserves in relation to this matter. Thus, the need to introduce the principle of One Stop Shop in the licensing procedure and the examination of the possibility of applying the declarative principle for some types of activity is obvious. Equally, it is necessary to analyze the need and procedure of issuing certain permits that are similar to licenses called "authorizations" that appeared when the number of licensed activities was reduced.

126. The issue of enterprises liquidation remains a major problem. Currently, the procedure of enterprises liquidation lasts for more than one year and requires a large number of documents, such as, publishing the announcement in two consecutive issues of the Official Gazette, certain payments for the publishing and for services provided by the State Registration Chamber and State Archive Service. Even though this issue was identified and qualified as one that requires immediate attention, progresses in the simplification of procedure is null at the moment.

127. Excessive reporting represents another serious issue for enterprises. While for large companies it is relatively easy to afford costs associated with fulfillment of requirements with regard to reporting, small companies suffer a lot as a result of this provision. The current arrangement of filling in various declarations is difficult: absence of a centralized information system of reporting involves certain expenses and time during the manual filling out of various forms with the same figures for various public authorities.

\section{Fiscal policy}

128. Following the objectives set forth in the EGPRS, the 2005 fiscal policy was consistent and predictable and was achieved through a gradual and planned reduction of the natural persons income tax rate, increase of personal and special relieves, reduction of the income tax rate on business activity, liquidation of fiscal facilities on indirect taxes unjustified from the 
economic point of view, development of new provisions and enhancement of existent provisions with regard to the application of tax legislation, and optimization of tax administration.

129. In order to support small income population and gradually transfer the burden on medium and high income population, the low and medium income tax rate on natural persons was reduced with no modifications to the annual tax grid, from 9 to $14 \%$ set for 2005 , to 8 and $13 \%$ in 2006 . The maximum rate of natural persons' income tax will be maintained at a level of 20\%. Further, personal annual relieves were increased from MDL 3,960 in 2005 to MDL 4,500 in 2006 and annual relieves for people under care (children, parents, other family members, etc) from MDL 600 in 2005 to MDL 840 in 2006.

130. Generally, the reduction of income tax rate had a positive result, both for natural persons and economic agents. In 2005, natural persons saved an additional MDL 60 million. According to estimations for 2006, the amount will make up approximately MDL 90 million that will be received from the reduction of income tax rates and relives increase.

131. The reduction of income tax rate on business activity from $20 \%$ in 2004 down to $18 \%$ in 2005 and 15\% in 2006, contributed to saving MDL 70 million in 2004 and MDL 112 million in 2005. These funds were allocated for industry development and reduction of arrears to the budget. According to 2006 estimates, funds from the reduction of income tax rate will amount to MDL 100 million Besides, fiscal facilities to income tax offered to economic agents who make investments in the purchase of fixed funds and constructions, small business entities contributed to saving from MDL 240 million to MDL 280 million, or 35\% from this tax collections to the budget.

132. Concurrently, there is a large group of inert activities, which are characterized by a null reaction to fiscal facilities. This measure had no influence on $47 \%$ of economic agents from the total number of businesses who are involved in business activity, since, both during 9 months of 2004 , the respective period of 2005, and the same period of 2005, the activity of these enterprises was non-profitable.

133. The analysis of cost price structure in the economy, both in 2004 and 2005, shows that the share of direct taxes in the cost price, except for compulsory payments to social fund and for medical insurance is so insignificant that it has no serious influence on the cost price or on the price of goods. Throughout 9 months of 2004, direct taxes made up $0.5 \%$ in the cost price and $0.6 \%$ for the same period of 2005 .

134. Taking into account compulsory payments to the social and medical insurance budget, these values are a bit higher and made up $4.4 \%$ for 9 months of 2004 and $4.8 \%$ for 9 months of 2005. Such a stability of social expenses in the cost price, shows that the policy in the field of compulsory contributions for social and medical social insurance, which is aimed at transferring the fiscal burden from economic agents to natural persons, virtually did not change the fiscal behavior of economic agents, and these expenditures are limited by them by means of indicating a reduced growth of labor retribution fund.

135. Hence, for 1 MDL indicated in the profit balance in the overall economy, the fiscal burden for the first 9 months of 2004 made up 1.9 MDL, for 9 months of 2005 -1.8 MDL (fiscal payments less the payments for the social and medical insurance were taken into account). The fiscal pressure as a proportion between the fiscal payments and GDP was not established during 2005. It made up $32.5 \%$ in the $1^{\text {st }}$ quarter, $31.3 \%$ in the $2^{\text {nd }}, 25.1 \%$ in $3^{\text {rd }}$ but registered a decreasing trend. The overall fiscal pressure was about $32 \%$. Fiscal pressure as a proportion between fiscal revenues and GDP is not large. Concurrently, the presence of a large number of 
non-profitable enterprises shows the existence of more issues besides those related to fiscal policy.

136. The broadening of the fiscal base within the fiscal policy promoted in the field of indirect taxes was achieved as a result of reducing fiscal facilities both for equipment, drugs and other imported goods and local goods, which contributed to the reduction of the amount of unjustified fiscal facilities for this tax until MDL 555 million according to estimates for 2006 and MDL 1.018 million in 2004. Saved funds were used firstly for the support, development and improvement of agricultural sector infrastructure where the poorest population is employed.

137. As a result of canceling the voluntary registration of VAT payers, VAT policy as a main source of revenues to the budget, created discriminatory conditions for the activity of small and medium business entities. This issue will be considered in the context of developing a strategy on fiscal administration reform.

138. The implementation of the policy in the fiscal area through property tax, as one of the main sources of local budget revenues was targeted at the broadening of the tax base by levying taxes on natural persons, dwellers of non-privatized apartments in 2005. This action does not comply exactly with strategy's objectives. The improvement of fiscal administration process did not allow for an essential increase of revenues from this tax in 2004-2005, by transferring the fiscal pressure from owners of properties with a high level of comfort to the owners of simple properties. During 2000-2005, the amount of real estate tax grew only by $18.9 \%$ until MDL 36.5 million in 2005, in spite of a sudden growth in the real estate constructions and commercial properties during these years.

139. Generally, the objective of diminishing the fiscal pressure set forth in the Strategy was not fully accomplished. The fiscal pressure, as a share of taxes in the GDP during 5 years, has evolved as follows: $24.6 \%$ in $2000 ; 24.2 \%$ in $2001 ; 25.6 \%$ in $2002 ; 27.3 \%$ in $2003 ; 29.5 \%$ in $2004 ; 31.9 \%$ in 2005 . The increase of fiscal burden indicator is determined by the increase of imports, and to a smaller extend by the elimination of some inefficient tax facilities, which deteriorated the fiscal administration system. The fiscal pressure may be reduced by decreasing the amount of imported goods and services, although according to estimations, the reduction of imports by at least 1\% may lead to loss of budget revenues in amount of MDL 63 million. By all estimates, the fiscal burden in Moldova is relatively low compared to countries in the region.

140. To improve and streamline tax administration, a series of measures were carried out for the enhancement of tax collection mechanisms. Throughout 2005, formulas were developed with regard to a computerized selection of taxpayers subject to verification. As a result of errors compilation (maximum probability with regard to law infringement by taxpayers) overall risk degrees were assessed subject to which the selection of taxpayers is done at document control. To minimize the direct impact of the human factor, the number of fiscal controls carried out on the basis of risk factors for 2005 was $60 \%$ and it is envisaged to select $70 \%$ of economic agents in 2006.

141. From January $1^{\text {st }}, 2006$ permanent fiscal posts are liquidated within enterprises producing ethyl alcohol and strong alcoholic beverages. Fiscal control within these enterprises will be carried out by fiscal bodies through operative verifications. A series of actions related to the enhancement in the IT field of the fiscal area will be carried out, as well.

142. Taking into account the fact that the fiscal policy as a tool for economic growth and poverty reduction is linked to other economic levers, such as public administration reform, institutional and legal reform, essential results of the fiscal policy will emerge only after the implementation of mentioned reforms. 


\section{Financial system}

143. The National Bank and the overall banking system have an important place in the economic system and play a significant role in ensuring economic growth. The results of banks activity registered during the last years show progress in this area. FSAP mission assessed the banking supervision and regulation comprehensive enough and generally compliant with the main principles of Basel Committee for an efficient banking supervision. Generally, the banking system proves reasonable levels of revenues, capitalization and liquidity, as well as a reduced level of non-performing assets.

144. The strengthening of country's banking system continued through 2005. Consolidated assets of the banking system increased by $35.4 \%$ compared to $25 \%$ in 2004 . As a share of GDP, bank assets increased from 42 to $49 \%$. The level of monetization of economy (ratio of money supply M2 to the GDP) increased from $25 \%$ in 2004 to $30 \%$ in 2005 . Equally, the degree of banking operations dolarization decreased from $56 \%$ in 2003 to $44 \%$ in 2005 . Capital multiplier increased - an indicator of a further consolidation of the banking system. If in 2003, one unit of capital accounted for assets valued at $4.76 \%$ than in 2005 it was already 5.98 .

145. Approximately, $60 \%$ from the assets of the banking system are composed of loans and they ensure $60 \%$ of banks' income. Due to insufficient floating capital at enterprises and the low level of domestic and foreign investments, the role of banking system as the main creditor of the economy grows significantly. Therefore, conditions for loans granting, amounts and loans terms, as well as the interest rate are important prerequisites of efficient restructuring of the economy and economic growth.

146. During 2004-2005, loans to economy in national and foreign currency increased by 1.8 and respectively 1.4 times (Figure 9). The total amount of loans granted in 2005 in MDL and USD made up MDL 9.0 and 4.4 billion and increased compared to 2004 by $58 \%$ and $27 \%$ respectively. The share of loans in national currency in the total amount of loans grew from $57 \%$ in 2003 and $58 \%$ in 2004 up to $63 \%$ in 2005 . Meanwhile, the share of deposits in MDL in the total amount of deposits grew from 50 and 55 to $58 \%$ Figure 9. Crediting of the economy accordingly.

147. As of 31.12.2005 the share of loans to industry and trade made up $48.1 \%$ registering an increase of 2.5 p.p. compared to the situation at the end of 2003 and loans to agriculture and food industry $-24 \%$, registering a decrease during the last two years by 4.8 p.p. The biggest growth during the respective period was registered by consumption loans by 5.1 p., accounting for $7.8 \%$ in the total amount of loans offered as of 2005 year end.

148. An important feature of the crediting process which characterizes directly its investment orientation is credit terms. Loans granted for over one year made up only $46 \%$ of all loans in MDL and $60 \%$ from loans provided in foreign currency. A positive thing is the fact that compared to the respective period of the previous year the rate of these loans grew from 31 to $46 \%$. As an absolute value this means that the value of loans provided for 1 year and mostly in 
MDL was MDL 2.4 billion and US\$8.4 million. The fact that approximately $60 \%$ of loans in MDL are offered for up to one year, limits significantly the investment activity. As a result, the share of bank loans in the total amount of investments in fixed capital decreased from $5.7 \%$ in 2003 and $4.8 \%$ in 2004 down to $2.7 \%$ in 2005 .

149. An important reserve for the increase of bank loans share in the amount of investments is the growth of loans attractiveness, including and especially through the optimization of banks interest rate. A decrease of loans interest rates and especially for long term loans will significantly improve the demand and lead to an increase of investments in the economy.

150. At the same time, while interest rates for deposits in MDL decreased in 2005 from 15.5 to $10.6 \%$ (by $31 \%$ ) interest rates for loans in MDL decreased only by $18 \%$ from 21.1 to $17.3 \%$. As a result, the interest rate margin for loans increased from 5.6 to $6.7 \%$. The net margin of the interest rate reduced from $8.46 \%$ in 2004 to $6.42 \%$ in 2005 i.e. by $24 \%$. As a result, assets profitability decreased by $15 \%$ and the banking activity efficiency indicator decreased by $3.5 \%$.

151. Banking credits remain an important source of real sector financing. The situation described above, characterized by the increase in the banking margin and the decrease in the banking sector efficiency shows not only a reduced level of competition in the banking sector, but also the inexistence of a competitive environment between the banking segment and the other segments of the financial market.

152. In this respect, there is a need to stimulate the creation of a competitive environment on the financial services market. This is feasible only by improving the regulatory mechanisms and through consolidating the supervision of non-banking segments of the financial market with the objective to increase the competitiveness and attractiveness of non-banking financial instruments.

153. During the reporting period, actions were taken to revitalize the insurance market. The assets of insurance companies in the $3^{\text {rd }}$ quarter of 2005, compared to the same period of 2004 increased by $17 \%$. The structure of insurance had some positive changes, as well. In 2005 , compared to 2004, the market of compulsory insurance revived, its share in the total amount of insurance grew from $14.1 \%$ in 2004 up to $20.7 \%$ in the $3^{\text {rd }}$ quarter of 2005 , whereas the share of voluntary insurance of assets from $17.4 \%$ up to $31.5 \%$.

154. With regard to civil insurance, its share grew by 4 times from $8.6 \%$ in 2004 to $32 \%$ in the $3^{\text {rd }}$ quarter of 2005 , which demonstrates increased responsibility of drivers and an increase in the credibility of the insurance system in general. It is important that the share of insured assets of agricultural producers grew within the system of voluntary insurance of assets. However, the system of insuring agricultural producers requested Government support and to this end, Government established funding arrangements in 2005, aimed at insuring agricultural production risks through insurance agencies.

155. In view of improving the legal and normative framework of the insurance system, the enhancement of the regulation and supervision mechanism of requirements towards financial assets of insurance companies was and continues to be carried out. The process of setting insurance premiums and payments in case of emergence of insured cases is enhanced. During the reporting period, the activity of adjusting normative acts in the area of insurance to the legal norms of Republic of Moldova and international norms continued.

156. The market of corporative movable estate has not yet become a tool to ensure the economy with quality services. Not only did the movable estate market fail to re-establish its position as provided in the strategy but on the contrary it lost ground. The total amount of 
registered issues decreased in 2003 versus 2004 by 4.4 times. Transactions in amount of MDL 216.3 million that makes up $77 \%$ compared to 2004 were register on the stock market. The share of movable estate market in the GDP in 2005 accounted for less than 1\%.

157. The unsatisfactory results of this segment of the financial market are caused by both objective and subjective factors. Objective factors are as follows: (a) concentration of the control stock on the account of a person or of an affiliated group of people, which results in a reduced attractiveness to make investments both through the primary market and the secondary one: (b) a deficient financial market expressed by the current monopoly of banks in country's financial system, which plays the role of distributor of responsibilities by means of attracting deposits and granting non-investment loans due to the reduced term and increased rates; (c) discriminatory provisions provided by the tax legislation as to the taxation of interest received from the ownership of corporate movable estate as compared to bank deposits and state securities, while interest received from their ownership is not taxed.

158. Subjective factors are as follows: (a) over-regulation of the capital market, constraints with regard to operations on the capital market, especially on the organized market, which limits the access of investors to financial tools provided by the respective segment; (b) lack of some well determined policies (visions) objectives of further development of the movable estate market; (c) ungrounded and unmotivated suspension of clearing and settlements for registered transactions on the movable estate market; (d) non-observance (extending) of fixed terms of examining the acts for the approval of a decision with regard to the registration of movable estate issue, as well as movable estate auctions.

159. In view of improving and developing the movable estate market in Moldova, the National Committee on Movable Estate developed the market development Strategy during the previous year providing for measures of enhancement of investments attraction mechanisms, increasing the level of investors interests and rights protection.

\section{Conclusions}

160. The implementation of reforms in the area of business activity regulation, a consistent tax policy, and ongoing enhancement of the legal and normative framework in the insurance field and consolidation of the banking sector, gradually improves the business climate in the country.

161. The experience of the first stage of regulatory reform, as well as the experience of other countries in this field, points out the need of transforming the regulatory reform in a whole of Government, ongoing, comprehensive and systematic effort to be supplemented by specific reforms of sectors. Capacity building of a good regulation will be achieved, as well through the creation of regulatory management system by means of verifying the quality of laws and regulations, improvement of transparency, as well as laws and regulations enforcement. An important element of reform is the creation and institutionalization of the regulatory impact assessment.

162. To a large extent, the successful implementation of this complex reform depends on the commitment of various local and central institutions with some of them unwilling to ease the burden of regulation or give up on additional incomes they receive within the current system.

163. The increase in fiscal burden is due to the increase in imports, but also due to the elimination of some inefficient tax facilities deteriorating the fiscal system. The fiscal burden in Moldova is relatively low compared to countries from the region. However, since the process of 
developing the fiscal system is not complete, the objective of ensuring fiscal stability is not fully met.

164. Generally, the reduction of income tax rate had a positive result both for natural persons and economic agents. Concurrently, the analysis of cost price structure in the economy, both in 2004 and 2005, shows that the share of direct taxes in the cost price, except for compulsory payments to the social fund and medical insurance is so insignificant that it has no serious influence on the cost price or on the price of goods. For 9 months of 2004, direct taxes made up $0.5 \%$ in the cost price and $0.6 \%$ for the same period of 2005 .

165. Absolute indicators of bank system functioning correspond to the economic development of the country in 2005 and in fact create necessary monetary conditions for it. When the nominal GDP grew by $14.7 \%$, total assets of the bank system grew by $35.4 \%$, the monetary mass in MDL (M2) increased by $36.7 \%$, the general monetary mass (M3) increased by $35 \%$, loans granting increased by $35 \%$, including in national currency - by $46.4 \%$, deposits by $40 \%$ of which in MDL - by $48 \%$. As a result, the share of banking system assets in the GDP increased from $42 \%$ in 2004 up to $49 \%$ in 2005 , the degree of industry monetization increased as well.

166. Concurrently, certain quality features of the banking system worsened. The profitability of assets and the banking activity efficiency indicator decreased. The dynamics of interest rates does not fully correspond to the task of an essential increase of investments and will not lead to an increase in crediting in desired amounts and for longer terms. At the same time, without an immediate reform of the economy and banking activity diversification, the decrease of interest rates may only lead to a reduction of banks profitability and may jeopardize the stability of the whole banking system, and in turn may cause major imbalance at a macro level. At the same time, only a more serious competition between banks may ensure a large diversification of bank products and more reduced inters rates.

167. It is necessary to create a competitive environment on the insurance services market so that the insurance activity is aimed at prevention and liquidation of negative consequences of alarming circumstances, especially in agriculture and infrastructure sectors. 


\section{REAL SECTOR}

\section{Industry and agriculture}

168. Industrial sector has a separate role in ensuring a sustainable economic growth. Following a threefold reduction of industrial production during the 90 s, industry started recovering together with the re-launch of economic growth in 2000. During the last five year, the aggregate growth of industry made up $67.5 \%$. With all that, the growth rates in 2004-2005 were decreasing and made up 8.2 and $6.3 \%$ respectively, and the share of GDP sector remained at a relatively low level $-17 \%$.

169. Moreover, the industrial sector is weakly diversified - food production and beverages account for more than $50 \%$, electricity, gas and water $-12 \%$ and nonmetal items $-9 \%$. The following production types lost their share in the structure during 2000-2004: tobacco products manufacturing (from 6.1 down to $2.5 \%$ ), vegetables and fruits processing and canning (from 5.1 down to $2.5 \%$ ), bakery products (from 2.0 down to $0.6 \%$ ), glass manufacturing and related items (from 5.1 down to $3.2 \%$ ). Concurrently, the share of: wines (from 16.9 to $20.6 \%$ ), oil (from 0.8 to $3.0 \%$ ), paper and cardboard (from 0.7 to $2.3 \%$ ) and furniture (from 0.9 to $1.4 \%$ ) increased in the aggregate industrial production.

170. Figure 10 shows the evolution of industrial branches with an important share in the structure of aggregate industry during 2000-2005. Tobacco products manufacturing had a discouraging evolution during this period, food and beverage industry had a downward trend, which conditioned a reduction of the industry in general. During 2005, the extraction industry, sugar, carpets, shoes, chemical industries and other products made from non metal minerals registered a significant growth. All of them have low shares in the structure except for the last one.

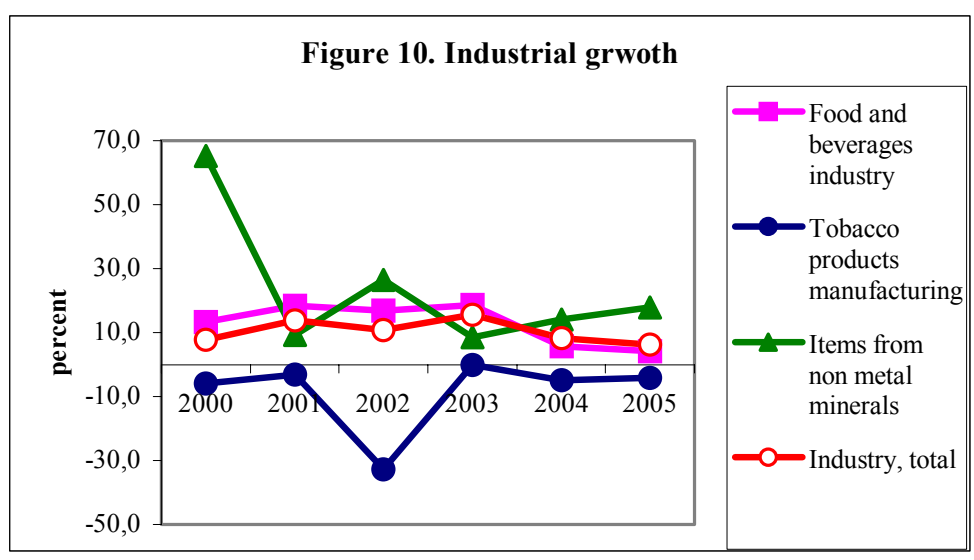

171. The growth of industrial output form the last years coincided with an increase in utilization capacities. As a result of a decline from the previous decade, most of the sectors registered a low level of capacities utilization ( $22 \%$ on average). With the economic re-launch, the degree of capacities utilization grew significantly. However, this possibility depleted gradually, and too little investment was made in new capacities. This explains the slowdown of growth in this sector.

172. The modest evolution of the industrial sector, explains the low performance of exports, which in turn are viewed as the "engine" of sustainable economic development. Both the growth and the industry structure define the dynamics and exports diversification. Food products, beverages and tobacco, textiles, vegetal products, leather, fur and related products were exported in 2005. The share of this group of goods in total exports in 2005, increased up to $72.8 \%$ versus $72.5 \%$ in 2004 . Throughout the time, the already strong concentration of export in some categories of products is becoming more obvious. 
173. Moreover, local exporters rely in general on producing and exporting alcoholic drinks and foods with a reduced degree of processing, thus lacking competitiveness with regard to goods with a high degree of added value. Hence, exports are dominated by agricultural and food products, and namely: wine made out of grapes, wine material, sunflower oil, spirits of wine or spent grains etc.

174. At the same time, imports performance is strictly linked to the development of the real sector of the local economy, especially that of industry. As it was mentioned above, Moldova inherited a system, which is dependant on imports at a level of $70 \%$. Structural reforms that were implemented since the declaration of independence so far were not sufficient to make significant changes. Hence, more than half of currently imported goods that are indispensable for economic development cannot be substituted.

175. On the other hand, there is a significant growth of internal and external demand on the markets from the region for current consumption goods for the production of which it is not necessary to make large investments in high end technologies. At present, Moldova imports large quantities of goods like: chemical products, textile materials, food products, beverages, plastic materials, vegetal products, etc. This findings show that domestic producers benefit little from an increasing demand, which stimulates economic growth in general. The benefits of this growth are collected by foreign economies to a large extent. This shows major problems of enterprises activity organization.

176. It is important to note that during this period of robust and continuous growth of demand, industry failed to consolidate its positions and in the situation of stagnation/reduction of consumption and growth, a phenomenon inherent to cyclic development of economy, this will become even more difficult.

177. It is very important thus, to understand the low performance of industry. Moldovan enterprises face low profits, arrears pile up, market loss. The main factors that contribute to this situation are: deficient corporate management, poorly organized production structures, obsolete production capacities and limited access to financial resources.

178. The analysis of investments in fixed capital shows a 9\% growth in 2005 compared to the level of 2004. The analysis of structure of investments in fixed capital according to ownership forms prove that intensified investment activities were determined by the non-government sector of enterprises. These economic agents account for $65 \%$ from the total amount of investments in fixed capital, 62\% from building and assembly jobs and $97 \%$ from commissioned apartment houses. The main sources of funding investment activity are private funds of economic agents and population (69\%) and foreign investments (19\%). Budget funds made up about $9 \%$ from the total amount of assimilated resources.

179. The low level of investment led to the de-capitalization of enterprises assets. This is happening especially with enterprises where the Government owns assets. This conclusion is confirmed by the study analysis of the activity of enterprises with Government participation carried out by the Ministry of Economy and Trade during 2005. Thus, according to the study, the average rate of net profit of these enterprises during 1999-2005 did not exceed the level of 4\%. In enterprise where the State holds between 10 and 33\%, the Government virtually cannot impact the management process. Concurrently, the presence of Government share represents an element of distrust which impedes investors from making investments in these enterprises. The evolution of financial indicators at enterprises where Government's share is between 33 and $51 \%$, shows their inefficient management. Often, the management from specialized bodies of the enterprise is on the backstage or its activity is reduced to formalities. A better performance 
is registered at enterprises where Government's share exceeds $51 \%$. Concurrently, the situation for this group of enterprises is determined to a large extent by the performance of Moldtelecom, which holds more than $20 \%$ from assets and generates about $20 \%$ from the net annual profit. ${ }^{9}$

180. In these circumstances, Government initiated a range of activities targeted towards the improvement of public assets management and devolution. The concept of the Law on devolution and management of public assets was drafted and has the following priorities: consolidation of public assets accounting, optimization of scale, structure and methods of managing public property, especially by introducing the principles of corporate management. At the same time, the draft Law on amending the law on state enterprises that provides for the implementation of corporate management principle at state enterprises. State enterprises will be placed in the same conditions as the JSCs they will calculate dividends and will be managed by councils with the participation of representatives of Ministry of Finance and Ministry of Economy and Trade. The requirement to calculate dividends will contribute to the improvement of public finance management system and identification of potential resources for public investments based on priorities.

181. Meanwhile, private sector confronts with issues related to assets de-capitalization and the share of this sector in the industry is much larger than that of Government sector. Many of the assets received through privatization are not actively used by owners. A possibility to remove these assets from "numbness" is the creation of competition on assets market through the privatization of Government assets. A tougher measure would be the increase of taxes on production estate that will impose a more efficient use of these or relinquishing on them in favor of more efficient owners. The enhancement of insolvency and restructuring of enterprises is another task on Government's agenda.

182. A serious effort initiated recently by the Government aimed at improving the competitiveness of local production is the process of converting the compulsory standards of technical regulation, as well as voluntary standards. To this end, the national Program on the development of technical regulations and setting priorities for the development of technical regulations for 2005-2007 was approved. It comprises a number of 103 documents and most of them need to be adjusted to European directives. The reform envisages that all MSTQ organizations of Moldova become part of corresponding international organizations and those of EU and the system of quality assurance be recognized by EU. Moreover, the Concept of quality infrastructure in the Republic of Moldova was developed. It envisages consistent actions with regard to removing barriers in the way of trade, especially those related to quality infrastructure, by establishing an efficient, competent and reliable system of quality assessment with a clear definition of fundamental principles. This reform is implemented with the World Bank support within the private sector development project - Competitiveness Enhancement.

183. It is obvious that these actions are not enough for the creation of a competitive industrial sector. EGPRS sets forth the identification of development priorities of the competitive industrial segment and development of concrete policies for the facilitation of its development as an immediate action. Although certain activities were initiated to this end, currently, there is no clarity as to the sub-sectors in which the country has a comparative advantage, neither policies/tools through which these sub sectors are supported.

184. An example in this sense is the experience of information technology sector identified as a priority area. Following the introduction of fiscal facilities at the beginning of 2005, companies from the information technology sector pointed out a number of shortcomings that

\footnotetext{
${ }^{9}$ Report on the assessment of enterprises with state capital, MET
} 
hampered the efficient enforcement of recently introduced facilities. Considering the proposals made by these companies, amendments to the legislation were carried out with regard to the granting fiscal facilities, both to economic agents that create software and to their employees. Preliminary assessment showed more activity in this sector, especially at the level of existent companies where the performance indicator is an increased number of employees and average wages and the extension of activity both on the domestic and external markets.

185. As it was mentioned above, agriculture has an important role both for poverty reduction as it is the main occupation for a large number of people who are concentrated around the poverty line but it is also a source for the development of industry and export growth.

186. Concurrently, the growth of the agricultural sector remains extremely modest. Agricultural production increased only by $16 \%$ in 2001-2005. In 2005, agricultural production registered just a $1 \%$ growth (in comparable prices) compared to the previous year. The major share in the structure of agricultural production is claimed by vegetal products, which account for $69 \%$ in the total agricultural production, animal origin production accounts for $31 \%$, respectively. In 2005, animal origin production increased by $8.6 \%$ compared to 2004 and the vegetal one decreased by $2.1 \%$. Agriculture continues to be characterized by the lowest level of productivity and labor retribution. With an $18 \%$ share in the GDP and employing $45 \%$ of the labor force, the low productivity and growth in the agricultural sector reduces the prospects for the rest of economy.

187. In addition to reduced access to funding, agricultural sector faces other major constraints: slow restructuring of the processing industry, excessive parceling of land plots, underdeveloped land market, and concentration of agricultural assets in the hands of unskilled managers, growth of fuel prices, reduced internal markets and high demands on external markets. The reduced level of investments led to the destruction of rural roads network, market infrastructure, and irrigation systems. Moreover, the vulnerability of the sector to natural disasters further complicates the process of agricultural recovery.

188. In 2005, budget subsidies for agriculture did not exceed $3 \%$ from total state budget expenditures. The largest share of these expenditures belongs to the Fund for subsidies and credit incentives to economic agents from agriculture (MDL 58.6 million). Other means were allocated for the partial funding of certain production activities, agricultural projects implementation Unit, education and scientific research institutions. During the reporting period, strategic objectives, basic principles and priority directions with regard to agricultural subsidies were developed, including through the support of vegetables growing sector, subsidizing sugar beets producers, stimulating the tobacco development branch, supporting the development of the ecologic agro-food production, subsidizing the users of phytosanitary (pesticides) products and fertilizers (mineral fertilizers), supporting the cattle breeding sector, stimulating the creation of the technological and machinery stations, as well as ensuring production related risks. The reviewed subsidizing scheme will be defined on the basis of these acts.

189. The experience of countries from the region points out that the re-launch of growth in agriculture may be achieved by vertical integration that may provide support of various types granting loans, investment loans, providing inputs, bank loans, guaranties, etc. Usually, processing enterprises are in a better position and may support primary agricultural development in order to receive quality raw materials. To a certain extent, in Moldova this is taking place only within the winemaking branch. Since budgetary funds for agricultural support will remain reduced, Government policies should be oriented towards the promotion of vertical coordination. 
190. Throughout 2005, awareness campaigns, professional trainings, consultancy and funding of small enterprises and micro-enterprises were realized together with NGOs. The investment project for agricultural business development in Moldova that has 10 information and consultancy centers and through which is distributes information to farmers has an important role. Thus, throughout 9 months of 2005, a number of 132 trainings for farmers were organized with regard to advanced technologies in agriculture, marketing, legal aspects, as well as round tables with discussions regarding issues agricultural producers confront with.

\section{Infrastructure}

191. Creation of a favorable climate for the economic growth based on market economy principles depends to a large extent on the re-establishment and development of infrastructure and namely roads network, water supply, heating, energy, telecommunications. In this regard, the modernization of infrastructure represents one of the main objectives of Government policies, as well as it is one of seven EGPRS priorities.

192. After the independence, public investments in infrastructure were limited and to a large extent originated from external sources. Within the framework of investment projects with the participation of development partners, funding was provided for investments in the energy sector, heating, water supply and roads, except for the national gasification project which is funded from internal sources, including from local budgets.

193. In view of the current situation of infrastructure, its re-establishment and maintenance presuppose enormous costs that the national budget cannot fully afford. Concurrently, the further delay of infrastructure rehabilitation, on the one hand, jeopardizes economic and social development and on the other hand leads to great rehabilitation costs in the future. In these circumstances, an effort to increase public investments is necessary, especially in areas where the private sector is not interested to invest, as well as the development of alternative funding arrangements, i.e. public-private partnership.

\section{Roads and transportation}

194. According to the agenda of EGPRS objectives for 2004-2006, the reform of roads and transportation infrastructure provides for the implementation of a program of commitments for the reconstruction and stopping of the degradation of roads network, creation of a sustainable and transparent system of funding, modernizing the technical assessment of roads and negotiation with international financial bodies in view of crediting rehabilitation operations of national roads of European significance.

195. The infrastructure of country's transportation networks worsened considerably during the transition period: out of a total of $3,325 \mathrm{~km}$. of national roads, $87 \%$ are totally worn out, of which $30 \%$ are in an appalling technical state. Approximately, $95 \%$ of roads are asphalted but most of them do not comply with technical standards.

196. The current efforts of roads maintenance, rehabilitation and construction are insufficient for the modernization of roads network at the appropriate level. With regard to roads, MTEF for 2004-2006 provided for the allocation of MDL 784.5 million and namely: MDL 178.6 million in 2004; MDL 291.6 million in 2005; MDL 321.6 million in 2006. Actual allocations made up MDL 158 million in 2004, MDL 179 million in 2005. Thus, $92.5 \%$ of the amount of projected works were carried out in 2004, only $61 \%$ in 2005 and $63 \%$ is planned for 2006 .

197. To compensate the limited resources allocated from the budget for the ongoing maintenance of roads network, attempts were made to secure external resources. Two regional 
projects were developed for the rural population that was discussed with the World Bank and three projects within the framework of cross-border cooperation. Regional projects are aimed at improving driving conditions on the network of public roads. The first project covers the network of public roads from Ialoveni and Hincesti, which is combined with the national road Chisinau -Hincesti. The second project covers the network of public roads in Balti, Telenesti and Singerei rayons. The estimated amount for works in this sector amounts to MDL 22.9 million Projects within the framework of cross-border cooperation provide for the rehabilitation of Chisinau-Hincesti, Hincesti-Luseni, Leuseni-Leova roads with costs amounting to US\$9.4 million. So far, no funding was secured for respective projects.

198. Creation of a sustainable and transparent funding system should be a priority on the agenda of central and public authorities. Concurrently, taking into account the huge costs for the rehabilitation and maintenance of roads infrastructure, as well as limited budget resources, it is necessary to involve the private sector, including foreign companies in view of (re)construction and management of national roads. In this case, if the investor is guaranteed the management right (through granting concessions) of the roads, funding will come from road taxes levied on drivers. However, this cost is much lower than that for cars repair due to a bad infrastructure.

199. If no immediate action is taken in this regard, Moldova risks to be removed from the European road corridors. Both Romania and Ukraine carry out major projects of roads construction and at a certain time these countries will identify routes that will by-pass Moldova. This however will result in major loss fro transit transportation.

200. Implementation of modern systems for the assessment of the technical state of roads and optimization of maintenance and repairs priorities is an important element of roads infrastructure improvement strategy. In this context, the implementation of pilot projects (Roads JSC: Straseni, Orhei, Anenii Noi) started with regard to the maintenance of roads on a contract base with external technical assistance provided by Swedish International Development Agency.

201. One of EGPRS objectives is the rehabilitation and streamlining of rail-roads transportation. According to the Memorandum agreement provisions between the Council of Creditors and Moldovan Railways, the frozen debt of Moldovan Railways in amount of MDL 25 million to the country's consolidated budget and the social insurance fund have been paid off, as well as US\$9 million to Ukrainian Railways. Concurrently, according to the schedule coordinated between Moldovan Railways and Russian Railways the historical debt of Moldovan Railways to Russian Railways are liquidated and they are reduced to the amount of 12.2 million Swiss Francs. Ministry of Transportation provides for the development of the public railways transportation reform Strategy in compliance with European requirements.

202. Progress was made in the area of rehabilitation of railways networks and namely completing the construction of $45 \mathrm{~km}$ long railway Revaca-Cainari. This segment facilitated the circulation of trains both on European arteries and within the country by-passing the railway junction Bender. Currently, the re-established route accommodates 2-3 goods-trains and passenger trains that make round trips from Chisinau to Basarabeasca. Moldovan Railways objective is to work on increasing the speed of trains on Revaca-Cainari railroad up to projected parameters.

\section{Energy}

203. The accomplishment of the objective related to the ensuring the country's energy system security remains to be a serious challenge. The events from the last two years and namely the 
significant increase of energy costs emphasized the already serious issue of energy sources diversification. The increasing prices for energy sources directly affect both the already reduced level of local production competitiveness and the overall situation of the population.

204. If there is no much room for action with regard to diversifying the gas supply, than for the rest of energy branches there is a greater possibility of maneuvers. Nonetheless, progress made in this area was modest.

205. The growth of capacities to generate electricity in the energy sector was not successful, as well as intentions to modernize existent thermal power stations (CET) as well as for the construction of new generation capacities. During 2005, the progress in this field consisted in the completion of construction and commissioning of the $34 \mathrm{~km}$ long $110 \mathrm{KV}$ line "Anenii-Nou - Causeni".

206. An even more disastrous situation is in the thermal power generation field, which is the main debtor in terms of gas consumption. In most of localities, heating systems face financial problems, low level of collections, and lack of investments. In order to improve the situation in this field, Government developed the national program of renewal and devolution of heating systems in Moldova whose main principle is the modernization of urban systems of heating supply.

207. Within projects accomplished with the support of development partners thermal power stations were built for the following rayons: Leova, Ialoveni, Nisporeni, Briceni, Floresti and for the lyceum from Leova. Concurrently, continued the metering of consumed thermal energy for all categories of consumers from Chisinau and Balti, which allows for a rational use of existent energy. Rehabilitation and modernization of the sector across the country presupposes huge costs. In this sense, it is necessary to attract private funds for rehabilitation projects.

208. Taking into account the fact that natural gas makes up around $80 \%$ of the total consumption of energy sources and one of the priority objectives of EGPRS is the extension of the gas pipeline and branch pipes by building inter city gas pipelines distribution stations, Floreşti-Soroca”, „Şendreni-Ungheni”şi „Antonovca-Şuri”, gas pipelines were finalized and commissioned in 2005. Throughout the year, 143 localities out of 190 planned were gasified.

\section{Water supply and sewerage}

209. The infrastructure of water supply and sewerage worsened across the country and most of these utilities face financial problems, a low level of collections and tariffs and big losses of water in the network. Moreover, almost $40 \%$ of the water delivered through these systems does not comply with sanitary, chemical or biological criteria. The purchase of good quality water represents a disproportionate level of household expenditures, which increases the burden for the poor population.

210. Reforming the water supply and sewerage systems is accomplished in the framework of EGPRS and MDG commitments that asset forth: "Halving the number of people with no sustainable access to potable water by 2015" which presupposes an increase in the ratio of people with a sustainable access to improved water sources from $38.5 \%$ in 2002 up to $47.7 \%$ in 2006 and $68.5 \%$ in 2015.

211. The desiderata of modernizing water supply systems, water treatment and evacuation of wastewater, water conservation and environment protection requires the urgent review of policies in this area on grounds that envisaged actions were partially accomplished because of the lack of financial support. 
212. In $2003-2005$ the water supply systems were built, reconstructed and renovated in 127 localities which is about 7\% growth in the level of water supply. In 2005, projects for the rehabilitation of water supply systems were implemented in 31 localities (out of 156 localities set forth in the strategy) at a cost of MDL 119.6 million, including from the state budget - MDL 25 million, local budgets MDL 42.0 million, external sources MDL 52.34 million (FISM, projects of the Swiss Agency for Development and Cooperation) from the national Ecologic Fund - MDL 0.10 million. Regional Development Agency renewed negotiations on the technical credit granted by the Polish Government for the rehabilitation and development of water supply systems of some localities from Moldova (Floreşti, Sîngerei, Teleneşti, Drochia, Rîşcani, Cimişlia, Ocnița, Leova şi Ungheni). The signing of the Credit Agreement is envisaged for the first quarter of 2006.

213. For 2006, it is envisaged to implement water supply projects in 49 localities of the country at a total cost of MDL 102 million, including MDL 41 million from the State budget and 61 million MDL from investment loans. Within the FISM project for 2006, it is planned to carry out water supply works at a cost of MDL 31.2 million and AEDC will finance aqueducts construction activities in 4 villages at a cost of US\$883 thousand. Concurrently, during the previous year, the Program of water supply and sewerage of localities from Moldova was approved until 2015.

214. However, these actions are not enough for the accomplishment of planned objectives and the chances to achieve MDGs targets are reduced. Insufficient allocations from budgets at all levels combined with a further promotion of a tariffs policy that does not allow costs covering, contributes to the further deterioration of water supply systems. Starting with the argument of scarce resources of current owners of infrastructure objects (in most cases municipalities will lack necessary resources to be invested in the objects in the nearest future) and the cost of these activities are rather high, it is necessary to take into account alternative solutions, i.e. public-private partnership.

215. In 2005, the Regulation on the collection of used wastewater, development of technical conditions and authorizations of discharging wastewater in the sewerage system of localities was developed and approved. The following Regulations drafts are being developed and approved: (i) on technical operating of water supply and sewerage systems (ii) on purchasing, planning, installing accepting and operating the measurement equipment of drinking water and hot house water.

216. During the previous year, more than 77 thousand wells or $83 \%$ from the total planned were cleaned and arranged. The 2005 implementation of pilot projects for ground water treatment with the elimination of hydrogen sulphate and ammonia azote by biological methods and for mechanical and biological wastewater treatment did not start due to the lack of financial resources.

217. Within the framework of objectives related to the system of supervising the level of underground water quality, 280 water wells were examined by the Stat Hydremeteorological Service of which 167 were repaired, and passports for underground water deposits are being developed for another 6.26 authorizations were issued for the planning of artesian wells.

218. The legal framework was enhanced by developing two regulations on water supply and sewerage and two instructions on applying tariffs and entering into of agreements between suppliers and consumers. 


\section{Telecommunications and information technologies}

219. Telecommunications and information technologies have a revolutionary impact on the pace and quality of economic growth and the population's living standards.

220. In 2004, the Law on Electronic Document and Digital Signature and the Law on Electronic Commerce were approved. In 2005 the draft law "On processing private data" was developed and approved by the Government. This drat was approved in accordance with the main principles of private data processing that are set forth in the European Convention for the protection of people with regard to the automated processing of private data, concluded at Strasbourg and ratified by the Republic of Moldova.

221. The National Strategy for the creation of an information society - "Electronic Moldova" was developed. It will be achieved by carrying out projects of a primary importance in the field. The implementation of these projects will contribute to the spreading of information technologies and telecommunications in all areas of activity based on a sole information and communication infrastructure. This strategy and the action plan for its implementation were developed with UNDP financial support. Currently, in view of implementing the action Plan, a "Regulation on the mechanism of carrying out "Electronic Moldova" was developed.

222. A number of proposals for pilot-projects to secure technical assistance from foreign donors that were included in the National Program for technical assistance for 2005-2006 were made with regard to the commitment set forth in the EGPRS, as to the development and implementation of a pilot-project for the establishment of seven collective access points to information based on post offices, schools, libraries etc. It is worth mentioning that six points of public access to Internet were created and are operational: two in Chişinău, one in Bălți, Drochia, Başcalia post office, Basarabeasca rayon. In December 2005, one point was opened in the post office of Plopi, Donduşeni rayon.

223. For the development of the implementation program of communication technologies, public administration bodies planned to spend US\$ 0,2 million. During 2005, these funds have not been allocated. The action plan to achieve the National Strategy "Electronic Moldova" wit regard to its $2^{\text {nd }}$ Compartment "Electronic Government and democracy" includes actions related to the implementation of information technologies within the activity of public administration bodies.

224. Concurrently, the Project "Implementation of e-Government Component" with UNDP support and funding from the Government of Japan was initiated. The main goal of the project was the support of Government in promoting the use of information and communication technologies in government processes and services, facilitating the access to public sources and improving the quality of public services.

225. During the reporting period, "Moldtelecom" JCS strategy to implement the NGN network and broad band access is due to start in 2006. The optical fiber network of Moldtelecom was developed and is $2,000 \mathrm{~km}$ long, thus ensuring communication with all main rayon telephone offices. Currently "Metro-Ethernet" network, broad band access network "MaxDSL", overlapped network of digital circuits "CrossNet" are extended. The broad band access network was created in urban localities, including in all rayon centers in 2005. The total capacity of the network is 2,616 ports of which 1,380 are used. This network is used to provide ADSL services, for Internet access with $1 \mathrm{Mbps}$ capacity in Chsinau and up to $256 \mathrm{Kbps}$ in all other rural localities. The number of fixed phones users increased by 41.1 thousand of which $(67 \%)$ in the rural area. Consequently, the level of fixed phone coverage made up $26.3 \%$ (41.3 in the rural area, 16.8 in the urban area). 
226. A Call Center, traditional free information services and 5 new added value services were created. The national numeration plan was almost fully realized. Still, the access of the population to a larger range of informational services remains to be limited.

\section{Conclusions}

227. During the last five years the aggregate growth of industry made up $67.5 \%$. Nonetheless, the growth pace in 2004-2005 was decreasing, making up 8.2 and $6.3 \%$ respectively and sector's share in GDP remained relatively low at $17 \%$. The modest evolution of the industrial sector, explains the low performance of exports, which in turn are viewed as source of sustainable growth. Both the growth and the industry structure determine the dynamics and exports diversification.

228. Imports performance is closely linked to the development of the real sector of the local economy, especially the industrial sector. The increase in import of goods which cannot be substituted as well as of current consumption goods shows a weak response of the domestic supply to the increase of internal demand.

229. Moldovan enterprises face low profits, arrears pile up, market loss. The main factors that contribute to this situation are: deficient corporate management, poorly organized production structures, obsolete production capacities and limited access to financial resources. The low level of investment led to the decapitalization of enterprises assets. This is happening both at enterprises where the State owns assets and in the private sector.

230. At the same time, the growth of agricultural sector is even more modest. The amount of agricultural production in 2001-2205 increased only by $16 \%$. In 2005, the amount of agricultural production registered a $1 \%$ increase (in comparable prices) compared to the previous year. Vegetal products account for the largest share in agricultural production with $69 \%$ from the total amount of agricultural production, whereas animal production accounts for $31 \%$ respectively.

231. Taking into account the current situation in infrastructure, its rehabilitation and maintenance presupposes huge costs that the national budget cannot fully afford. In these circumstances, an effort to increase public investments is necessary, especially in the areas where the private sector is not interested to invest, as well as the development of alternative funding arrangements, i.e. public-private partnership.

232. The efforts made during the last years with regard to maintenance and rehabilitation of roads is not enough to modernize the rods network. Thus, $92 \%$ of the amount of projected works was carried out in 2004, only $61 \%$ in 2005 and the same $63 \%$ ceiling was planned for 2006. To compensate the limited resources allocated from the budget for the ongoing maintenance of roads network, attempts were made to secure external resources. None of them however were successful.

233. The accomplishment of the objective related to ensuring the country's energy system security is still a serious challenge. The increasing prices for energy sources directly affect both an already reduced level of local production competitiveness and the overall situation of the population.

234. The growth of capacities to generate electricity in the energy sector was not successful, as well intentions to modernize existent combined thermal power stations as well as for the construction of new generation capacities. An even more difficult situation is in the heating 
distribution field, which is the main debtor in terms of gas consumption. In most of localities the heating system faces financial problems, low level of collections, and lack of investments.

235. More serious efforts are needed to ensure the achievement of MDGs indicator of improving the access of the population to water supply and sewage. 


\section{THE IMPACT OF SOCIAL POLICIES}

\section{Education}

236. The Education Policies represent one of the most important human capital development factors, which, in its turn, is one of the economic growth and social cohesion pillars in the country. Acknowledging the decisive role played by the Education and taking into account the Constitution provisions and other arrangements, the Government of the Republic of Moldova has formulated the following general objective of EGPRS: Ensuring access to quality education and ensuring sustainable functioning of the education system in a way that facilitates its role in the development of human resources and the economy ${ }^{10}$. Likewise, one of the Millennium Development Objectives is focused on ,accomplishing universal access to gymnasium education" ${ }^{\prime 11}$.

237. In the context of political desiderata for a European integration centered on performance and quality systems, an important step undertaken in this direction was the adhesion to the Bologna Process. Thus, during the last two years, the legal and regulatory bases have been revised and adjusted, while the mechanism of building the higher education architecture has been oriented towards the European mechanism composed from two university cycles and confirmed by the compulsory implementation of the European Transferable Credit System in the higher education institutions. Concomitantly, the Supplement to Diploma has been introduced, which is a unique European model, filled out in the official language of the country and in English and issued obligatory to each graduate student, starting with the 2005 graduates.

238. Another aspect of the reform promotion in the field of higher education is the approval of the Catalogue of professional fields and specialties for the first Cycle, which has replaced the previous catalogues that contained very narrow specialties and specializations. The new Catalogue has the goal to reflect the requirements of the local and European labor markets, keeping intact the continuity of the professional formation base done by the previous catalogues.

239. In order to improve the legal and regulatory acts with respect to strengthening and utilization of community funds intended for school enrolment, especially for poor people, a draft Law on General Secondary Education has been developed, which stipulates that parents shall ensure school attendance by their children, and punishment is provided for the failure to enroll children in school. As of December 2005, the number of children who did not attend any school was $157(0.036 \%)$.

240. A draft Project „Better Education to rural areas of the Republic of Moldova” aimed at improved access to and better quality educational services to children from the rural area has been developed with the support of the World Bank. The Project's objectives are: (i) improvement of the education process quality in rural schools, (ii) enhanced efficiency in the use of resources, and (iii) strengthened planning and monitoring capacities in the field of Education. The Project, which approved budget accounts for 10 million US dollars, will be launched in July 2006.

241. Plans for optimization of the education institutions network have been developed in the context of establishing "constituency schools" in the rural area. This activity implies reorganization of secondary schools in lyceums or gymnasiums. Thus, during the 2005 school

\footnotetext{
${ }^{10}$ Economic Growth and Poverty Reduction Strategy Paper (2004-2006), Chisinau, page 104.

${ }^{11}$ Government Decision No. 288 from March 15, 2005.
} 
year 16 secondary schools were reorganized in lyceums, two institutions were reorganized in gymnasiums and two new gymnasiums were established.

242. Children alimentation within the education institutions represents an efficient mechanism in attracting children from poor families into the educational system. Thus, during the 2004-2005 school year, the share of pupils from the I-IV grades of primary schools, gymnasiums, secondary schools and lyceums who received free of charge alimentation accounted for $83.6 \%$, representing an increase in comparison with the 2003-2004 school year when it accounted for $79.4 \%$. At the same time, by the Ministry Order, the norms established for expenses on children alimentation from preschool institutions and boarding schools were increased annually.

243. In order to support talented pupils and students from poor families, the Regulation to support the gifted children was approved by the Decision of the Government, which provides support to children with outstanding results at school from the rural area and poor families through their preparation in rest camps, and providing them with bonuses and scholarships.

244. At the same time, according to the official data from the National Bureau of Statistics, the enrolment rates, except for the preschool level, have not registered any increase during the last years. Thus, in $2004^{12}$, the net enrolment rate registered $91 \%, 95.5 \%$ in the urban area and $88.7 \%$ in the rural area, respectively (Chart 11 ). The net enrolment rate in the gymnasium education was $88.5 \%$ : $92.1 \%$ in the urban area and $86.3 \%$ in the rural area, respectively. Meanwhile, the net enrolment rate in preschool education increased from $54 \%$ in 2002 to $64 \%$ in $2004 .{ }^{13}$

245. The development of the preschool educational system constitutes the starting point for the quality education modeling process. In 2004 the enrolment rate at preschool level in the urban area increased by $5 \%$ in comparison with 2003 and by $45 \%$

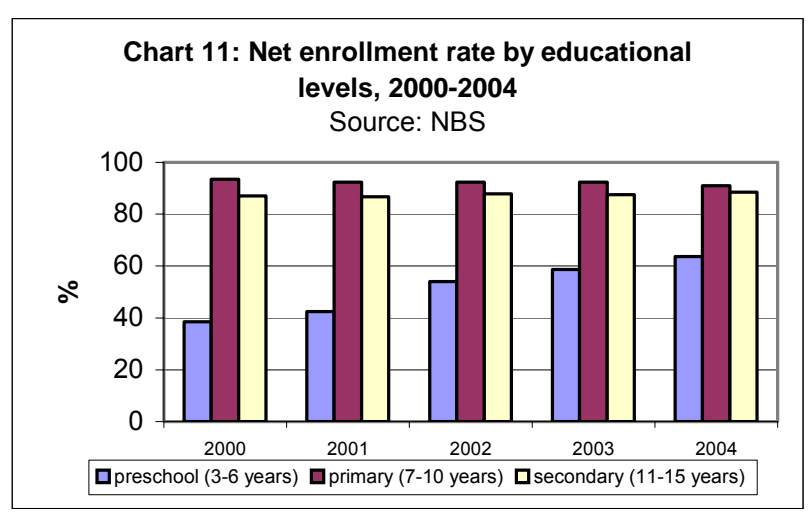
in comparison with 2000 . The enrolment rate in the rural areas increased by $11 \%$ compared to the level registered in 2003, and doubled compared to the 2000 level. Thus, $82 \%$ of children of preschool age were enrolled in the urban area and 54\% of children from the rural areas. Nevertheless, the enrolment rate at the preschool level remains low in comparison with the EU member countries and the Central and Eastern Europe countries(over 70\%), and with the average enrolment rate registered in the CIS countries $(65 \%)^{14}$ as well.

246. The reopening process of the institutions on matter has been enhanced along with the approval of the Action Plan with regard to the improvement of activities carried out by preschool institutions ${ }^{15}$, which defines the priority directions of system reforming, i.e.: i) setting up a stable regime of preschool institutions functioning; ii) increasing the financing level of expenses incurred by the preschool institutions for children sustenance; iii) setting up conditions

\footnotetext{
${ }^{12}$ Data for 2005 are not available

${ }^{13}$ Gross rate of enrolment: the share of children enrolled in school at a specific school level, regardless of their age; Net rate of enrolment: the share of children of specific age enrolled in school at a specific school level.

${ }^{14}$ Moldova Education Policy Note: Analysis in support to Education Sector quality, fairness and efficiency improvement, March 2005

${ }^{15}$ Government Decision No.1057 from October 12, 2005, Official Monitor of the Republic of Moldova, No.142144/1162 from October 28, 2005
} 
for the enrolment of children between 5-7 years old for their mandatory preparation for school; iv) modification of tutor staff within the preschool institutions in compliance with the requirement in effect; v) remuneration of educators according to the norms used for the didactic staff; vi) ensuring (free of charge) the preschool children with didactic supports and necessary materials etc.

247. The enrolment rate at the primary level decreased slightly in 2004 , conditioned by the continuous reduction in the rural areas, where the net enrolment rate reached $89 \%$ in 2004 . According to the data of the Ministry of Education, Youth and Sport, over 3,700 cases of school abandon were registered during 2004 due to the fact that children left the country along with their parent for other states. ${ }^{16}$ Another source of concern is the fact that many school aged children have been left to neighbors and relatives, while their parents work abroad. Based on the estimates, there are as many as 21,000 children in such situation. ${ }^{17,18}$

248. The enrolment trends in the secondary education registered an insignificant increase, reaching the net level of $89 \%$ or $93 \%$ at the global level. It is worth mentioning that while considering the net enrolment rate dynamics compared to 2000, the increase registered in the rural areas accounted for $3.4 \%$, while in the urban area - only $0.1 \%$. This fact illustrates the tendency of rural population to invest in educational services despite the aforementioned difficulties.

249. According to the information delivered by HBS, the data regarding the educational services used by the family members and expenses related to these services have been analyzed. ${ }^{19}$ Thus, $90 \%$ of children aged between 3 and 15 years were enrolled in school in 2004, regardless of their place of residence: either urban or rural. The problem is that children from poor families tend to abandon the educational system earlier. Already at age of 13 the enrolment rates of such children start decreasing as compared to children from prosperous families. The basic differences can be observed at the preschool age and after the graduation from high school. Children from poor families start attending school later (at the age of $7-8$ ) and abandon school earlier (at the age of 15). According to the World Bank research, during nine years of studies circa $13 \%$ of pupils left school within one school promotion. The highest rates of school abandon have been registered for grades VIII and IX. ${ }^{20}$ From the gender point of view, girls usually stay longer in school than boys.

250. Amongst those aged between 16 and 24, the reasons not allowing them to continue their education differ. Although money plays a major role in the decision taking process to continue the education, a more important reason is the lack of incentives. $37 \%$ of those who do not attend any education institution mentioned that they do not like studying. This rate is even higher amongst teenagers $-45 \%{ }^{21}$ From the total number of graduates from the vocational school only $70 \%$ were employed in 2004 . This situation could be explained by the low level of qualification combined with the lack of work experience and age peculiarities, which reduce the level of competitiveness within the current labor market framework.

\footnotetext{
${ }^{16}$ Prohnitchi, V. (2005), Poverty of children belonging to migrants from Moldova, Group of Experts, Chisinau, page 9.

${ }_{17}$ According to the information provided by the Ministry of Education, Youth and Sport, August 2005.

${ }^{18}$ According to Mr. V. Prohnitchi (2005), this figure may reach 40,000 children.

${ }^{19}$ Chapter 9 of the Questionnaire, HBS 2004 (CNGC).

${ }^{20}$ World Bank (2005), Moldova Education Policy Note, first project, page 14.

${ }^{21}$ According to the data of METS, annually 12-16 thousand graduates from secondary schools aged between 15 16 years abandon the education system without any professional qualification
} 
251. Along with the financial problems, another major impediment in granting access to quality education is the absence of educational institutions in some of the rural communities or the fact that their have been closed. $38 \%$ of children from the rural areas have not been enrolled due to the absence of schools in the close neighborhood, while $36 \%$ of children indicated the lack of money.

252. A separate Chapter regarding the development of educational services is devoted to children with special educational requirements. Pauperization of population and the lack of opportunities to have access to specialized services within the community for children with disabilities encourage the increase of the institutionalization rate of children in the Republic of Moldova. Currently, there are 63 special institutions and boarding schools in Moldova, comprising 11,180 children, most of them aged between 10 and 14 year. $^{22}$

253. The reasons for children enrolment in boarding schools are diverse: $36 \%$ of children have been enrolled due to their health condition, i.e. diseases or disabilities, $16 \%$ - after the decease of their parents, $27 \%$ - due to poverty of their parents, $8 \%$ - due to problems in their family and $4 \%$ - due to unemployment of their parents. It is worth mentioning that some children have been enrolled in special schools due to their poor performance at regular school $(1.6 \%)$ and due to the absence of any primary school in their community $(0.2 \%)$. Very often children are enrolled in special schools under permanent supervision knowing in advance that their parents will leave the country to work abroad.

254. The undertaken efforts have been channeled lately toward the shift from the actual system of children support in residential institutions to a system of social services specialized at the community level targeted to keep the children within families or in an alternative familytype environment. In this context, the family-type houses represent an alternative form of services aimed at child care rendered by special institutions, which offer protection to children deprived from their family environment. At present there are 30 such family-type children houses in the republic. During 2003 two alternative services were launched, while in 2005 six family-type children houses were established within the Joint Program „Concordia - The Town of Childhood". The financial means provided for children nutrition, procurement of cloths, footwear, personal hygienic supplies, medicines, including compensations and allocations for children, are transferred monthly to the individual accounts of parents-educators in compliance with the approach and procedure established by the Government.

255. Although the national regulatory framework stipulates a series of provisions regarding the family-type children houses, including the minimal quality standards for the services rendered by them, till now there is no mechanism developed regarding the contribution of parents-educators to the social insurance system and state compulsory medical insurance, which affects their rights to have sick leaves or leaves for temporary inability to work and the right to get a old age pension. At the same time the parents-educators' rights and duties in their relationship with children have not been defined yet, nor the children' rights and obligations within these services. There is no information available on children status within those houses: their level of adaptability, cases of child abuse by parents-educators, including exploitation through work.

256. Having considered the situation with respect to expenditures for education we can ascertain that the effective public expenditures within this sphere are very low in comparison

\footnotetext{
${ }^{22}$ Ministry of Education, Youth and Sport, Special Education Division, January 2005
} 
with the 1990s. In 1996 - 1997 the share of expenditures for education amounted for $10 \%$ of $\mathrm{GDP}^{23}$. Today it makes up $6.8 \%$ of $\mathrm{GDP}^{24}$.

257. Appropriation of public financial resources for schools is based on a financial formula for unit MDL/pupil and in some cases varies 2-3 times from one school to another, while the amounts are very small and do not allow the school management to use them in a more flexible way. The most part of the appropriated amounts is used for teachers' wages, then for investing into materials, repairing, furniture etc.

258. The parents' extra budgetary contribution continues to rise within the existing conditions. ${ }^{25}$ Today $35 \%$ of universities and $21 \%$ of colleges are private. Circa $77 \%$ of students from the higher education institutions pay education fee ${ }^{26}$. In 2003 the average monthly expenses on education increased and reached 29 MDL, in 2004 such expenses reached 33 MDL. Likewise, it is worth mentioning the great discrepancies between the poor and non-poor households as well as between the rural and urban households. Thus, in 2004 the poor families spent for education $0.3 \%$ of their total budget, while the non-poor families $-1.2 \%$. Families from the large towns spent 2.5 times more than families from the rural areas and 6 times more than those from the small towns. A prosperous household spends 20 times more than a poor family.

259. During the reporting period a great attention has been paid to the increase of didactic staff wages. Respectively, in 2004 the teaching staff wages from the preschool, primary, gymnasium and lyceum systems were increased by $30 \%$, representing an average increase by $3.5 \%$ in comparison with 2000. Despite these increases in 2004 the nominal average wage of an employee from the education system accounted for only $64.4 \%$ of the average wage in the economy as a whole compared to $68.5 \%$ in 2003.

260. At the same time, the allocated financial means are not sufficient for the material needs so necessary in the educational process. The lack of didactic materials and of modern means of teaching lead to reduction of the quality of studies, having a negative impact on the level of assimilation of new information.

261. A major problem to be taking into consideration while developing and formulating new solutions is the provision of professional staff to schools from the rural areas, including the identification of opportunities to minimize the pressure of over requesting the role in case of the pupils/teachers ratio. Out of the total number of didactic staff who works in the educational system over six thousand are persons at pension age. The estimated number of necessary staff accounted for 2,400 persons; only $58 \%$ of graduates from pedagogical institutions were employed in 2004.

\section{Healthcare}

262. Healthcare is a fundamental need during all life cycles, from the naissance till death. Its relevance is well defined in the Millennium Development Goals (MDG), which comprise a series of important health indicators. Due to the fact that healthcare is characterized by expensiveness trends, depending more and more on private contributions, the poor households confront with greatest difficulties in getting the necessary health assistance. Keeping in mind this fact and also the risks it brings to worsening the health status of the poop, the main

\footnotetext{
${ }^{23}$ Country Evaluation performed by the UN agencies in the Republic of Moldova, Chisinau, May 2005.

${ }^{24}$ According to the data delivered by the Ministry of Finance.

${ }^{25}$ World Bank (2005), Moldova Education Policy Note, first project.

${ }^{26}$ MTEF 2006-2008. Annex 11, Education Sector, page 148
} 
objective of the EGPRS with regard to healthcare policies is: Strengthening the access of population, and, especially, of the poor, to basic health services through the development of primary medical care. ${ }^{27}$

263. The healthcare system finds itself in the transition period, the compulsory medical insurance having been introduced since January 2004. The medical assistance provided through the system of mandatory medical insurance is carried out based on a unique Program of mandatory medical insurance that provides specific volumes for different types of medical assistance (emergency pre-hospital, primary, ambulatory specialized, hospital, adjacent services). At present it is pretty difficult to assess the impact of the policy new approach regarding the population access, especially of the poor categories, to medical services.

264. Like in the social assistance system, the mechanism of state free medical insurance is focused on category principle 28 . Initially the state committed itself to insure the following categories ranked at that time as vulnerable: (i) children of preschool age; (ii) pupils from the primary, gymnasium, lyceum and secondary education; (iii) students from the secondary vocational education; (iv) full-time students from the secondary specialty education (colleges); (v) full-time students from the higher university education; (vi) residents from the mandatory postgraduate studies; (vii) children who have not been enrolled in the education system until the age of 18 years. During 2004, three additional categories were added to the list of categories insured by the state: pregnant women and those on postpartum care, and officially registered unemployed persons.

265. Implementation of the mandatory medical insurance system presumes the performance of a series of activities aimed at monitoring the population access to primary medical care, the calls for emergent medical assistance, doctor visits, the number of hospitalized patients and the number of days spent at hospital, the birth rate and the death rate. During 2005 the number of calls for emergent medical assistance increased by $18 \%$ in comparison with 2004 , including the 1.4 times rise in the rural communities, thus, the discrepancy between the access of rural and urban population to emergent medical care was diminished substantially.

266. The continuous rise of costs for medical services created difficulties for very poor households regarding their access to relevant services. Due to the fact that the budgets of poor people are very limited, circa one third of them do not have the possibility to buy an insurance policy, while the medical care they can afford is minimal. A large part of noninsured persons are people holders of land plots in the rural areas. According to the data provided by HBS, the prosperous households spend on medical services 8 times more than the poor households, and 17 times more compared to extremely poor households. Expenses incurred for medical assistance made up $1.5 \%$ of the total budget in poor families, while the non-poor families spent $4 \%$ of their total budget. Thus, a non-poor family from the urban area spends circa 30 MDL per month, while a poor family from the rural area spends only 3 MDL.

267. The expenditures for public medical assistance remained at a relatively stable level during the last few years, making up approximately 4\% of GDP. About one fifth of the total expenditures of the social sector are used for medical assistance. The allocated proportion on this regard remained similar to the level spent in $2002-17 \%$. In 2004, 76\% of the consolidated budget intended for healthcare was allocated to mandatory medical insurance funds.

\footnotetext{
${ }^{27}$ Government of the Republic of Moldova (2004), Economic Growth and Poverty Reduction Strategy Paper (2004-2006), Chisinau: page 109.

${ }^{28}$ Ibid. page 108 .
} 
268. In case we analyze how efficient the resources channeled through mandatory medical insurance funds were used by types of ambulatory medical services (primary medical care and ambulatory by specialty), it is worth mentioning that services rendered at hospitals are very expensive, the delivered services are not always targeted towards the most serious diseases, while the level of resource use was estimated at $60 \%$ of the total amount spent by the mandatory health insurance funds (MHIF). In this situation there is a high risk of concentrating more resources intended for curative medical services than for programs of preventive medicine financed from the State Budget, which, according to the international experience, have a greater impact on health condition of poor families in particular. Likewise, such a substantial increase rises the question on how well the resources have been used within the sector. Expenses for healthcare are derived from the state budget and shall be planned and managed based on financial approaches and substantial policies. In this context it has been proposed to implement regulatory and control mechanisms over the financial flows and the rendered services quality, ensuring transparency in the functioning of the National Company of Medical Insurance ${ }^{29}$.

269. The increase of MHIF inflows during the last few years is generated by the effects of the nominal average monthly wage increase in the republic, keeping the size of contribution at the level of 4\% (2+2) and shows an increase until 2005 with positive forecasts for the next years. This increase, in its turn, is caused by the raised amounts of transfers from the State Budget for the categories of populations (pensioner, the unemployed people, children aged up to 18 years, students, disabled people and other categories) insured by the State through the MHIF. Transfers from the State Budget make up the prevalent part of MHIF revenues - over $60 \%$, registering a 28.9\% increase in 2005 in comparison with 2004.

270. Another priority direction for achieving the EGPRS objectives is the National Health Programs. Children' health and death, maternal health and death, fighting and applying prophylactic measures against HIV/AIDS, sexually transmitted infections and TB are the priority fields of the aforementioned programs.

271. The Republic of Moldova has registered important results in achieving the MDG objective that deals with the reduction of children' death rate. Compared to the $1990 \mathrm{~s}$, the mortality indicators have been improved substantially. These trends have been continued during the current decade. Thus, the infantile mortality rate was diminished from 18.3 per 1,000 of new-born children in 2000 to 12.2 in 2004 (staying at the same level in 2005), while the mortality coefficient of children up to five years decreased from 23.3 to 15.3 per 1,000 for the same period. The reduction trends continued during $2005^{30}$. Realization of the Program "Promotion of perinatal services" has brought its contribution to the improvement of the situation in this field through enhancement of the regional system of perinatal medical care, promotion of quality services, continuous education of medical staff, development of the perinatal care supervision system.

272. Another decisive factor that contributes to the enhancement of children health status is vaccination. No big results have been registered in this field, the ratio of vaccinated children under the age of two years reaching $99.1 \%$ in 2004. However, regarding the policy implementation, the National Immunization Program achieved good results from the point of view of ensuring financial sustainability. The share of funds allocated for procurement of vaccines and syringes increased from $12 \%$ in 2000 to $84 \%$ in $2004^{31}$.

\footnotetext{
${ }^{29}$ MTEF 2006-2008.

${ }^{30}$ NBS. Preliminary data for 2005.

${ }^{31}$ Common Country Assessment. UN in the Republic of Moldova. Chisinau 2005
} 
273. The maternal mortality rate, the objective for 2006 being 23 , was 18.6 per 100,000 life births in 2005, in comparison with 23.5 registered in 2004. The main reasons of Maternal Mortality in the Republic of Moldova are the following: risky miscarriages (30\%), hemorrhages $(19 \%)$, puerperal sepsis $(18 \%)$, embolism $(17 \%)$ and conditions related to pregnancy $(9 \%)^{32}$. One forth of incidences of Maternal Mortality happened at home, especially because women and their families are neither informed nor know how to recognize life dangerous problems, therefore they do not ask for assistance ${ }^{33}$.

274. So far no significant results have been registered with respect to the reduction of mortality rate due to TBC, the rate being higher than in 2002 although the incidence of TBC has fallen. Thus, the mortality rate associated with Tuberculosis increased from 16.93 per 100,000 people in 2000 to 18.50 in 2005 . Over one third of the total TBC cases have been registered amongst children and youth. TBC incidence amongst men is threefold higher than amongst women. ${ }^{34}$ This could be explained by the increased number of convicted men in prisons, where the TBC incidence is surprisingly higher: 43 times more than the country average ${ }^{35}$. During 2002-2003, the number of TBC cases amongst children up to 14 years old varied from $5.8 \%$ to $7 \%$. Severe (destructive) forms that require expensive and long lasting treatment represent 15 $23 \%$ of the new TBC cases diagnosed amongst children ${ }^{36}$.

275. According to the data for 2004, the total number of live persons who have got HIV/AIDS reached 2,308 people. The incidence of 8.53 per 100,000 inhabitants in 2005 places Moldova on the fifth place amongst the most affected CIS countries ${ }^{37}$. Likewise, a dangerous trend has been noticed with respect to transmission of this malady through sexual contacts, which marked an increase from $20 \%$ in 2001 to $55.4 \%$ in $2004^{38}$. In case no immediate measures are undertaken, it could happen that by 2011 circa $2 \%$ of the country population would be contaminated with HIV/AIDS ${ }^{39}$.

276. Non-contagious affections continue to be the main reason of morbidity, invalidity and premature death in the Republic of Moldova. Cardiovascular diseases cause more than half of decease cases $(57 \%)$, while cancer $-11.6 \%$ of the total number of deceases ${ }^{40}$. Based on the data provided by HBS we can also distinguish the incidence of chronic diseases amongst the poor and the ones noticed amongst the non-poop. Thus, the affections of digestive tract and arterial hyper blood pressure prevail amongst the non-poor respondents. Renal and cardio-pathological diseases are more frequent amongst the poor along with the group of „other” diseases claimed by the poor respondents.

277. HBS, likewise, offers data on population subjective perception of their health status. Thus, in $2004,35 \%$ of population responded that their health status was good or excellent, $49 \%$ were satisfied by their health status, and $16 \%$ assessed their health status as non-satisfactory or even critical. As it was expected, the more aged the person the worse his/her perception of his/her health status. More than $50 \%$ of population aged 65 years and higher think they have a satisfactory health status, while $43 \%$ think their health status is non-satisfactory of even critical.

\footnotetext{
${ }^{32}$ Public Health in Moldova. National Centre for Public Health and Management. Chisinau 2004

${ }^{33}$ Access to quality primary healthcare services in Moldova. UNICEF. Chisinau, August 2004

${ }^{34}$ Public Health in Moldova. National Bureau of Statistics. Chisinau 2004.

${ }^{35}$ TB Assessment in Moldova. The World Bank, July 2001.

${ }^{36}$ Constantin Iarovoi. Note on TB epidemiologic situation in the Republic of Moldova 2003-2004. Chisinau 2004.

${ }^{37}$ National Anti-AIDS Centre, February 2005.

${ }^{38}$ National Anti-AIDS Centre, 2004.

${ }^{39}$ The World Bank. Moldova Health Policy Note: the Healthcare System in Transition. November 2003.

${ }^{40}$ Moldova Healthcare System. The National Bureau of Statistics. Chisinau 2004.
} 
The share of women who think they have non-satisfactory health status exceeds the share of men who perceive their own health status as satisfactory or even good. Poverty does not have anything in common with the perception of health status due to the fact that the ratios for both groups are more or less similar.

\section{Social Protection}

278. Social Protection Policies provide a security system for those who are not able to earn enough money for living. The Social Protection in the Republic of Moldova comprises two policies: Social Insurance and Social Assistance. The Social Insurance payments are based on contributions and are intended for the insured persons. The Social Assistance is provided through social compensations and social services. Payments from the Social Insurance System represent an important source of income for a large group of families and persons, and, as it has been mentioned by the EGPRS, due to this reason, the dynamics, incidence, deepness and harshness of poverty depend on the efficient functioning of this system. The main objectives formulated by the EGPRS refer to financial strengthening, concordance among risk, contributions and allocations and the improvement of the computation methodology and review of quantum of social insurance contributions, including the access principles to the Social Insurance System and more efficient management of the budgetary resources allocated for this purpose $^{41}$.

279. The State Social Insurance Budget represents a considerable share in the national public budget. The evolution of revenues and expenditures of the State Social Insurance Budget during 2001-2004 had an ascendant trend. The State Social Insurance Budget Revenues as a share of GDP made up $9.2 \%$ in 2004 and $10 \%$ in 2005 . Respectively, the expenditures made up $8.7 \%$ in 2004 and $10 \%$ in 2005 .

280. The rise of the State Social Insurance Budget revenues was generated by: (i) the increase of wages in the economy as a whole; (ii) implementation of redistributing the contribution fee between the employer and the employee; (iii) the change of the principle for computing the contribution of landowners, enrolled in associations, by applying the fee of 1.7 MDL per a grade/hectare of agricultural land under the ownership while calculating the contributions to the payroll fund.

281. $77 \%$ of the total expenses incurred by the Pension Fund were used to pay old age pensions and pensions to disabled people. In 2004 31,587 new pensions were set up, while the number of registered pensioners decreased by $1 \%$ in comparison with 2003 . As a result of indexation by $22 \%$ in April 2004 as well as of recasting in the month of November, the average size of old age pensions made up 336.75 MDL as of January 1, 2005, registering a 55\% increase compared to the previous year. The minimal pensions were subject to indexation and recasting, thus, starting with November 1, 2005 the minimal pension for agricultural workers reached 219 MDL and 246 MDL for the other beneficiaries ${ }^{42}$.

282. The Family (with Children) Protection Fund Expenditures made up 111.37 million MDL in 2004. The Expenditure nominal value was by $61 \%$ more as relative to 2003 . The real increase of the Fund relevant expenditures accounted for $43.1 \%$, representing the most efficient

\footnotetext{
${ }^{41}$ Law No. 398-XV from December 2, 2004, Economic Growth and Poverty Reduction Strategy Paper (20042006), Chisinau: page 111.

${ }^{42}$ According to the data provided by the Ministry of Health and Social Protection, these changes have been applied only to pensions established in general terms, except for the pensions established in compliance with other legal acts that provide retirement regulations.
} 
increase compared to other funds. This phenomenon could be explained, first of all, by the strong increase of the contingent of beneficiaries, of compensations for children support between 1.5 - 16 years of age as a result of raising up the income threshold that grants the right to get compensation and of increasing the compensation quantum ${ }^{43}$. As compared to 2003 , the number of beneficiaries receiving such compensations rose by $22.6 \%$, while the costs incurred for such payments increased 2.3 fold.

\section{Social Insurance}

283. In 2004 the discrepancy between the men and women life expectance was emphasized even more. The situation with men' life expectance on average is more favorable in the Republic of Moldova as relative to other CIS countries (64.5 year compared to 61.8 years in CIS), and less favorable in comparison with the EU countries (68 years for men and 79 years for women $^{44}$ ). The life expectances for women are comparable (72.2 in the Republic of Moldova in 2004, 72.9 in CIS in 2001).

284. The population demographic ageing phenomenon should be taken into consideration while formulating the decision policies with respect to the retirement system, and the impact of those decisions over the financial stability of the State Social Insurance Budget. The analysis of the demographic situation in the Central and Eastern Europe countries as well as in the former Soviet Union republics (Lithuania and Georgia) indicates that by the government intention to minimize the bankruptcy risks of the pension systems, the standard retirement age was increased by 5 years. In the Republic of Moldova the situation was tackled differently. Although the retirement system reform was launched very confidently in 1998, any increase in the retirement age for both men and women was stopped in 2003, sticking to 62 and 57 year respectively, which led to stagnation at the level of 2002. The decision impact on the number of newly established pensions in 2003 was huge ( 2.5 times more in comparison with 2002), while in 2004 that increase amounted $14 \%{ }^{46}$.

285. The average old age pension increased by $18.2 \%$ in 2005 compared to 2004 , and by $82.6 \%$ in comparison with the 2003 level. The real size of the old age pension (with the adjustments for the Consumer Price Index) made up 300.9 MDL, recording a 39\% increase ${ }^{47}$.

286. The replacement coefficient was $30.7 \%$ for the old age pensions as of January 1, 2005 (in $2004-30.5 \%$, in $2003-24.5 \%)^{48}$. The replacement coefficient has been gradually

\footnotetext{
${ }^{43}$ According to the Decision of the Government of the Republic of Moldova No. 416 from April 26, 2004, starting from January 1, 2004 the monthly allowance for child care (for both the insured and non-insured persons) is paid in the amount of $50 \mathrm{MDL}$ to families with low income in case the average monthly income level did not exceed 54 MDL per family member during the previous semester. In 2003 the amount of this allowance (for both the insured and non-insured persons) made up 25 de MDL and was paid only in case when the monthly average income level per family member did not exceed in the previous semester $18 \mathrm{MDL}$ for families with one-two children, $27 \mathrm{MDL}-$ for families with three and more children, and $54 \mathrm{MDL}$ for families supported alone by single mothers.

${ }^{44}$ European Database Healthcare for All (HFA-DB). January 2005.

${ }^{45}$ CIS Figures: WHO-HFA Database in: the World Bank Report (2004), Recession, Recovery and Poverty in Moldova, Report No. 28024-MD, Washington DC: page 13.

${ }^{46}$ Source: RSA 2004

${ }^{47}$ Source: The National Bureau of Statistics.

${ }^{48}$ In 2003 the average wage made up 890.8 MDL, in 2004 - 1,104 MDL, in 2005 (April - June - 1,296.1 MDL. The National Bureau of Statistics
} 
increased, but remains pretty small if compared to the subsistence level. The average old age pension for this category of population covers $59 \%$ of the subsistence level ${ }^{49}$.

287. The principle of social solidarity and the lack of private and professional pension funds, including the privileged pensions, make the system less attractive for the population participation. If at the beginning of the social insurance system general reform $^{50}$ the taxpayer/pensioner ratio was 1.7, then at the beginning of 2004 the ratio was 0.8 .

288. In order to maintain the financial sustainability of the pension system, enhance the social fairness and ensure a tight relationship among the insured risks, contributions and benefits, in 2004 the process of redistributing the contribution ratio between the employer and the employee was started, aimed at reducing the proportion paid by the former and increasing the proportion paid by the latter with the concomitant reduction of the general contribution rate from $30 \%$ in 2004 to $29 \%$ in 2005 . Thus, in 2005 the employer's contribution was $27 \%$, and the employee's contribution was $2 \%$.

289. Participation to the social insurance system of people working in the agricultural sector continues to be a stringent problem because the accumulated amounts from their contributions do not cover even one third of the necessary resources to be paid to them. At present the employees from the agricultural sector contribute with just $6 \%$ to the State Social Insurance Budget revenues, while benefiting from $53 \%$ of them. The problem could be resolved through the implementation of a Strategy on reforming the retirement system for persons working in the agricultural sector, which provides the transition to the principle of fixed amount contribution from the derived income, including partial subsidies from the State. The application of the new policy approaches may generate both positive (recovery of resources spent within the State Social Insurance Budget from the Sate Budget) and negative (increased pressure on the State Budget) effects.

290. The use in 2004 of cumulative measures aimed at increasing the pensions through recasting along with the mechanism of annual indexation of pensions required additional financial resources, and, as a result, led to depletion of funds and marked the economic instability of the State Social Insurance Budget. Concomitantly, the indexation procedure interfered with a changed formula for pension computation for the realized period until $1999^{51}$, which led to system errors. Thus, small pensions, which, as a result of recasting based on the new formula, did not reach at least $25 \%$ of the established pension level, were increased to reach the established pension level, and this action was not fair with regard to people receiving larger pensions. Although there was noticed a rise in the nominal size of the pension, its real value and the wage replacement coefficient remained very low.

\section{Social Assistance}

291. The performance of social assistance programs was pretty inefficient during the last years, especially duet to irrelevant channeling of resources. The main objectives set up for the

\footnotetext{
${ }^{49}$ The minimal subsistence level: 2003 - 615.8 MDL, 2004 - 702.0 MDL, 2005 (January - March) - 771.78 MDL. The National Bureau of Statistics

${ }^{50}$ The National Pension System Reform was launched in 1999 and is ongoing.

${ }^{51}$ Unlike the recasts applied in 2001-2002, performed through the establishment of a fixed amount for the pension increase or of a specific percent of pension increase, in 2004 the pensions were recalculated based on the pension new computation formula for the pension proportion computed before January 1, 1999 .
} 
social assistance are oriented on increased efficiency of social benefits and social services and their targeting towards the poorest people and focusing on the social groups at risk. ${ }^{52}$.

292. The EGPRS lists the main shortcomings of the Social Assistance System: (i) the establishment of social benefits is based on category principle, except for two types of benefits based on testing of resources; (ii) social services are weak and not adjusted to the local needs of communities, being targeted towards a limited number of groups; (iii) the lack of financial resources does not allow to satisfy the request for social services, thus, resulting in a pretty expensive care rendered broadly.

293. The costs of social assistance programs in 2004 amounted for circa $28 \%$ of the total expenses for social protection or 829.6 million MDL. The major part, about $90 \%$, of the expenses on social assistance is borne by the State Budget and only a small part - by the administrative-territorial unit budgets ${ }^{53}$.

294. Currently the social assistance system comprises 15 cash benefits expressed in compensations, social allocations, and other cash payments, being regulated by 16 legal and normative acts. Most social benefits are delivered based on category principle, while the quantum of each benefit differ depending on its type and the category of beneficiaries. The most representatives, both by the number of beneficiaries and by costs, are the individual compensations $(45 \%)$. Compensations for children rank second (19\%), being followed by the state social allocations and monthly state allocations to veterans and war participants $(12 \%)$. Respectively, the largest annual average is represented by the state monthly allocations delivered to a pretty small number of people ${ }^{54}$. In 2004, the social assistance benefits paid from the transfers from the state budget through the National Social Insurance House (NSIH) amounted for 455 million MDL. 272 thousand persons benefited form assistance in the amount of 41 million MDL, rendered from the means of the Republican Fund of Social Support to Population.

295. The lack of a single database of all social assistance beneficiaries makes it impossible to identify both the number of beneficiaries of social assistance and the number of social benefits rendered to them (because one beneficiary may get concomitantly up to 11 types of benefits). Another problem is related to the lack of a recording mechanism focused on a "family" approach, because within one family there may be two or even more persons entitled to separate benefits, which makes it impossible to evaluate the total amount of the assistance delivered by the state to vulnerable groups. The state social insurance budget remains fragmented and little transparent from the point of view of fund flows circuit. Thus, within the budget the money are not strictly channeled to funds but circulate from one fund to another depending on the payment needs, hence, it is not possible to analyze the efficiency of the budget transfers by program performance.

296. According to the Concept on efficiency increase of the social assistance system, it has been proposed to introduce a system based on a filter combined with a simple testing of resources. It is expected that the efficiency of channeling the resources will be enhanced through the reduction of both errors - inclusion and exclusion (inputs and outputs). Regretfully, this document does not provide clear policy steps to be undertaken during the next year for

\footnotetext{
52 Ibid: page 118 .

${ }^{53}$ Data from the Project of Midterm Expenditure Framework. DFID/Ministry of Finance

${ }^{54}$ We mention that single compensations paid to families (participants to liquidation of consequences of Chernobyl catastrophe) that lost their family support person have been established to a very small number of persons, thus it does not have a representative value within the present Analysis.
} 
integral reorganization of the system, which presumes a program of simplified and transparent benefits combined with social services that should be assessed on time.

297. The poverty profile reflects that the poverty rate amongst the households, which income is derived from social transfers, is higher than the average poverty rate. $36 \%$ of population who lives in such households is poor and $20 \%$ - extremely poor. Households managed by pensioners, likewise, are characterized by an increased risk to poverty (31\%). Nevertheless, having analyzed based on HBS data, the risk to be exposed to poverty by age categories, it has been noticed that the approach itself is erroneous and leads to a hyper inclusion in the system, hence, aged people are not so poor as it is usually thought. A separate segment to be taken into consideration are persons aged over 75 years, who, due to the age and health peculiarities, and the insufficient social services in the community, are exposed to high risk of dependency on social system.

298. The incidence of benefits remained unchanged during 2003-2004. Generally speaking, in $2004,53 \%$ of all households benefited from social transfers. The most frequent payments are old age pensions and state social allocations. Circa half of households have a member who receives a type of pension.

299. Social assistance transfers are allocated to fewer households. In 2004 only $16 \%$ of households benefited from Social Assistance Transfers. Individual compensations represent the most frequent transfers because this program includes 12 categories of beneficiaries ${ }^{55}$, which means that the system access level is pretty free. More than half of beneficiaries are people with disabilities. $16 \%$ of individual compensation beneficiaries are participants to the Second World War and $14 \%$ are single pensioners.

300. Although only $15 \%$ of households that are part of the richest categories receive social benefit they receive $30 \%$ of the allocations total value. The poorest quintile, from the other hand, received only $13 \%$ in 2004 .

301. In spite of the fact that the Compensations for Children Program is considered to be one of the most important and successful social assistance programs, its impact on the families with children welfare is not significant because of the small quantum and permanent variation of the amount due to inflation. In 2004 only $12 \%$ of all families with children aged up to 16 years benefited from compensations for children compared to $9 \%$ in 2003 .

302. In 2004 the real value of monthly compensations for children care marked a $114 \%$ increase for the insured persons and a $60 \%$ increase for the non-insured persons. The value of compensations for children care aged up to 16 years based on income testing, both for the insured and non-insured persons, increased by $114 \%$ in comparison with 2000 . Having considered the compensations for children from the point of view of their real growth we can notice that this value also varies depending on the legislative initiatives in the field of family policies promoted each year, which, in fact, are pretty vague. Hence, in 2004 only the nominal value of compensations for children aged up to 16 years was raised, resulting in a real $78 \%$ increase compared to 2003, but no increase was applied to compensations for child care, thus their real value was reduced by $11 \%$ as relative to 2003 .

303. The current „State Basic Package” includes the following services: residential, care services at home and services rendered by social canteens. Alternative services are developed and rendered by the civil society, at the same time there is no state mechanism to certify the social assistance services and control their quality. This state of matters does not allow to

\footnotetext{
${ }^{55}$ Law No. 933-XIV from April 14, 2000, regarding the special social protection of certain categories of population, amended and complemented through the Law No. 447-XV from December 30, 2004.
} 
control the situation in the field, to assess the costs of services and to create a competitive market for all social service suppliers.

304. In 2004 the institutionalization rate grew by $1.2 \%$ as compared to 2003 , and by $14.7 \%$ in comparison with 2000 . Out of the total inmates $55 \%$ were persons from the category with chronic psychic diseases, $22.6 \%$ - aged people and $22.4 \%$ - children with deficiencies. The great demand for institutional care is caused by the reduced capacities of the local public administration authorities to develop social services and render such services upon the community needs. The aged people care services are most demanded in communities after the institutions. During 2004 the number of served persons increased by $7.2 \%$ as relative to 2003 . The most ardent problem in this respect is the limited number of persons who could benefit from these services (single old persons and immobilized invalids). A large part of the population at risk (disabled children, invalids from childhood etc.), being deprived from the access to such services, generates a great demand for institutional services.

305. The number of beneficiaries using the services rendered by the social canteens as well as the costs incurred for their sustenance marked an ascendant trend. ${ }^{56}$ In 2004 the number of beneficiaries using the services rendered by the social canteens grew by $25 \%$ as relative to 2003, and twofold in comparison with 2000. This phenomenon could be explained by the applied rotation mechanism and by the outdated questionnaires, which do not allow filtering the access to the respective services. ${ }^{57}$

\section{Labor Market}

306. The situation on the labor market is characterized by the dynamics of labor resources, population activity and occupation rate, unemployment rate and capacity of national economy to use available human resources at maximum capacity. The current labor force market continues to be rigid, inflexible and unable to answer to economic requirements, thus generating structural, territorial, occupational and professional imbalances. The economic crisis from 1998 led to a considerable reduction of work places, increase of unemployment and migration. Although, staring with 2000, economy picked up, economic growth did not trigger the essential enhancement of employment opportunities. Population's economic activity rates continued to be reduced, which indicates the withdrawal of discouraged people. In light of these achievements, EGPRS sets forth: "Economic growth should be followed by a more active participation of labor force, enhancement of employment rate, as well as the increasing role of wage revenues in poverty reduction"

307. Despite the decline in the rate of active population in 2003 the general rate of active population was only 2 p.p. lower than in the 25 EU member states $(56.5 \%)$. The share of active population among women is smaller than among men, though the difference is decreasing.

308. The rate of occupation remained almost unchanged during 1999-2002, at about 54\%. This indicator has decreased to $49.7 \%$ in 2004 . The gender analysis of the occupation rate also

\footnotetext{
${ }^{56}$ Due to financial reasons, the number of social assistance canteens is being changed permanently. As of January 2004, the number of functioning canteens was 54, while by the end of the year the number of canteens reached 73. The activity of social assistance canteens is financed from the administrative-territorial unit budgets and from the extra budgetary resources (the Republican Fund and the local funds of social support to population, sponsors, philanthropic organizations, non-governmental and religious organizations, legal and physical persons).

57 The existing scheme allows the solicitors to enter the system manifold per year without affecting their welfare.

58 The Government of the Republic of Moldova (2004) Economic Growth and Poverty Reduction Strategy Paper (2004-2006). Chisinau, pag.117-118.
} 
shows a downward trend for both men and women. However, the decline of the occupation rate for men is higher ( 9 p.p.) than for women (7 p.p.).

309. The analysis of the occupation rat eby age shows that youth face a smaller rate. The occupation rate among youth registered a steep reduction of about 15 p.p. between 1990 and 2004.

310. The distribution of employment by sectors is changing slowly. If in 1999, agriculture accounted for $50 \%$ of total employment, in 2004 this figure decreased down to $41 \%$. The services sector continues to win ground, in 2004 it accounted for $47 \%$ of employments. $78 \%$ of employed people work in the formal sector, $13 \%$ in the non-formal one, and $9 \%$ are employed in the sector of households which is generally related to household production. ${ }^{59}$

311. In 2005, employees made up $62.9 \%$ from occupied population. This is a reduction of $12.6 \%$ compared to 2000 . The rate of occupied un-paid population grew from $37.2 \%$ until $39.1 \%$. Of the total 495 thousand, 406 thousand unpaid people are occupied in agriculture (selfemployed (73.5\%); employers, non-paid family assistants (4.2\%); cooperative members. Only 135 thousand $(23 \%)$ of people occupied in agriculture are employed in agricultural units and receive salaries.

312. In 2004, the unemployment rate remained at a relatively low level, representing $8.1 \%$, which is an insignificant reduction by $0.5 \%$ compared to 2003 . In 2005 , the unemployment rate calculated according to BIM methodology registered a country level of $7.3 \%$. It reaches $10 \%$ for men and $6.3 \%$ form women. The unemployment rate among the population aged from 15 to 29 is twice as high compared to the country's average. Disparities between the unemployment rate in the urban area $(10.7 \%)$ and rural $(3.4 \%)$ are still present.

313. Most of the able bodied population aged between 15 and 64 years earn the largest part of their income either from the private agricultural household $(28 \%)$ or from employment in the private sector $(27 \%)$. Social transfers are the main source of income for $15 \%$ of the active population.

314. Poverty is influenced by the degree of occupation of people and by the main income source. With all that, the fact that a person is employed in the work force is not a guarantee against poverty. The poverty rates are higher for people who work, than for invalids, sick or those on study.

315. This situation forces the population to look for jobs abroad and immigrate. The preliminary results of the 2004 census show that about 367,000 thousand Moldovan citizens work aboard. The rate of people who left abroad is increasing. In 2005 they made up 27.7\% from the economically active population and $18 \%$ from the economically inactive population. Consequently, the number of migrants grew by $14.3 \%$ in 2005 versus 2004 . Compared to 2000, the growth is 85.95 .

316. In 2004, the average monthly wage of an employee grew by 2.7 times, including in the real sector by 2.55 and in the budget sector by 2.83 , thus providing for an annual growth of the real wage. In January-October 2005, the average wage increased compared to the same period of 2004 by $19.3 \%$. The minimum state remuneration guarantees increased (the minimum wage in the economy and the tariff wage for the $1^{\text {st }}$ qualification category in the real sector of economy). Although political efforts are made, the general level of remuneration is at a reduced rate, which is not a guarantee for a way out of poverty.

\footnotetext{
${ }^{59}$ Source: NBS
} 


\section{Conclusions}

317. The access to education has been slightly improved during the last few years. The enrolment rates have been stable except for the enrolment in primary school from the rural environment (the National Bureau of Statistics data). Children from poor households and rural households start school attendance at later stages and abandon the school earlier in comparison with children from other households. These children start their studies with arrears because they did not attend preschool institutions. The main reasons the children between 3-16 years of age do not attend schools are the following: schools do not function in their community $(33 \%)$ and financial difficulties $(27 \%)$. The poverty analysis shows that a person's education level has a tight relationship with his/her living standards. Households, which Head has not completed a secondary school, are more exposed to poverty. Hence, poor children who do not have possibilities to acquire an education level higher than the mandatory have the chance to be poor in the future. In this context, children alimentation within the educational institutions represents an efficient mechanism to attract children from poor families into the educational system.

318. Institutionalization of children is continuously regarded as a viable solution in case of family problems and in case of lack of specialized educational services in the community. The family-type children houses would be a solution in case they comply with the minimal quality Standards for the rendered services.

\section{Healthcare}

319. The increased volume of chargeable medical services places the poor households especially in a difficult situation. The introduction of mandatory insurance does not resolve the problem for all these households: one third of the poor are not covered by the medical insurance policy. Due to the fact that the poor households' budgets are weak, these persons can afford less medical services in comparison with the non-poor people.

320. The expenditures for public medical assistance remained at a relatively stable level during the last few years, making up approximately 4\% of GDP. About one fifth of the total expenditures of the social sector are used for medical assistance. The increased MHIF resources during the last few years are generated by the effects of the nominal average monthly wage increase in the republic and by the raised amounts of transfers from the State Budget for the categories of populations (pensioner, the unemployed people, children aged up to 18 years, students, disabled people and other categories) insured by the State through the MHIF.

321. Having analyzed how efficient the resources channeled through mandatory medical insurance funds were used by types of ambulatory medical services (primary medical assistance and ambulatory by specialty), it is worth mentioning that services rendered at hospitals are very expensive, the delivered services are not always targeted towards the most serious diseases, while the level of resource use being estimated at $60 \%$ of the total amount spent by the mandatory medical insurance funds (MMIF).

322. The Republic of Moldova has registered good results in achieving the MDC objectives in the field of Healthcare. Both the infantile mortality and the mortality of children under the age of five years have fallen continuously in both the rural and urban areas. The ratio of vaccinated children under two years old reached $99.1 \%$ in 2004 . The maternal mortality rate was 18.6 per 100,000 live births in 2005 . So far no significant results have been registered with respect to the reduction of mortality rate due to $\mathrm{TBC}$ as well as stopping the increase of HIV/AIDS incidence. An important problem is the prevention of non-contagious diseases that represent the main reason of morbidity, disability and premature death in the Republic of Moldova. Insufficient financing of informative and preventive activities, reduced initiative of 
medical workers from the primary medical assistance as well as the lack of informative and educational materials contribute to minimization of efforts to reduce the incidence of these diseases.

\section{Social Insurance}

323. The retirement system reform is being implemented pretty slowly, while the financial stability of the State Social Insurance Fund is a source of concern. The delay in implementing the system of personal records and the lack, in general, of an adequate incentive system both for the employers and the employees do not improve the situation at all.

324. The average old age pension was increased by applying an indexation rate of $18.2 \%$. The real size of the old age pension (with the adjustments for the Consumer Price Index) made up 300.9 MDL, recording a $39 \%$ increase ${ }^{60}$. The replacement coefficient was $30.7 \%$ for the old age pensions as of October 1, 2005, and although it increased gradually, it still remains pretty small if compared to the subsistence level. The average old age pension for this category of population covers $59 \%$ of the subsistence level ${ }^{61}$.

325. The principle of social solidarity and the lack of private and professional pension funds, including the privileged pensions, make the system less attractive for the population participation. If at the beginning of the social insurance system general reform ${ }^{62}$ the taxpayer/pensioner ratio was 1.7 , then at the beginning of 2004 the ratio was 0.8 .

326. Participation to the social insurance system of people working in the agricultural sector continues to be a stringent problem because the accumulated amounts from their contributions do not cover even one third of the necessary resources to be paid to them. At present the employees from the agricultural sector contribute with just $6 \%$ to the SSIB revenues, while benefiting from $53 \%$ of them.

327. The policy of redistribution of contributions between the employer and the employee is being implemented forwards. Although it was planned to implement personalized recording of payers to the Social Insurance System starting from 2000 this task has not been completed in full yet till now.

\section{Social Assistance}

328. The performance of social assistance programs was pretty inefficient during the last years, especially due to irrelevant channeling of resources.

329. The costs of social assistance programs in 2004 amounted for about $28 \%$ of the total expenses for social protection or 829.6 million MDL. The major part, about $90 \%$, of the expenses on social assistance is borne by the State Budget and only a small part - by the administrative-territorial unit budgets ${ }^{63}$.

330. Currently the social assistance system comprises 15 cash benefits expressed in compensations, social allocations, and other cash payments, being regulated by 16 legal and normative acts. Most social benefits are delivered based on category principle, while the quantum of each benefit differs depending on its type and the category of beneficiaries. The most representative, both by the number of beneficiaries and by costs, are the individual

\footnotetext{
${ }^{60}$ Source: NBS.

${ }^{61}$ The subsistence minimum: 2003 - 615.8 MDL, 2004 - 702.0 MDL, 2005 (January - March) - 771.78 MDL. NBS

${ }^{62}$ The National Pension System Reform was launched in 1999 and is ongoing.

${ }^{63}$ Data provided by the Project on the Midterm Expenditure Framework. DFID/Ministry of Finance
} 
compensations (45\%). Compensations for children rank second (19\%), being followed by the state social allocations and monthly state allocations to veterans and war participants $(12 \%)$. Respectively, the largest annual average is represented by the state monthly allocations delivered to a pretty small number of people.

331. The poverty profile reflects that the poverty rate amongst the households, which income is derived from social transfers, is higher than the average poverty rate. $36 \%$ of population who lives in such households is poor and $20 \%$ - extremely poor. Households managed by pensioners, likewise, are characterized by an increased risk exposure to poverty (31\%).

332. The lack of a single database comprising all social assistance beneficiaries as well as the lack of a recording mechanism focused on a „family" approach makes it impossible to identify the total number of beneficiaries of social benefits and the total amount of the assistance delivered to them.

333. The state social insurance budget remains pretty fragmented and little transparent from the point of view of money flow circuit amongst the funds.

334. The current „State Basic Package” includes the following services: residential, care services at home and services rendered by social canteens. Alternative services are developed and rendered by the civil society, at the same time there is no state mechanism to certify the social assistance services and control their quality.

\section{Labor Force Market}

335. The current labor force market continues to be tight, inflexible and incapable to respond to economic exigencies, thus generating structural, territorial, occupational and professional imbalances. In 2005 , the economically active population made up $41.9 \%$ of the total population and reduced by $14 \%$ compared to 2000 .

336. The labor force Ocuparea decreased in 2003 - 2004 to $49.7 \%$ in 2004 . The analysis of the labor force ocupare by gender indecates a decreasing tenency for both men and women.

337. In 2005, the unemployment rate calculated according to BIM methodology registered a country level of $7.3 \%$. It reaches $10 \%$ for men and $6.3 \%$ form women. The unemployment rate among the population aged from 15 to 29 is twice as high compared to the country's average.

338. The rate of population who left abroad is increasing. In 2005 they made up $27.7 \%$ from the economically active population and $18 \%$ from the economically inactive population.

339. In 2004, the average monthly wage of an employee grew by 2.7 times, including in the real sector by 2.55 and in the budget sector by 2.83 , thus providing for an annual growth of the real wage. In January-October 2005 , the average wage increased by $19.3 \%$ compared to the same period of 2004. The minimum state remuneration guarantees increased (the minimum wage in the economy and the tariff wage for the $1^{\text {st }}$ qualification category in the real sector of economy). Although political efforts are made, the general level of remuneration is at a reduced rate, which is not a guarantee for a way out of poverty. 


\section{CENTRAL PUBLIC ADMINISTRATION REFORM}

340. The need to adjust to profound and radical changes of Moldova's economy during the last period and the influence of external factors imposes new requirements towards the overall political system and that of Moldovan Government in particular. Starting with the need to enhance country's competitiveness in the international economy as provided in the EGPRS, Government took the lead in implementing a fundamental reform of central public administration in Moldova.

341. The goal of reform launched in the first half of 2005 is the creation of a modern and efficient system of central public administration, in compliance with good governance principles of EU member-counties. The reform envisages the transformation and modernization of public administration in Moldova based on the central public administration reorganization, optimization of the decision making process, enhancement of human resource management and public finance.

342. Within the framework of the participatory council, the Strategy of public administration reform was developed and approved. The strategy envisages: (i) redefining competences and attributions of central bodies of public administration, and (ii) reconfiguring the central executive structure, taking into account Government priorities. During the previous year, the first stage of the functional analysis and the analysis of the decision making process in the central bodies of public administration was carried out. A sector assessment of the public service was undertaken. Currently, public administration reform comprises 28 specialized public bodies of public administration from the central executive.

343. For the enhancement of the decision making process, the Strategy envisages the following measures: (i) improving the development, approval, implementation and assessment of normative acts and policies in particular; (ii) developing ministries capacities to develop, analyze and monitor policies implementation;(iii) streamlining the system of planning and reporting; (iv) improving the quality of approved documents.

344. The strategy provides for the development and promotion of the draft Law on public service and the status of the civil servant that should regulate: (i) the functioning of the central administrative body responsible for the public service management; (ii) ensuring and promoting people in the civil service on the basis of competition; (iii) separating political functions from administrative ones,

345. Competences, functions and organizational structure of central public administration bodies will be targeted and focused on accomplishing Government priorities set forth in the main policy documents (Government activity program "Country modernization - people's welfare"), EGPRS, Moldova -EU Action Plan and others). The activity and resources of Government and ministries will be focused on policy making, monitoring and control, by delegating functions for policy implementation, as well as those related to the micromanagement of institutions subordinated to ministries.

346. An adequate legal framework will be adopted and implemented that will clearly define the type of central public administration organizations, their main competences and mutual relations with regard to monitoring, control and clear reporting arrangements.

347. The implementation of the public administration reform is a precondition for the development and successful implementation of structural reforms in all EGPRS areas. 


\section{REGIONAL DEVELOPMENT}

348. One of EGPRS priorities is the balanced and sustainable social and economic development across the country and reduction of disparities in the development of all regions, especially the capital and the rest of the country. Rayon and municipal Councils have developed and approved action plans for EGPRS implementation for respective regions, developed in conformity with the Government Decision nr. 116 from February 3, 2005. These plans identify general objectives for the medium term social-economic regional development (2005-2006) that are detailed in measures and actions of local public administration.

349. Despite the importance and relevance of regional policies in promoting sustainable economic growth, registered progress in this area is not sufficient. Until now, clear policies and priorities in relation to regional development are lacking. A study was carried out with the support of development partners and a law draft was developed for a system of future laws in this area. This law suggests specifying the main functions of central administrative bodies in the area of regional development.

350. One of the fundamental priorities of regional development policy set forth in the draft law is the principle of devolution, which represents a process of administrative responsibility and authority transfer from the central to the local level. Today there is not a clear and detailed delimitation of functions between the central and local public administration bodies, as well as between the authorities of territorial-administrative units of the first (city) and second level (rayon).

351. On one hand, the lack of economic base for budget revenues formation represents a major problem for the development of the regions. On the other hand, the unsatisfactory state of economic and social infrastructure prohibit the development of businesses and hence of the tax base. Moreover, even if some companies decide to initiate businesses in this space, very often the hostile attitude of local authorities spulbera interest.

352. The current situation is worsened by a chronic lack of investments. During 2003-2004 out of the total amount of investments in fixed capital of MDL 8,8 billion, the economy of Chisinau and Balti received MDL 5,3 billion or $60 \%$ of the total, while the rural sector received just MDL 3,5 billion. In 2003-2004 the share of investments in fixed capital except for Chsinau and Balti, made up 32\% in the north, 38\% in the center, and $40 \%$ in the South. The lowest level of per capita investments in fixed capital was in the center, $20 \%$ less than the average in rayons and $28 \%$ in the South, which is above the average.

353. Transfers from the state budget did not prove to be a flexible mechanism of financial support for territories able to change their capacity to self financing. On average, transfers account for about $48-75 \%$ of the total budgetary revenues of rayons.

354. The existence of a range of fundamental problems generates regional, social and economic disproportions and imbalances between rayons. Taking into account the level of economic development, regional imbalances are more visible in small towns and are highlighted by a selective location of investments. Chsinau and Balti are cities with performances, improved situation and dynamics of economic growth. The share of Chisinau in the total amount of industrial production is $55 \%$, and that of Balti is $12 \%$. Most of small business agents are in Chisinau. In this regard, Chisinau accounted for $73 \%$ in 2004, followed by Balti with $5 \%$.

355. Based on statistical data for 2004 with regard to the level of industry, agriculture, trade, paid services to the population, investments in fixed capital, density of public roads, it should be 
pointed out that in $2 / 3$ of rayons, the total average value for this indicators calculated per capita is below the average for rayons.

356. As to the amount of per capita industrial production, Briceni, Criuleni, Leova, Ocnița, Rîşcani, Teleneşti rayons registered the lowest rates that were within the 250 limit in 2004 for (Briceni, Criuleni, Leova) and MDL 4,930 (Cahul, Taraclia, Găgăuzia ATU).

357. Except for Chisinau and Balti, business opportunities tend to concentrate almost equally in central and southern rayons, each of them accounting for about $8 \%$ in the total amount of revenues from sales per capita, and $6 \%$ for the northern part.

358. As to the rural infrastructure, the analysis of public roads density highlight the discrepancies between the highest levels registered in the north, which is by $28 \%$ larger compared to south and by $23 \%$ compared to center.

359. Taking into account the amount of retail sales calculated per capita, the highest level is registered in the center, followed by northern regions and south, the difference between the regions is insignificant and is within $2-5 \%$.

360. Economic disparities affect population revenues, living standards, labor force occupation. The level of the monthly nominal average wage of an employee (according to statistical data for 2004) in the center and south is the same and if compared to northern rayons there is a slight advance of about $4 \%$. With regard to labor force occupation, the unemployment rate in center and south is virtually at the same level, whereas for the northern part this indicator is about $20 \%$ lower compared to center and south.

361. During 2003-2005, south accounted for about 40\% in total workplaces, north and center account for 30\% each. Most jobs during this period were created in Gagauzia ATU (GagauzYeri), and Cahul, Căuşeni, Hînceşti, Orhei, Soroca rayons.

\section{Conclusions}

362. Regional development is an issue with many variables, of which the factor related to investments is dominant. The ultra-concentration of national investment potential in Chisinau and Balti does not reflect the Government objectives in the area of regional development. The phenomenon of two investment epicenters (Chsinau and Balti) may be viewed as a counter social and economic performance in terms of regional development.

363. The policy of regional development is based on elements of social and financial cohesion. Fiscal tools, the private sector, the component of social and economic infrastructure represent the landmarks for the quantification of the impact of this policy. These elements may cooperate only subject to their financial cohesion.

364. Following the actions or lack of actions of public authorities in the regional development policy, we find an absence of continuity in their attempts to promote a well thought policy based on the same principles and objectives. 


\section{COMMUNICATION AND PARTICIPATION PROCESS}

365. In conformity with EGPRS provisions, the Participation Council has the task to facilitate the participation of all interested parties on the national and local level, from within and outside the Government in order to: (i) provide EGPRS transparent implementation; (ii) to involve and train different partners in the process of Strategy implementation; (iii) to create an environment for discussions with participation of different parties, interested in problems and challenges settlement; (iv) to facilitate the participative monitoring and independent evaluation of obtained results; (v) to ensure the drafting and implementation of an efficient communication strategy in related with interested parties. The Secretariat of the Participation Council was instituted as its executive body.

366. Once the EGPRS implementation stage was launched, the Participation Council was auto-organized to ensure active participation of the civil society in Strategy implementation, monitoring and evaluation process, new members from the Parliament, civil society, private sector and development partners being co-opted.

367. To realize its tasks, the Participation Council has assigned the following objectives: (i) to draft and implement a Communication Strategy aimed to inform the interested parties on the EGPRS implementation, monitoring and evaluation process; (ii) to initiate some public discussions on subjects of major interest (draft laws, strategies, studies, policies impact evaluation reports, etc); (iii) civil society representatives' capacities consolidation within the EGPRS monitoring process.

368. In conformity with the Communication Strategy, approved by the Council at the beginning of 2005, several actions have been undertaken. The public was informed through the EGPRS Information Bulletin regarding the implementation of the Strategy in different areas: health, agriculture, private sector development, environment protection, youth and infrastructure development, social protection, tourism development, etc. Five editions of the Bulletin have been issued and distributed as a supplement to 17 local and national newspapers. Each edition included about 90,000 copies (in Romanian and Russian). The electronic version of the Bulletin can be accessed on the site: http://www.scers.md/.

369. The radio broadcast cycle "EGPRS - steps to a better life" presented a series of reportages, interviews, news regarding EGPRS implementation process. Public employees, leaders of opinion, experts, and simple citizens had the possibility to analyze and to comment on the manner how the objectives of the Strategy have been implemented and what was their impact on citizens' welfare. The broadcast was issued by the National Radio on a weekly basis (100.5 FM and 873 AM). The electronic version can be accessed on the site: www.scers.md/index.php?id=52 .

370. The web page www.scers.md was conceived as an instrument of information for some, more specialized segments. There are placed studies, reports, last news regarding the EGPRS implementation process. The page includes a forum which can be utilized by users to express their opinions, request information, ask questions, etc. Some draft laws and strategies for public discussions were also placed on the website. During 2005 the page was accessed by 7,000 users and it was awarded the III place within the contest „WEBTOP” 2005 on the category „Public Administration and Law".

371. To adequately inform the interested parties with respect to EGPRS provisions and modalities of involvement into the process of implementation, monitoring and evaluation, the booklet "EGPRS in Brief. Practical Guide for those who wish to know what is EGPRS" was 
prepared and published. 8,000 copies in Romanian and 2,000 in Russian have been published. The distribution was made through NGOs national and local networks, central and local public institutions, etc. The electronic version can be accessed on the site: www.scers.md .

372. The communication activities organized by public institutions since EGPRS approval have been sporadic and haven't emerged into a well formulated strategy. These actions were limited to publishing information regarding the implementation of EGPRS commitments of the web pages of these institutions or to using different instruments offered by the Participation Council. Being aware of the role that communication might have for the initiation of participative processes, providing transparency to actions, not raising misinterpretations with respect to latter utility, stimulating the credibility degree of institutions representing the state and reducing to maximum the communication blockage which don't permit efficient dialogue between various institutional categories, the Government proposed to draft the EGPRS Communication Strategy.

373. Consequently, the draft Communication Strategy and Actions Plan for 2006-2009 was drafted. The internal objectives of the Strategy are: (a) to create a functional mechanism of population efficient information explaining why a reform or the other is needed, what it exactly means, who are the beneficiaries and what are the advantages to be obtained if one set's his/her shoulder to its implementation; (b) to draft and transmit clear cut - correctly directed messages under the configuration of target groups; (c) to provide reforms transparency by disseminating genuine information regarding their step by step implementation; (d) to provide continuity of the information flux; (e) to establish an climate of confidence in the future, in real growth of population welfare and poverty reduction; and (f) to increase the level of state institutions credibility among population.

374. Externally, it is meant to present the Republic of Moldova by an efficient country communication profile and to increase the level of truthful information about the Republic of Moldova with the purpose to raise the attention of donors community, and, even more important, to determine the foreign businessmen to consider the Republic of Moldova as a favorable investment climate.

375. During 2005, there were organized 22 public debates discussing different draft laws, strategies and reports from such areas as: regional development, small and medium size enterprises development, access of poor population to potable water and sewerage, policies impact on poverty evaluation, etc. During the discussions the representatives of civil society, state institutions, and development partners exchanged their opinions, comments and proposals. This modality became a tradition within EGPRS implementation process and is worth continuing.

376. The Government supports the initiative of the Participation Council which committed to facilitate an independent monitoring and evaluation of policies, by developing complementary reports for specific EGPRS areas and confirms its availability to provide stakeholders with official reports, data on monitoring indicators, and other relevant information and to launch public debates to discuss the findings and conclusions of these reports.

377. The Government also encourages the involvement of the civil society in the communication process and in mobilizing the communities in the implementation of policies at the national and local level. Following the debates on the drat Report at the national level, regional discussion will be organized with the aim to ensure a larger involvement of local public administration of the first and second level, local businesses and NGOs. Timely and correct information of citizens will ensure their support to the promoted policies. With this objective in 
mind, partnerships between central and local public institutions and non-government organizations are welcomed as a mechanism for a continuous cooperation and interaction. 


\section{MONITORING AND EVALUATION SYSTEM}

378. The creation within the Government institutions of an efficient system of monitoring and evaluation of development programs implementation requires serious efforts. A more complicated task is building a participative system of monitoring and evaluation. Creation and institutionalization of such a system presumes the existence of strong public institutions and a high degree of cooperation among them. In its turn, this presumes an improvement of public service capacities, personnel training regarding modern methods of data collection, monitoring and analyses methods. All these activities can be implemented within the public administration reform. Respectively, the creation of an EGPRS and other development programs monitoring and evaluation process is a lengthy period and directly depends on the promotion of public administration reform.

379. The Program of the Government activity for 2005-2009 "Country Modernization People Welfare" establishes as the priority objective of the Government for this period the integral and in due term implementation of the EGPRS. In conformity with Program provisions the Plan of Actions was worked out, which, in the majority, represents a synthesis of EGPRS actions and Plan of Actions Republic of Moldova - European Union. Thus, the commitments incorporated in these two documents were included in the daily agenda of Government institutions.

380. A special unit - General Division for Macroeconomic Policies and Development Programs was created within the Ministry of Economy and trade, which task is to coordinate the process of monitoring and evaluation of development programs implementation, especially EGPRS (as medium term policy document) and MDG (as long term objectives). Poverty monitoring is also included into the competences of this Division. During the reference period, the majority of monitoring and evaluation activities were unfolded on this level.

381. Pursuant to EGPRS commitments, some efforts to create and institutionalize the system of poverty monitoring were undertaken. Therefore, the Decision of the Government regarding poverty monitoring system establishing (no. 851 from August 15, 2005) delimited the functions of the Ministry of Economy and Trade, the National Bureau of Statistics and other Government institutions in this area (Annex A3). In conformity with Decision provisions beginning on 2006, the NBS calculates the poverty rates and the respective unit of the MET analyzes the evolution of poverty indices and evaluates the impact of policies on the poverty level. In continuation, the Ministry of Economy and Trade drafted the Regulation regarding the procedure of poverty absolute thresholds calculation (Annex A3).

382. The institutionalization of poverty monitoring process allows the Government to provide continuous monitoring of poverty evolution. Within this context in 2005 the MET prepared the Poverty Report and Social Policies Impact, where the evolution of poverty for 2003- 2004 was analyzed and the impact of social policies on poverty indices was evaluated. The findings of the Report were discussed with public institutions and interested parties from outside the Government.

383. In 2005, for a better definition of poverty phenomenon geographic distribution, the process of deprivation indices calculation for each locality of the country up to commune level was initiated. With this purpose questionnaires have been drafted and distributed, based on which economic and social development Passports for each locality will be drafted. These passports, which will be filled in during the first half of 2006, will include economic, social, population infrastructure, education, etc. and other indices, data which could be used for different policies formulation. 
384. The transformation of policies impact monitoring and evaluation in a continuous and comprehensive process assumes the involvement of all public institutions. With this purpose, once the strategy of central public administration reforming was approved, a pilot project of constituting, upon the model of the MET Directorate, policy and analysis units within six Ministries: Agriculture and Food Industry, Transports, Industry and Infrastructure, Justice, Education, Youth and Sports, and Health and Social Protection was initiated. In order to provide better coordination between the monitoring activities of EGPRS commitments and the Plan RM - EU, it was proposed to transfer the monitoring functions on both Programs to these Directorates. This year it is planned to create these units de facto, providing training of the personnel and technical equipment. This activity will permit to improve the quality of analyses and evaluation process of own policies on the level of sector Ministries. In addition, activities to increase the capacities on the local public administration level, with the support of development partners, are provided.

385. The continuous monitoring of actions undertaken by the Executive and the evaluation of their impact will permit to improve the decision taking process, in general. This process assumes: (i) the improvement of monitoring and evaluation process coordination by unifying the format and reporting terms of different national programs, in view of duplication eliminating and (ii) transition from a simple reporting by actions to a system of results evaluation and formulation of proposals for policies improvement/ correction. Within this context, the Ministry of Economy and Trade has prepared a draft Instructions regarding EGPRS monitoring and evaluation, which will be discussed during the next period (Annex C). The two reports implemented till present, the preliminary report on EGPRS implementation from September 2005 and this first annual report, represent a result of efforts oriented to improve the policies impact evaluation process and development tendencies analysis

386. Both for EGPRS monitoring indicators (Annex B) and for the Millennium Development Objectives (MDG), the MET adapted the DevInfo data basis, (offered by UNICEF), which permits to stock and disseminate all intermediary and final monitoring indicators. During the current year, this data basis permitting a high level of desegregation (may include indices up to the level of commune) will be made available for all central and local public institutions, as well as for other stakeholders, which will permit the participative monitoring and evaluation of the EGPRS, MDG and other strategic documents implementation. 


\section{ANNEX A1: Main data sources and methodology}

\section{Main data sources}

Poverty evaluation and analysis requires a system of indicators and detailed information, which characterize the quantitative and qualitative aspects of this concept. This section describes the available data sources used in this report.

\section{Household Budget Survey}

The Household Budget Survey is considered an important source and in some cases the only one for the assessment of the quantitative aspect of the population's living standards. The survey is conducted by the NBS (since 1997) on a regular (annual) basis on the nation-wide representative probability sample. The sample contains 6480 households distributed equally (by 540 households) over 12 months, using monthly rotations system. Households provide information on the land used in a household, dwellings and amenities, demographic characteristics, the employment of household members, goods available in households, education and expenditures for education and health, access to public institutions, income, purchases and consumption for the respective month, purchase of non-food items over the last 3-12 months. Information is collected don the basis of the main household questionnaire (by specially trained persons, during three visits in the survey month) and the diary with daily records. The diary allows a household to keep record of income, expenditure, as well as food consumption from own production. The survey includes a panel component, which allows observing the poverty trends. The panel data were analyzed on the basis of the Household Budget Survey for 2001-2004.

\section{The household's opinion about poverty}

An aspect, which is equally important when analysing poverty, is the assessment of the situation by the population itself. The voices of the poor about the main causes leading to poverty in their opinion, and their understanding of the concept of ,,being poor" provide important information revealing the people's expectations. This information was obtained as a result of the selective survey „Households' opinion about poverty phenomenon". The survey has been conducted by the NBS since 2001, with the support of UNDP, each year in August, within the HBS network based on a monthly sample of 540 households. The survey allows analysing the concept of poverty as perceived by the poor themselves, causes leading to poverty, perspectives of the poor, ways in which the poor overcome critical financial situations.

\section{Administrative data}

While evaluating poverty one should take into account its complex nature, which is reflected both in its economic, social and cultural aspects etc. For that purpose, a list of social-economic indicators has been collected providing information on the demographic aspects, health care, education, public expenditures for education and health, and employment. Overall, about fifty indicators are used at various disaggregation levels (total per country, urban-rural, sex, age groups, etc). These data are calculated and summarized by ministries, departments, and other state bodies.

\section{Poverty Indicators}

\section{Poverty indicator}

The basic unit of the poverty analysis is the household (as defined in the Household Budget Survey). The basic measure of population's welfare is household's consumption expenditures, which is considered to be a more reliable and accurate measure of welfare than income, which is frequently underreported in statistical surveys. Household consumption expenditures include expenditures for food consumption (including imputed market value of items taken from household's production), non-food items and payment for services. 
To ensure comparability between households surveyed in different months, income and expenditure indicators were adjusted to January, using the monthly Consumer Price Index (CPI), for each component: food products, non-food items and services.

The OECD equivalence scale is used to adjust total household consumption to per adult equivalent consumption (the first adult in the household is given the value $1 ; 0.7$ to each other adult; and 0.5 to each child aged under 15).

An individual is considered poor if his/her welfare (consumption per adult equivalent) is below the poverty line. It is assumed by default that all individuals of a household have the same living standards; if such equivalized consumption expenditures are below the established poverty line, the household is considered to live in poverty, and its members are considered poor.

\section{Measures of poverty}

The FGT (Foster-Greer-Thorbecke) family of poverty measures (poverty headcount, poverty gap and squared poverty gap or severity) is used to characterize poverty status in the country and in the major groups of population. Poverty is measured annually, on the basis of the HBS data.

\section{Poverty lines}

The report uses mainly two poverty lines, the first one being based on the food component while the second one also includes the non-food component and services. For comparative purposes, the international poverty line of USD 2.15 per capita per day in Moldovan Lei and adjusted for purchasing power parities, the Minimum Living Standard and a relative poverty line are presented as well (see the statistical annex).

The extreme poverty line is based on the monetary value of food items only, defined in terms of the minimum of daily calories intake, equal to $2282 \mathrm{Kcal}$ per household member per day. Since food energy intakes vary across welfare level, the calculation base on the consumption pattern of the population in deciles 2 nd to 4 th of the distribution of total consumption expenditure per capita. A household is classified as extremely poor if its total consumption expenditures per adult equivalent are below the cost of a basic food basket. In 2004 the extreme poverty line was equal to 258.1 MDL per month.

The absolute poverty line was estimated on the basis of the total consumption expenditures, by increasing the food poverty line with a supplement for non-food items and services. The nonfood component was estimated for the segment of sampled households, whose consumption expenditure per capita was within the interval of one standard deviation $10 \%(+/-)$ from the level of the food poverty line. The absolute poverty line for the year 2004 was estimated at 327.0 MDL.

The relative poverty line has relativity at its focus; this line was set at the level of 50 percent of the average household equivalized consumption expenditure, equalling 294.3 MDL according to the HBS data for the year 2004.

Subjective and participatory methods of poverty assessment: The methods based on selfperception of welfare play key role in understanding of the poverty situation. The subjective poverty line has been estimated using self-assessments of material well-being (of the amount of money necessary to meet basic needs, according to the Leiden method, using HBS data). In addition to the above, the household self-assessment method was used, on the basis of the selective survey „Household opinion about poverty phenomenon" included in the HBS questionnaire.

\section{Issues relating to poverty monitoring}


Despite informational richness of the HBS data, they suffer from certain problems that need to be recognized as limitations in the poverty measurement and analysis, such as: 'weak' sampling frame (in lieu of the lacking census files, non-computerized electoral district lists 1996 were used), small number of primary sampling units (PSUs), affecting the overall accuracy of the poverty estimates, a small-scale stratification (cities, towns, rural areas). Starting with 2006 the NBS will launch the survey on a new master sample, developed on the basis of population Census data for 2004, which will allow a deeper assessment and study in this field.

Another problem arises with respect to the official price statistics. The same Consumer Price Index (CPI) should be applied in order to adjust the household income and expenditure measures for inflation and seasonality in both urban and rural segments of the population. Since the CPI is based on information collected in urban areas only (in selected 750 price-watch centres dispersed over 11 towns across country) it makes difficult to establish separately the cost of living index for households residing in urban and rural areas, even though the HBS reported are actual prices that a household pays, at the local market prices. This may lead to underestimation or overestimation of household consumption expenditures by area of residence. If the methodology for computing the regional consumer price Index is implemented, in order to improve the comparability of households in different areas of residence, consumption expenditures may be adjusted using the regional price deflator. 


\section{ANNEX A2: Statistical Annex for poverty evaluation}

Table A. 1. Poverty indicators (Rate, Gap, Severity), 1998-2004 ${ }^{1,2}$

\begin{tabular}{|c|c|c|c|c|c|c|c|}
\hline Indicators and sources & 1998 & 1999 & 2000 & 2001 & 2002 & 2003 & 2004 \\
\hline $\begin{array}{l}\text { Absolute Poverty Line (MDL p.a.e. per } \\
\text { month) }\end{array}$ & 128.9 & 179.2 & 234.8 & 257.3 & 270.7 & 303.5 & 327.0 \\
\hline Absolute Poverty Rate & 52.0 & 73.0 & 67.8 & 54.6 & 40.4 & 29.0 & 26.5 \\
\hline Absolute Poverty Gap & 19.5 & 32.3 & 27.0 & 19.3 & 12.4 & 7.3 & 6.8 \\
\hline Absolute Poverty Severity & 9.8 & 17.7 & 13.7 & 9.1 & 5.2 & 2.7 & 2.5 \\
\hline $\begin{array}{l}\text { Extreme Poverty Line (MDL p.a.e per } \\
\text { month) }\end{array}$ & 101.0 & 140.4 & 183.9 & 201.5 & 212.0 & 235.5 & 258.1 \\
\hline Extreme Poverty Rate & 37.4 & 59.7 & 52.2 & 38.0 & 26.2 & 15.0 & 14.7 \\
\hline Extreme Poverty Gap & 12.4 & 22.7 & 17.6 & 11.6 & 6.6 & 3.1 & 3.2 \\
\hline Extreme Poverty Severity & 5.9 & 11.4 & 8.2 & 5.1 & 2.4 & 1.0 & 1.1 \\
\hline $\begin{array}{l}\text { Relative poverty line Line (MDL p.a.e. per } \\
\text { month) }\end{array}$ & 82.1 & 80.3 & 115.9 & 158.4 & 202.3 & 257.5 & 294.4 \\
\hline Relative Poverty Rate & 25.8 & 25.4 & 22.3 & 23.7 & 23.6 & 19.4 & 20.3 \\
\hline Subsistence Minimum, MDL, p.a.e. & 274.1 & 309.5 & 413.11 & 468.7 & 538.4 & 628.1 & 679.9 \\
\hline $\begin{array}{l}\text { Poverty rate by expenditures per } \\
\text { equivalent }\end{array}$ & 87.25 & 90.98 & 90.49 & 84.47 & 79.64 & 77.14 & 75.27 \\
\hline $\begin{array}{l}\text { International Line } \$ 2.15 \text { PPP per } \\
\text { person/day (MDL/person/month) }\end{array}$ & 91.6 & 127.6 & 167.5 & 183.9 & 193.7 & 216.2 & 239.5 \\
\hline Poverty rate (expenditures per equivalent) & 31.9 & 53.2 & 45.0 & 32.3 & 21.0 & 11.5 & 11.4 \\
\hline $\begin{array}{l}\text { Source: MET calculations based on HBS } \\
\text { Notes: } \\
1 \backslash \text { Numbers are weighted and are nationally } \\
2 \backslash \text { Poverty lines are calculated per adult equ } \\
3 \backslash \text { Adjusted for Purchasing Power Parity. V }\end{array}$ & rese & & & te & & & \\
\hline
\end{tabular}

Table A. 2. Poverty rates and poverty gap by area of residence, $2002-20041$

\begin{tabular}{|c|c|c|c|c|c|c|c|c|c|c|c|c|c|c|c|}
\hline & \multicolumn{5}{|c|}{ City } & \multicolumn{5}{|c|}{ Town } & \multicolumn{5}{|c|}{ Rural } \\
\hline & 2000 & 2001 & 2002 & 2003 & 2004 & 2000 & 2001 & 2002 & 2003 & 2004 & 2000 & 2001 & 2002 & 2003 & 2004 \\
\hline Absolute poverty rate & 40.0 & 30.0 & 16.5 & 12.8 & 6.9 & 80.7 & 73.1 & 46.8 & 42.4 & 34.9 & 73.9 & 58.2 & 45.1 & 31.1 & 31.2 \\
\hline Extreme poverty rate & 25.7 & 17.2 & 8.5 & 5.3 & 2.9 & 67.4 & 56.5 & 33.9 & 23.4 & 17.5 & 57.2 & 40.3 & 30.2 & 16.2 & 18.0 \\
\hline
\end{tabular}

Table A.3. Poverty rate and structure by household characteristics, 2004 (sampled population)

\begin{tabular}{|c|c|c|c|c|c|}
\hline & \multirow{2}{*}{$\begin{array}{c}\begin{array}{c}\text { All household } \\
\text { members }\end{array} \\
\text { Structure } \\
\end{array}$} & \multicolumn{2}{|c|}{ Poor } & \multicolumn{2}{|c|}{ Extremely poor } \\
\hline & & Poverty rate & Structure & Poverty rate & Structure \\
\hline \multicolumn{6}{|l|}{ 1. Residence $^{1}$} \\
\hline Urban & 37.2 & 18.5 & 26.0 & 9.0 & 22.8 \\
\hline Rural & 62.8 & 31.2 & 74.0 & 18.0 & 77.2 \\
\hline Total & 100.0 & 26.5 & 100.0 & 14.7 & 100.0 \\
\hline \multicolumn{6}{|l|}{ 2. Household size } \\
\hline 1 person & 11.2 & 24.6 & 10.0 & 12.3 & 9.1 \\
\hline 2 persons & 24.0 & 21.7 & 18.9 & 9.8 & 15.4 \\
\hline 3 persons & 23.9 & 21.5 & 18.7 & 11.6 & 18.0 \\
\hline 4 persons & 22.9 & 28.6 & 23.8 & 17.5 & 26.3 \\
\hline 5 persons & 10.8 & 41.5 & 16.2 & 24.4 & 17.2 \\
\hline 6 and more persons & 7.2 & 47.4 & 12.4 & 30.1 & 14.2 \\
\hline Total & 100.0 & & 100.0 & & 100.0 \\
\hline \multicolumn{6}{|l|}{ 3. Household type } \\
\hline One-member Household & 11.2 & 24.6 & 10.0 & 12.3 & 9.1 \\
\hline Couple without children & 16.5 & 21.6 & 13.0 & 9.6 & 10.4 \\
\hline Couple with under- 18 children & 26.6 & 26.2 & 25.3 & 14.8 & 25.7 \\
\hline $\begin{array}{l}\text { Lone parent with under-18 } \\
\text { children }\end{array}$ & 4.5 & 27.0 & 4.4 & 13.9 & 4.1 \\
\hline Other households with under- 18 & 27.2 & 34.8 & 34.4 & 21.1 & 37.6 \\
\hline
\end{tabular}




\begin{tabular}{|c|c|c|c|c|c|}
\hline & \multirow{2}{*}{$\begin{array}{c}\begin{array}{c}\text { All household } \\
\text { members }\end{array} \\
\text { Structure }\end{array}$} & \multicolumn{2}{|c|}{ Poor } & \multicolumn{2}{|c|}{ Extremely poor } \\
\hline & & Poverty rate & Structure & Poverty rate & Structure \\
\hline \multicolumn{6}{|c|}{ 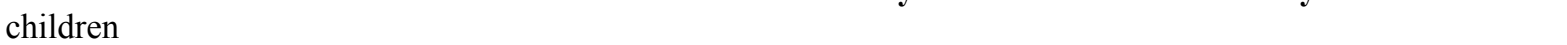 } \\
\hline Other households without children & 13.9 & 25.5 & 12.9 & 14.5 & 13.2 \\
\hline Total & 100.0 & & 100.0 & & 100.0 \\
\hline \multicolumn{6}{|l|}{ 4. Household composition } \\
\hline Household with 1 child & 26.6 & 24.9 & 24.1 & 14.2 & 24.6 \\
\hline Household with 2 children & 22.6 & 32.4 & 26.7 & 18.6 & 27.5 \\
\hline Household with 3 children & 6.9 & 40.7 & 10.2 & 27.0 & 12.2 \\
\hline $\begin{array}{l}\text { Household with } 4 \text { and more } \\
\text { children }\end{array}$ & 2.3 & 38.6 & 3.2 & 20.6 & 3.0 \\
\hline Household without children & 41.6 & 23.8 & 35.9 & 12.0 & 32.6 \\
\hline Total & 100.0 & & 100.0 & & 100.0 \\
\hline \multicolumn{6}{|l|}{ 5. Social-economic groups } \\
\hline Farmers & 23.6 & 35.0 & 30.0 & 23.0 & 35.5 \\
\hline Agricultural employees & 10.0 & 37.0 & 13.5 & 22.1 & 14.5 \\
\hline Non-agricultural employees & 34.8 & 19.2 & 24.3 & 9.1 & 20.8 \\
\hline Entrepreneurs & .6 & & & & \\
\hline Pensioners & 26.2 & 30.7 & 29.2 & 15.4 & 26.3 \\
\hline Others & 4.8 & 17.4 & 3.0 & 9.5 & 3.0 \\
\hline Total & 100.0 & & 100.0 & & 100.0 \\
\hline \multicolumn{6}{|l|}{ 6. Main source of income } \\
\hline Remunerated activity & 36.9 & 24.2 & 32.4 & 13.1 & 31.5 \\
\hline Individual agricultural activity & 32.9 & 33.1 & 39.6 & 19.2 & 41.4 \\
\hline Individual non-agricultural activity & 3.0 & 14.8 & 1.6 & 6.1 & 1.2 \\
\hline Social allowances & 17.5 & 36.3 & 23.1 & 19.9 & 22.7 \\
\hline Other sources & 9.6 & 9.4 & 3.3 & 5.1 & 3.2 \\
\hline Total & 100.0 & & 100.0 & & 100.0 \\
\hline \multicolumn{6}{|l|}{ 7. Number of employees } \\
\hline \multicolumn{6}{|l|}{1 person households } \\
\hline Without an employee & 7.4 & 28.8 & 7.8 & 14.2 & 6.9 \\
\hline 1 employee & 3.8 & 16.5 & 2.3 & 8.8 & 2.2 \\
\hline \multicolumn{6}{|l|}{$\begin{array}{l}\text { Households with } 2 \text { and more } \\
\text { employed }\end{array}$} \\
\hline Neither person works & 12.4 & 25.0 & 11.2 & 10.8 & 8.7 \\
\hline 1 employee & 23.4 & 23.1 & 19.6 & 12.9 & 19.8 \\
\hline Two employees & 39.6 & 27.1 & 38.9 & 14.7 & 37.9 \\
\hline Three and more employees & 13.4 & 41.5 & 20.2 & 28.0 & 24.5 \\
\hline Total & 100.0 & & 100.0 & & 100.0 \\
\hline \multicolumn{6}{|l|}{ 8. Educational level of HH head } \\
\hline $\begin{array}{l}\text { Higher and incomplete higher } \\
\text { education }\end{array}$ & 11.4 & 7.6 & 3.1 & 3.0 & 2.2 \\
\hline Secondary and vocational studies & 57.2 & 24.5 & 50.8 & 13.4 & 50.0 \\
\hline $\begin{array}{l}\text { Incomplete secondary and primary } \\
\text { education }\end{array}$ & 28.6 & 39.4 & 40.9 & 23.5 & 43.9 \\
\hline No primary education or illiterate & 2.8 & 49.7 & 5.1 & 20.8 & 3.9 \\
\hline Total & 100.0 & & 100.0 & & 100.0 \\
\hline \multicolumn{6}{|l|}{ 9. Age group of $\mathrm{HH}$ head } \\
\hline below 25 year old & 2.5 & 7.0 & 0.6 & 5.7 & .9 \\
\hline 25 - 34 year old & 12.5 & 22.6 & 10.3 & 11.7 & 9.5 \\
\hline 35 - 44 year old & 25.3 & 27.4 & 25.2 & 14.9 & 24.7 \\
\hline 45 - 54 year old & 26.3 & 30.4 & 29.0 & 18.8 & 32.2 \\
\hline 55 - 64 year old & 15.3 & 25.9 & 14.5 & 14.3 & 14.4 \\
\hline 65 and more year old & 18.0 & 31.2 & 20.4 & 15.5 & 18.3 \\
\hline Total & 100.0 & & 100.0 & & 100.0 \\
\hline \multicolumn{6}{|l|}{ 10. Sex of HH head } \\
\hline Male & 66.5 & 28.1 & 67.9 & 15.9 & 69.2 \\
\hline Female & 33.5 & 26.4 & 32.1 & 14.0 & 30.8 \\
\hline Total & 100.0 & & 100.0 & & 100.0 \\
\hline
\end{tabular}

Source: MET calculations based on HBS

Note: $1 \backslash$ Numbers are weighted and are nationally representative. 


\section{ANNEX A3. Government Decree on establishing the poverty monitoring and evaluation system}

With the purpose of monitoring poverty and assessing the impact of anti-poverty policy and with a view of implementing provisions of art. 2 of the Law no.398-XV of 2 December 2004 on the approval of the Economic Growth and Poverty Reduction Strategy (2004-2006) (Official Monitor of the Republic of Moldova, 2005 no.5-12 art. 44), the Government of the Republic of Moldova decides:

1. The Ministry of Economy and Trade:

- $\quad$ will develop and approve, within two months jointly with the National Bureau of Statistics and other interested institutions, with the support of the UNDP/UNICEF Joint Programme "Support for formulation, monitoring and evaluation of strategic policies in Moldova", Instructions on the method of calculation of absolute poverty lines;

- $\quad$ will establish and manage an integrated data base on basic poverty indicators;

- will monitor and analyse poverty and the impact of anti-poverty policies, also various stakeholders;

- $\quad$ will present to the Government, on an annual basis:

- $\quad$ by 15 June, a brief summary (short report) on poverty in Moldova;

- $\quad$ by 1 November, a Poverty and Policy Impact Report;

- jointly with the National Bureau of Statistics, relevant ministries and scientific institutions, will improve, upon need, the methods of poverty calculation

- jointly with the local public authorities and scientific institutions, will continue activities in the field of poverty mapping and local poverty monitoring and make the results available to the local public authorities for policy development at the local level.

- will determine, within one month from the date of entry into force of this decision, community socio-economic indicators and will develop relevant explanations (descriptions) for each indicator;

- will provide methodological and practical support to the local public authorities in the development and calculation of socio-economic indicators for poverty monitoring.

2. The National Bureau of Statistics

- will ensure the collection of data required and improvement of the toolkit for the Household Budget Survey, which is the main source for poverty analysis;

- $\quad$ will calculate the absolute poverty lines;

- $\quad$ will calculate basic indicators for poverty monitoring and evaluation;

- $\quad$ will develop and present to the Ministry of Economy and Trade, on a yearly basis by 30 April, a standard set of tables with annual data on poverty trends and an explanatory (technical) note on the method of calculation of poverty lines and poverty indicators;

- will ensure continuity in collecting, processing and presenting information for poverty analysis as well as data accessibility for users.

3. Ministries and other central public authorities responsible for monitoring and evaluation of sector policies:

- $\quad$ will evaluate jointly with the Ministry of Economy and Trade the socio-economic indicators required for the analysis of non-monetary dimensions of poverty and policy impact on poverty;

- will provide to the Ministry of Economy and Trade, on a yearly basis by 1 July, information for the analysis of the impact of sector policies on poverty.

4. Local public authorities, on a yearly basis by 1 July, will collect and provide to the Ministry of Economy and Trade additional data on community socio-economic indicators.

5. To inform the civil society about the impact of anti-poverty policies:

- $\quad$ The Ministry of Economy and Trade, on a yearly basis by 20 December, will inform the central and local public authorities, research institutions and donors on the results of poverty analysis, by posting them on the web-site; 
- $\quad$ The National Bureau of Statistics will ensure data accessibility for users, placement of the HBS database (after adjustment and depersonification of individual data) and the Explanatory (Technical) Note, with the standard set of tables, on the National Bureau of Statistics web-site.

6. The National Bureau of Statistics will create an internal subdivision comprising 2 persons with their main duties stipulated in paragraph 2 above of this decision, within the staff of the head office of the National Bureau of Statistics, approved by the Government decision no. 560 of 10 June 2005.

7. The Ministry of Economy and Trade will supervise the execution of this decision.

8. The Government Decisions stipulated in the annex shall be cancelled:

Prime-minister

Countersigned:

Minister of Economy and Trade

Minister of Finance

Minister of Justice

Chisinau, 15 August 2005

No. 851

\section{Vasile TARLEV}

\section{Valeriu Lazar \\ Zinaida Grecianii \\ Victoria Iftodi}

Annex

to the Government Decision no.851

of 15 August 2005

\section{LIST}

of Government Decisions to be cancelled

1. The Government Decision no.564 of 14 June 2000 "On the approval of the National Poverty Alleviation Programme" (Official Monitor of the Republic of Moldova, 2000, no.70-72, art. 649).

2. The Government Decision no.639 of 12 July 2001 "On the progress of the National Poverty Alleviation Programme in January-May 2001" (Official Monitor of the Republic of Moldova, 2001, no.81-83, art. 680).

Published in the Official Monitor of the Republic of Moldova, no.110-112 of 19 August 2005, art. 916. 


\section{ANNEX B: Indicators for Monitoring EGPRSP Implementation}

(as per 01.03.2006)

\begin{tabular}{|c|c|c|c|c|c|c|c|}
\hline Monitoring Indicators & Source & 2000 & 2001 & 2002 & 2003 & 2004 & 2005 \\
\hline \multicolumn{8}{|l|}{$\begin{array}{l}\text { Objective I: Inclusive and sustainable } \\
\text { economic growth }\end{array}$} \\
\hline GDP growth rate, $\%$ & NBS & 2.1 & 6.1 & 7.8 & 6.6 & 7.4 & 7.1 \\
\hline Total external debt as share of GDP, $\%$ & NBM & 133.0 & 115.1 & 111.2 & 92.1 & 73.6 & 69.1 \\
\hline $\begin{array}{l}\text { Final consumption of households as a } \\
\text { share of GDP, \% }\end{array}$ & NBS & 87.6 & 86.0 & 82.0 & 89.5 & 87.8 & 91.6 \\
\hline $\begin{array}{l}\text { Fixed capital investment as a share of } \\
\text { GDP, } \%\end{array}$ & NBS & 15.4 & 16.7 & 16.3 & 18.6 & 21.2 & 24.4 \\
\hline Processing industry as a share of GDP, $\%$ & NBS & 14.2 & 15.8 & 14.9 & 15.4 & 14.5 & 14.5 \\
\hline \multicolumn{8}{|l|}{$\begin{array}{l}\text { Objective II: Reducing poverty and } \\
\text { inequality and enhancing the } \\
\text { participation of poor in economic } \\
\text { development }\end{array}$} \\
\hline $\begin{array}{l}\text { Share of population under the absolute } \\
\text { poverty line (total per country), } \%\end{array}$ & NBS & 67.8 & 54.6 & 40.4 & 29.0 & 26.5 & ... \\
\hline $\begin{array}{l}\text { Share of population under the food } \\
\text { poverty line (total per country), } \%\end{array}$ & $\mathrm{NBS}^{\mathrm{i}}$ & 52.2 & 38.0 & 26.2 & 15.0 & 14.7 & $\ldots$ \\
\hline $\begin{array}{l}\text { Share of population under the poverty } \\
\text { line at the level of } 2.15 \$ / \text { day (to PPP), } \\
\text { MDL per month (incidence), (total per } \\
\text { country), } \%\end{array}$ & $\mathrm{NBS}^{\mathrm{i}}$ & 64.5 & 52.4 & 39.8 & 28.9 & 27.8 & ... \\
\hline $\begin{array}{l}\text { Share of first quintile in national } \\
\text { consumption, } \%\end{array}$ & NBS & 6.7 & 6.6 & 6.8 & 7.5 & 7.2 & $\ldots$ \\
\hline $\begin{array}{l}\text { Gini Coefficient by consumption } \\
\text { expenditures }\end{array}$ & NBS & 0.4 & 0.4 & 0.4 & 0.4 & 0.4 & $\ldots$ \\
\hline Unemployment rate, ILO, \% & NBS & 8.5 & 7.3 & 6.8 & 7.9 & 8.1 & 7.3 \\
\hline \multicolumn{8}{|l|}{$\begin{array}{l}\text { Objective III: Development of Human } \\
\text { Resources }\end{array}$} \\
\hline \multicolumn{8}{|l|}{ Life expectancy at birth, years: } \\
\hline Men & NBS & 63.9 & 64.5 & 64.4 & 64.5 & 64.5 & $\ldots$ \\
\hline Women & NBS & 71.2 & 71.7 & 71.7 & 71.6 & 72.2 & $\ldots$ \\
\hline Mortality rate (per 1000 residents) & NBS & 11.3 & 11.0 & 11.6 & 11.9 & 11.6 & 12.4 \\
\hline $\begin{array}{l}\text { Net rate of enrolment in the primary } \\
\text { education, } \%\end{array}$ & NBS & 93.5 & 92.4 & 92.4 & 92.4 & 91.0 & $\ldots$ \\
\hline $\begin{array}{l}\text { Gross rate of enrolment in the primary } \\
\text { education, } \%\end{array}$ & NBS & 99.4 & 99.5 & 99.5 & 99.8 & 97.9 & $\ldots$ \\
\hline $\begin{array}{l}\text { Net rate of enrolment in the secondary } \\
\text { education, \% }\end{array}$ & NBS & 87.0 & 86.8 & 87.9 & 87.5 & 88.5 & $\ldots$ \\
\hline $\begin{array}{l}\text { Gross rate of enrolment in the secondary } \\
\text { education, } \%\end{array}$ & NBS & 90.2 & 91.1 & 92.3 & 92.2 & 92.5 & $\ldots$ \\
\hline \multicolumn{8}{|l|}{ 1. Ensuring macroeconomic stability } \\
\hline Nominal GDP, billion MDL & NBS & 16,020 & 19,052 & 22,556 & 27,619 & 32,032 & 36,755 \\
\hline
\end{tabular}




\begin{tabular}{|c|c|c|c|c|c|c|c|}
\hline Monitoring Indicators & Source & 2000 & 2001 & 2002 & 2003 & 2004 & 2005 \\
\hline $\begin{array}{l}\text { Rate of growth of Consumer Prices (end } \\
\text { of year), } \%\end{array}$ & NBS & 18.4 & 6.3 & 4.4 & 15.7 & 12.5 & 10.0 \\
\hline $\begin{array}{l}\text { Rate of growth of Consumer Prices (year } \\
\text { average), } \%\end{array}$ & NBS & 31.2 & 9.6 & 5.2 & 11.6 & 12.4 & 11.9 \\
\hline Trade balance as a share of GDP, $\%$ & NBM & -22.8 & -21.3 & -22.7 & -31.5 & -29.0 & -39.1 \\
\hline $\begin{array}{l}\text { Share of transfers of Moldovan citizens } \\
\text { from abroad in GDP, } \%\end{array}$ & NBM & 13.8 & 16.4 & 19.4 & 24.4 & 27.0 & 30.5 \\
\hline Average exchange rate, MDL/USD & NBM & 12.4334 & 12.8668 & 13.5730 & 13.9426 & 12.3283 & 12.6003 \\
\hline $\begin{array}{l}\text { National public budget deficit (-) as a } \\
\text { share of GDP, \% }\end{array}$ & MF & -1.6 & 1.0 & -1.2 & 1.4 & 0.5 & 2.1 \\
\hline $\begin{array}{l}\text { External private not guaranteed by } \\
\text { Government debt (principal plus interest) } \\
\text { servicing as share of export of goods and } \\
\text { services, } \%\end{array}$ & NBM & 8.7 & 3.1 & 12.0 & 7.6 & 9.6 & 8.5 \\
\hline $\begin{array}{l}\text { External public and publicly guaranteed } \\
\text { debt servicing (principal plus interest) as } \\
\text { share of revenues of state budget, } \%\end{array}$ & NBM & 31.3 & 34.7 & 25.1 & 18.8 & 21.4 & 12.8 \\
\hline $\begin{array}{l}\text { Current account balance as a share of } \\
\text { GDP, } \%\end{array}$ & NBM & -7.6 & -1.8 & -4.0 & -6.8 & -2.7 & -9.8 \\
\hline $\begin{array}{l}\text { Official reserves in foreign currency, in } \\
\text { months of import }\end{array}$ & NBM & 2.8 & 2.5 & 2.5 & 2.1 & 2.7 & 2.7 \\
\hline \multirow[t]{2}{*}{$\begin{array}{l}\text { Foreign direct investments in national } \\
\text { economy (net flow) as a share of GDP, } \%\end{array}$} & NBM & 9.8 & 6.9 & 8.0 & 4.0 & 5.5 & 7.0 \\
\hline & NBM & 34.0 & 36.2 & 40.6 & 38.1 & 34.7 & $\ldots$ \\
\hline \multicolumn{8}{|l|}{ 2. Poverty reduction } \\
\hline $\begin{array}{l}\text { Share of population under the absolute } \\
\text { poverty line (incidence), } \%\end{array}$ & $\mathrm{NBS}^{\mathrm{i}}$ & 67.8 & 54.6 & 40.4 & 29.0 & 26.5 & $\cdots$ \\
\hline Cities & $\mathrm{NBS}^{\mathrm{i}}$ & - & - & 16.5 & 12.8 & 6.9 & $\ldots$ \\
\hline Towns & $\mathrm{NBS}^{\mathrm{i}}$ & - & - & 46.8 & 42.4 & 34.9 & $\ldots$ \\
\hline Rural areas & $\mathrm{NBS}^{\mathrm{i}}$ & - & - & 45.1 & 31.1 & 31.2 & $\ldots$ \\
\hline $\begin{array}{l}\text { Share of population under the food } \\
\text { poverty line (incidence), } \% \text {, total }\end{array}$ & $\mathrm{NBS}^{\mathrm{i}}$ & 52.2 & 38.0 & 26.2 & 15.0 & 14.7 & $\cdots$ \\
\hline Cities & $\mathrm{NBS}^{\mathrm{i}}$ & - & - & 8.5 & 5.3 & 2.9 & $\ldots$ \\
\hline Towns & $\mathrm{NBS}^{\mathrm{i}}$ & - & - & 33.9 & 23.4 & 17.5 & $\ldots$ \\
\hline Rural areas & $\mathrm{NBS}^{\mathrm{i}}$ & - & - & 30.2 & 16.2 & 18.0 & $\ldots$ \\
\hline $\begin{array}{l}\text { Poverty gap ratio for the absolute poverty } \\
\text { line, } \% \text {, }\end{array}$ & $\mathrm{NBS}^{\mathrm{i}}$ & 27.0 & 19.3 & 12.4 & 7.3 & 6.8 & $\ldots$ \\
\hline Cities & $\mathrm{NBS}^{\mathrm{i}}$ & - & - & 4.2 & 2.8 & 1.3 & $\ldots$ \\
\hline Towns & $\mathrm{NBS}^{\mathrm{i}}$ & - & - & 17.1 & 11.6 & 8.3 & $\ldots$ \\
\hline Rural areas & $\mathrm{NBS}^{\mathrm{i}}$ & - & - & 14.1 & 7.8 & 8.3 & $\ldots$ \\
\hline
\end{tabular}




\begin{tabular}{|c|c|c|c|c|c|c|c|}
\hline Monitoring Indicators & Source & 2000 & 2001 & 2002 & 2003 & 2004 & 2005 \\
\hline $\begin{array}{l}\text { Poverty gap ratio for the food poverty } \\
\text { line, } \% \text {, }\end{array}$ & NBS $^{\mathrm{i}}$ & 17.6 & 11.6 & 6.6 & 3.1 & 3.2 & $\ldots$ \\
\hline Cities & $\mathrm{NBS}^{\mathrm{i}}$ & - & - & 1.8 & 1.0 & 0.5 & $\ldots$ \\
\hline Towns & NBS $^{i}$ & - & - & 9.5 & 5.5 & 3.6 & $\ldots$ \\
\hline Rural areas & NBS $^{i}$ & - & - & 7.5 & 3.2 & 4.0 & $\ldots$ \\
\hline \multicolumn{8}{|l|}{ 3. Private sector development } \\
\hline Share of private sector in GDP, $\%$ & NBS & 75.0 & 76.0 & 70.5 & 69.7 & 68.6 & $\ldots$ \\
\hline $\begin{array}{l}\text { Share of private sector employees in total } \\
\text { national economy employees, } \%\end{array}$ & NBS & 68.4 & 71.0 & 72.3 & 70.9 & 69.4 & 69.6 \\
\hline $\begin{array}{l}\text { Employees of enterprises staffed up to } 10 \\
\text { persons as a share of total national } \\
\text { economy employees, } \%\end{array}$ & NBS & $\cdots$ & $\cdots$ & 6.6 & 8.0 & 8.8 & $8.9^{\text {ii }}$ \\
\hline $\begin{array}{l}\text { Share of small business enterprises in the } \\
\text { total number of enterprises, } \%\end{array}$ & NBS & $\ldots$ & 89.4 & 89.7 & 90.0 & 91.7 & $92.2^{\mathrm{i}}$ \\
\hline $\begin{array}{l}\text { Employees of small business enterprises } \\
\text { staffed up to } 50 \text { persons as a share of } \\
\text { total national economy employees, } \%\end{array}$ & NBS & $\ldots$ & 23.6 & 25.4 & 28.0 & 30.2 & $30.7^{\mathrm{i}}$ \\
\hline $\begin{array}{l}\text { Number of SMEs that worked more than } \\
2 \text { years }\end{array}$ & NBS & $\ldots$ & 21.9 & 22.7 & 22.2 & 25.8 & $25.5^{\mathrm{i}}$ \\
\hline \multicolumn{8}{|l|}{ 4. Public sector reform } \\
\hline $\begin{array}{l}\text { Share of servants of public central } \\
\text { administration in total employed } \\
\text { population (beginning of the year), \% }\end{array}$ & NBS & 0.6 & 1.5 & 1.6 & 1.4 & 1.4 & 1.6 \\
\hline $\begin{array}{l}\text { Average monthly salary in public central } \\
\text { administration, MDL }\end{array}$ & NBS & 518 & 742 & 989 & 1050 & 1205 & 1364 \\
\hline $\begin{array}{l}\text { Average monthly salary in public } \\
\text { administration, defense and mandatory } \\
\text { social insurance, as a share of the average } \\
\text { monthly nominal salary per employee in } \\
\text { the economy, \% }\end{array}$ & NBS & 126.9 & 136.5 & 142.9 & 117.9 & 109.2 & 103.3 \\
\hline $\begin{array}{l}\text { State and ATU budget expenditures for } \\
\text { maintenance of public authorities as a } \\
\text { share of GDP, \% }\end{array}$ & MF & 15.0 & 11.4 & 11.3 & 10.8 & 10.6 & $\ldots$ \\
\hline \multicolumn{8}{|l|}{ 5. Budget policy } \\
\hline $\begin{array}{l}\text { Revenues of the national public budget as } \\
\text { a share of GDP, } \%\end{array}$ & MF & 34.8 & 32.6 & 33.1 & 34.5 & 35.6 & 40.0 \\
\hline $\begin{array}{l}\text { Revenues of the state budget (base) as a } \\
\text { share of GDP, \% }\end{array}$ & MF & 19.0 & 15.1 & 14.6 & 16.4 & 17.3 & 21.1 \\
\hline $\begin{array}{l}\text { Tax income of national public budget as } \\
\text { a share of GDP, } \%\end{array}$ & MF & 24.7 & 24.2 & 25.6 & 27.3 & 29.4 & 32.0 \\
\hline
\end{tabular}




\begin{tabular}{|c|c|c|c|c|c|c|c|}
\hline Monitoring Indicators & Source & 2000 & 2001 & 2002 & 2003 & 2004 & 2005 \\
\hline $\begin{array}{l}\text { Share of direct taxes in the state budget } \\
\text { and ATU budgets for all components, } \%\end{array}$ & MF & 16.5 & 18.5 & 18.0 & 18.8 & 21.2 & 17.1 \\
\hline $\begin{array}{l}\text { Share of indirect taxes in the state budget } \\
\text { and ATU budgets for all components, \% }\end{array}$ & MF & 50.5 & 50.2 & 48.8 & 55.9 & 56.8 & 58.3 \\
\hline $\begin{array}{l}\text { Share of social sector expenditures in the } \\
\text { national public budget, } \%\end{array}$ & MF & 53.2 & 56.7 & 62.6 & 62.4 & 62.6 & 63.3 \\
\hline $\begin{array}{l}\text { External debt service expenditures for } \\
\text { debts managed by Government as a share } \\
\text { of total base income of the state budget, } \\
\%\end{array}$ & MF & 23.5 & 38.8 & 24.5 & 16.2 & 22.7 & 8.5 \\
\hline $\begin{array}{l}\text { Share of social sector expenditures in } \\
\text { GDP, } \%\end{array}$ & MF & 19.4 & 17.9 & 21.4 & 20.7 & 22.0 & 24.0 \\
\hline \multicolumn{8}{|l|}{ 6. Finance sector } \\
\hline $\begin{array}{l}\text { Commercial banks assets as a share of } \\
\text { GDP, } \%\end{array}$ & NBM & 29.1 & 31.4 & 35.1 & 37.2 & 41.5 & 49.0 \\
\hline $\begin{array}{l}\text { Rate of growth of bank credits to the } \\
\text { economy, } \%\end{array}$ & NBM & 40.12 & 35.36 & 35.17 & 44.45 & 22.20 & 35.02 \\
\hline $\begin{array}{l}\text { Share of bank credits over } 12 \text { months in } \\
\text { the total amount of bank credits in MDL } \\
\text { to the economy, } \%\end{array}$ & NBM & 21.31 & 18.89 & 27.22 & 33.72 & 31.15 & 46.34 \\
\hline $\begin{array}{l}\text { Share of unfavorable credits in total } \\
\text { banking credits provided by banks in } \\
\text { Moldova, \% }\end{array}$ & NBM & 20.6 & 10.4 & 7.6 & 6.4 & 6.9 & 4.3 \\
\hline Interest rate of credits in MDL, $\%$ & NBM & 33.29 & 28.46 & 23.14 & 19.18 & 20.96 & 18.93 \\
\hline Interest rate of credits in USD, $\%$ & NBM & 16.7 & 13.99 & 12.18 & 10.85 & 11.39 & 11.07 \\
\hline $\begin{array}{l}\text { Monetization of economy (M3 as share } \\
\text { of GDP), } \%\end{array}$ & $\mathrm{NBM}$ & 21.91 & 25.13 & 28.86 & 30.81 & 36.59 & 43.06 \\
\hline \multicolumn{8}{|l|}{ 7. Infrastructure development } \\
\hline $\begin{array}{l}\text { Share of length of hard-surface roads in } \\
\text { the total length of public roads, } \%\end{array}$ & NBS & 99.9 & 99.9 & 99.8 & 99.8 & 99.8 & $\ldots$ \\
\hline Housing, million square meters & NBS & 75.60 & 75.90 & 76.20 & 76.77 & 76.8 & $\ldots$ \\
\hline Share of housing with gas supply, $\%$ & NBS & 82.6 & 83.2 & 83.3 & 84.4 & 85.1 & $\ldots$ \\
\hline urban areas & NBS & 91.0 & 91.2 & 91.1 & 91.4 & 91.8 & $\ldots$ \\
\hline rural areas & NBS & 78.2 & 78.9 & 79.4 & 80.7 & 81.6 & $\ldots$ \\
\hline $\begin{array}{l}\text { Share of housing with sewerage, by area } \\
\text { of residence, } \%\end{array}$ & NBS & 29.4 & 29.9 & 30.0 & 30.4 & 30.6 & $\cdots$ \\
\hline urban areas & NBS & 75.9 & 76.3 & 76.6 & 77.8 & 77.8 & $\ldots$ \\
\hline rural areas & NBS & 4.7 & 5.2 & 5.4 & 5.5 & 6.0 & $\ldots$ \\
\hline Share of housing with water supply, $\%$ & NBS & 33.4 & 33.2 & 33.4 & 33.9 & 34.3 & $\ldots$ \\
\hline urban areas & NBS & 77.0 & 77.2 & 77.5 & 78.7 & 78.9 & -... \\
\hline rural areas & NBS & 10.3 & 9.8 & 10.0 & 10.4 & 11.0 & $\ldots$ \\
\hline $\begin{array}{l}\text { Electric power consumption (million } \\
\text { KW-hour) }\end{array}$ & MII & $3,386.1$ & $3,400.8$ & $3,793.6$ & $4,636.3$ & $4,389.6$ & $4,500.0$ \\
\hline
\end{tabular}




\begin{tabular}{|c|c|c|c|c|c|c|c|}
\hline Monitoring Indicators & Source & 2000 & 2001 & 2002 & 2003 & 2004 & 2005 \\
\hline $\begin{array}{l}\text { Share of electric power losses in electric } \\
\text { power consumption, } \%\end{array}$ & NBS & 26.8 & 12.9 & 10.9 & 8.0 & 12.5 & ... \\
\hline $\begin{array}{l}\text { Number of home telephone sets in the } \\
\text { public network or with access to it (per } \\
100 \text { resident) }\end{array}$ & NBS & 14.1 & 15.6 & 17.3 & 19.3 & 21.2 & $\cdots$ \\
\hline in urban network & & 24.5 & 26.1 & 27.5 & 29.2 & 30.3 & $\ldots$ \\
\hline in rural network & & 6.9 & 8.1 & 10.1 & 12.2 & 14.7 & $\ldots$ \\
\hline $\begin{array}{l}\text { Share of length of optical fiber lines in } \\
\text { the total length of interurban cable } \\
\text { telecommunication lines, } \%\end{array}$ & NBS & 23.9 & 43.1 & 43.3 & 43.6 & 43.6 & $\ldots$ \\
\hline $\begin{array}{l}\text { Share of export of services in the total } \\
\text { exports, } \%\end{array}$ & NBM & 25.7 & 23.2 & 24.7 & 24.0 & 25.3 & 27.2 \\
\hline \multicolumn{8}{|l|}{ 8. Industry } \\
\hline $\begin{array}{l}\text { Employment in industry as a share of } \\
\text { employment in economy, \% }\end{array}$ & NBS & 11.0 & 11.0 & 11.4 & 12.1 & 12.3 & 12.1 \\
\hline $\begin{array}{l}\text { Labor productivity in large industries, \% } \\
\text { vs. last year }\end{array}$ & NBS & 112 & 119 & 112 & 111 & 107 & 111 \\
\hline Industry as a share of GDP, $\%$ & NBS & 16.3 & 18.7 & 17.3 & 17.6 & 17.1 & 17 \\
\hline $\begin{array}{l}\text { Rate of growth of industrial output, \% vs. } \\
\text { last year }\end{array}$ & NBS & 7.7 & 13.7 & 10.8 & 15.6 & 8.2 & 6.3 \\
\hline \multicolumn{8}{|l|}{ 9. Research and innovations } \\
\hline $\begin{array}{l}\text { Number of organizations which executed } \\
\text { research and development works }\end{array}$ & NBS & 83 & 81 & 76 & 79 & 86 & $\cdots$ \\
\hline $\begin{array}{l}\text { Number of employees who executed } \\
\text { research and development works, } \\
\text { thousand }\end{array}$ & NBS & 8.2 & 7.9 & 6.9 & 6.9 & 6.7 & ... \\
\hline $\begin{array}{l}\text { Execution of research and development } \\
\text { works, million MDL }\end{array}$ & NBS & 113.3 & 108.0 & 144.6 & 144.3 & 178.2 & ... \\
\hline $\begin{array}{l}\text { Share of research and innovations } \\
\text { expenditures in GDP, } \%\end{array}$ & MF & 0.17 & 0.17 & 0.19 & 0.19 & 0.26 & 0.38 \\
\hline \multicolumn{8}{|l|}{$\begin{array}{l}\text { 10. Agri-food sector and rural } \\
\text { development }\end{array}$} \\
\hline $\begin{array}{l}\text { Employment in agriculture, hunting and } \\
\text { forestry as a share of employment in } \\
\text { economy, } \%\end{array}$ & NBS & 50.9 & 51.0 & 49.6 & 43.0 & 40.5 & 40.7 \\
\hline Agriculture as a share of GDP, $\%$ & NBS & 25.4 & 22.4 & 21.1 & 18.3 & 17.5 & 14.3 \\
\hline $\begin{array}{l}\text { Rate of growth of value added in } \\
\text { agriculture, hunting and forestry (year } \\
2000 \text { is used as base year), } \%\end{array}$ & NBS & 100 & 107.2 & 112.6 & 100.2 & 120.7 & 122.9 \\
\hline $\begin{array}{l}\text { Share of irrigated land in total } \\
\text { agricultural land at the beginning of the } \\
\text { year, } \%\end{array}$ & NBS & 11.8 & 11.9 & 11.1 & 11.1 & 9.1 & 9.0 \\
\hline
\end{tabular}




\begin{tabular}{|c|c|c|c|c|c|c|c|}
\hline Monitoring Indicators & Source & 2000 & 2001 & 2002 & 2003 & 2004 & 2005 \\
\hline $\begin{array}{l}\text { Share of investments in agriculture, } \\
\text { hunting and auxiliary services in total } \\
\text { investments, } \%\end{array}$ & NBS & 3.3 & 4.9 & 5.6 & 5.1 & 6.0 & $\ldots$ \\
\hline $\begin{array}{l}\text { Share of housing with gas supply in rural } \\
\text { areas, \% }\end{array}$ & NBS & 78.2 & 78.9 & 79.4 & 80.7 & 81.6 & ... \\
\hline New hard-surface roads in rural area, $\mathrm{km}$ & NBS & 10.9 & 6.5 & 14.5 & 2.1 & - & - \\
\hline \multicolumn{8}{|l|}{ 11. Regional development policy } \\
\hline $\begin{array}{l}\text { Share of Chisinau municipality in total } \\
\text { industrial production, } \%\end{array}$ & NBS & 56.0 & 57.0 & 55.7 & 55.5 & 55.0 & $50.0^{\mathrm{iii}}$ \\
\hline $\begin{array}{l}\text { Share of Chisinau municipality in total } \\
\text { fixed capital investments, } \%\end{array}$ & NBS & 63.7 & 61.3 & 52.1 & 52.2 & 54.9 & 56.6 \\
\hline \multicolumn{8}{|l|}{ 12. Tourism development } \\
\hline $\begin{array}{l}\text { Number of arrivals of foreign visitors in } \\
\text { the country, thousand persons }\end{array}$ & NBS & 19.0 & 15.7 & 20.2 & 23.6 & 26.0 & 25.1 \\
\hline $\begin{array}{l}\text { Number of departures of visitors from the } \\
\text { country, thousand persons }\end{array}$ & NBS & 32.5 & 30.3 & 51.6 & 67.3 & 67.8 & 57.2 \\
\hline $\begin{array}{l}\text { Investments in restoration of cultural- } \\
\text { historical monuments, thousand MDL }\end{array}$ & $\mathrm{MCT}$ & & & 50 & 450 & 4,200 & 12,700 \\
\hline \multicolumn{8}{|l|}{$\begin{array}{l}\text { 13. Environmental protection and } \\
\text { sustainable use of natural resources }\end{array}$} \\
\hline $\begin{array}{l}\text { Lands of the forestry fund and protected } \\
\text { areas at the beginning of the year, total } \\
\text { per country, thousand ha }\end{array}$ & NBS & 354.4 & 354.6 & 356.2 & 388.3 & 405.8 & 428.5 \\
\hline Share of lands covered by forest, $\%$ & MENR & 10.5 & 10.5 & 11.4 & 12.4 & 12.6 & ... \\
\hline $\begin{array}{l}\text { Share of population with sustainable } \\
\text { access to improved water sources, } \%\end{array}$ & $\mathrm{RDA}$ & 37.8 & 38.1 & 38.5 & 39.7 & 44.5 & $\cdots$ \\
\hline $\begin{array}{l}\text { Share of population with access to } \\
\text { improved sanitation, } \%\end{array}$ & $\mathrm{RDA}$ & 41.1 & 40.0 & 41.7 & 41.5 & 43.6 & $\ldots$ \\
\hline $\begin{array}{l}\text { Share of areas protected to preserve } \\
\text { biodiversity, } \%\end{array}$ & MENR & 1.96 & 1.96 & 1.96 & 1.96 & 1.96 & $\cdots$ \\
\hline $\begin{array}{l}\text { Air pollution by motor transport, } \\
\text { thousand tons of noxious gas and liquid } \\
\text { emissions }\end{array}$ & MENR & 118.8 & 122.9 & 130.9 & 139.3 & 150.0 & ... \\
\hline Waste generation, thousand tons & NBS & 2226.4 & 2039.8 & 2753.4 & 2537.2 & 3142.2 & $\ldots$ \\
\hline Waste utilization, thousand tons & NBS & 1117.4 & 836.9 & 1746.0 & 455.0 & 745.1 & $\ldots$ \\
\hline \multicolumn{8}{|l|}{ 14. Education } \\
\hline $\begin{array}{l}\text { Net rate of enrolment in primary } \\
\text { education, } \% \text {, total }\end{array}$ & NBS & 93.5 & 92.4 & 92.4 & 92.4 & 91.0 & $\ldots$ \\
\hline urban areas & NBS & 95.1 & 94.6 & 94.8 & 96.4 & 95.5 & $\ldots$ \\
\hline rural areas & NBS & 92.5 & 91.3 & 91.6 & 90.4 & 88.7 & $\ldots$ \\
\hline $\begin{array}{l}\text { Gross rate of enrolment in primary } \\
\text { education, } \% \text {, total per country }\end{array}$ & NBS & 99.4 & 99.5 & 99.5 & 99.8 & 97.9 & ... \\
\hline
\end{tabular}




\begin{tabular}{|c|c|c|c|c|c|c|c|}
\hline Monitoring Indicators & Source & 2000 & 2001 & 2002 & 2003 & 2004 & 2005 \\
\hline $\begin{array}{l}\text { Net rate of enrolment in secondary } \\
\text { education, } \% \text {, total per country }\end{array}$ & NBS & 87.0 & 86.8 & 87.9 & 87.5 & 88.5 & $\ldots$ \\
\hline urban areas & NBS & 92.2 & 91.2 & 91.6 & 90.8 & 92.1 & $\ldots$ \\
\hline rural areas & NBS & 83.5 & 84.0 & 85.7 & 85.4 & 86.3 & $\ldots$ \\
\hline $\begin{array}{l}\text { Gross rate of enrolment in secondary } \\
\text { education, } \% \text {, total per country }\end{array}$ & NBS & 90.2 & 91.1 & 92.3 & 92.2 & 92.5 & $\ldots$ \\
\hline $\begin{array}{l}\text { Literacy rate for 15-24 year-old persons, } \\
\%\end{array}$ & NBS & 99.7 & 99.7 & 99.5 & 99.4 & 99.4 & 99.5 \\
\hline $\begin{array}{l}\text { Education expenditures as a share of } \\
\text { GDP, } \%\end{array}$ & MF & 5.5 & 5.8 & 6.9 & 6.7 & 6.8 & 7.3 \\
\hline $\begin{array}{l}\text { Education expenditures as a share of } \\
\text { national public expenditures, } \%\end{array}$ & MF & 15.2 & 18.5 & 20 & 20.1 & 19.3 & 19.4 \\
\hline $\begin{array}{l}\text { Share of total primary education } \\
\text { expenditures in the total education } \\
\text { expenditures from the national public } \\
\text { budget, } \%\end{array}$ & MF & 1.3 & 1.5 & 1.4 & 1.3 & 1.4 & 1.3 \\
\hline $\begin{array}{l}\text { Student/Teacher ratio (day schools, } \\
\text { gymnasiums, lyceums) }\end{array}$ & NBS & 15 & 15 & 14 & 14 & 13 & ... \\
\hline \multicolumn{8}{|l|}{ 15. Health care } \\
\hline $\begin{array}{l}\text { Infant mortality rate (under } 1 \text { year per } \\
1000 \text { newborn) }\end{array}$ & NBS & 18.3 & 16.3 & 14.7 & 14.4 & 12.2 & 12.2 \\
\hline in urban areas & NBS & 19.3 & 16.9 & 15.1 & 13.9 & 12.0 & $\ldots$ \\
\hline in rural areas & NBS & 17.8 & 16.0 & 14.4 & 14.6 & 12.3 & $\ldots$ \\
\hline $\begin{array}{l}\text { Under } 5 \text { mortality rate (per } 1000 \\
\text { newborn) }\end{array}$ & NBS & 23.3 & 20.3 & 18.2 & 17.8 & 15.3 & $\ldots$ \\
\hline in urban areas & NBS & 23.1 & 19.8 & 17.6 & 16.1 & 14.2 & $\ldots$ \\
\hline in rural areas & NBS & 23.5 & 20.6 & 18.5 & 18.8 & 16.0 & $\ldots$ \\
\hline $\begin{array}{l}\text { Maternal mortality rate (per } 100000 \text { live- } \\
\text { born) }\end{array}$ & NBS & 27.1 & 43.9 & 28 & 21.9 & 23.5 & 18.6 \\
\hline in urban areas & NBS & 23.6 & 47.8 & 23.5 & 15.6 & 7.1 & $\ldots$ \\
\hline in rural areas & NBS & 28.9 & 41.8 & 30.5 & 25.3 & 33.0 & $\ldots$ \\
\hline $\begin{array}{l}\text { Mortality rate associated with TB (deaths } \\
\text { per } 100000 \text { persons) }\end{array}$ & MSPS & 16.93 & 15.01 & 15.76 & 15.60 & 18.70 & 18.50 \\
\hline AIDS morbidity (per 100000 persons) & $\begin{array}{l}\text { NBS } \\
\text { (based on } \\
\text { MHSP) }\end{array}$ & 0.1 & 0.2 & 1.2 & 1.4 & 1.4 & 1.6 \\
\hline HIV carriers (per 100000 persons) & $\begin{array}{l}\text { NBS } \\
\text { (based on } \\
\text { MHSP) }\end{array}$ & 4 & 6 & 5 & 5 & 6 & 8 \\
\hline HIV/AIDS prevalence, $\%$ & MHSP & 4.06 & 4.06 & 5.46 & 4.66 & 6.20 & 8.53 \\
\hline
\end{tabular}




\begin{tabular}{|c|c|c|c|c|c|c|c|}
\hline Monitoring Indicators & Source & 2000 & 2001 & 2002 & 2003 & 2004 & 2005 \\
\hline $\begin{array}{l}\text { HIV prevalence among } 15-24 \text { year-old } \\
\text { people, (per } 100000 \text { persons) }\end{array}$ & MHSP & 11.9 & 10.9 & 9.7 & 6.1 & 9.7 & 11.7 \\
\hline $\begin{array}{l}\text { Share of children under } 2 \text { years } \\
\text { immunized against: }\end{array}$ & \multirow{4}{*}{$\begin{array}{l}\text { NBS } \\
\text { (based on } \\
\text { MHSP) }\end{array}$} & & & & & & \\
\hline measles, \% & & 98.6 & 99.4 & 99.1 & 99.4 & 99.2 & 99.1 \\
\hline $\begin{array}{l}\text { diphtheria, convulsive cough, and } \\
\text { tetanus, } \%\end{array}$ & & 97.6 & 98.5 & 98.6 & 98.6 & 98.1 & 99.0 \\
\hline poliomyelitis, \% & & 97.6 & 98.5 & 98.6 & 98.6 & 98.3 & 99.4 \\
\hline Number of visits to physicians, per capita & $\begin{array}{l}\text { NBS } \\
\text { (based on } \\
\text { MHSP) }\end{array}$ & 5.3 & 6.2 & 6.8 & 6.4 & 5.5 & $\ldots$ \\
\hline $\begin{array}{l}\text { Health care expenditures from national } \\
\text { public budget as a share of GDP, } \%\end{array}$ & MF & 3.2 & 3.2 & 4.0 & 4.0 & 4.2 & 4.3 \\
\hline $\begin{array}{l}\text { Health care expenditures as a share of } \\
\text { national public budget expenditures, } \%\end{array}$ & MF & 8.9 & 10.0 & 11.8 & 12.0 & 11.9 & 11.3 \\
\hline $\begin{array}{l}\text { Share of expenditures for primary care in } \\
\text { total health care expenditures, } \%\end{array}$ & MHSP & $\ldots$ & 18.6 & 16.7 & 17.0 & 18.0 & 20.8 \\
\hline $\begin{array}{l}\text { Share of expenditures for preventive } \\
\text { medicine in total health care } \\
\text { expenditures, } \%\end{array}$ & MHSP & 3.2 & 4.8 & 4.2 & 3.7 & 4.7 & 4.1 \\
\hline $\begin{array}{l}\text { Share of persons with hepatitis „B” (per } \\
100000 \text { persons) }\end{array}$ & MHSP & 17.2 & 15.9 & 14.4 & 11.6 & 10.6 & 9.6 \\
\hline $\begin{array}{l}\text { Share of funds for health insurance in } \\
\text { total allocations for health }\end{array}$ & MHSP & - & - & - & 1.1 & 70.2 & 74.0 \\
\hline $\begin{array}{l}\text { Number of health emergency calls per } \\
1000 \text { residents }\end{array}$ & MHSP & $\ldots$ & 144 & 152 & 162 & 169 & 253.9 \\
\hline Urban areas & MHSP & 256.2 & 269.1 & 268.7 & 259.8 & 293.7 & 323.7 \\
\hline Rural areas & MHSP & 55.7 & 69.6 & 87.3 & 104.5 & 160.7 & 204.7 \\
\hline \multicolumn{8}{|l|}{ 16. Social insurance and assistance } \\
\hline $\begin{array}{l}\text { Ratio of monthly pension to average } \\
\text { monthly salary, \% }\end{array}$ & MHSP & 21.1 & 25.8 & 24.1 & 24.5 & 30.5 & 30.1 \\
\hline Real growth of average pension, $\%$ & MHSP & 87 & 150 & 114 & 113 & 138 & 107 \\
\hline $\begin{array}{l}\text { Ratio of pensioners to employees in } \\
\text { economy, } \%\end{array}$ & $\begin{array}{l}\text { NBS } \\
\text { (based on } \\
\text { MHSP) }\end{array}$ & 48 & 47 & 45 & 48 & 49 & ... \\
\hline $\begin{array}{l}\text { Social Assistance expenditures as a share } \\
\text { of GDP, } \%\end{array}$ & MF & 10.0 & 8.3 & 9.9 & 9.3 & 10.2 & 11.5 \\
\hline
\end{tabular}




\begin{tabular}{|c|c|c|c|c|c|c|c|}
\hline Monitoring Indicators & Source & 2000 & 2001 & 2002 & 2003 & 2004 & 2005 \\
\hline $\begin{array}{l}\text { Social Assistance expenditures as a share } \\
\text { of national public budget, } \%\end{array}$ & MF & 27.6 & 26.4 & 28.8 & 28.1 & 29.1 & 30.4 \\
\hline $\begin{array}{l}\text { Distribution of social benefits (without } \\
\text { pensions) for consumption quintiles I and } \\
\text { V per adult equivalent (\%) }\end{array}$ & NBS $^{i}$ & & & & & & \\
\hline quintile I & NBS $^{i}$ & & & 8.0 & 13.1 & 13.7 & $\ldots$ \\
\hline quintile $\mathrm{V}$ & NBS $^{i}$ & & & 37.3 & 24.8 & 24.8 & $\ldots$ \\
\hline \multicolumn{8}{|l|}{ 17. Labor market } \\
\hline $\begin{array}{l}\text { Unemployment rate (according to ILO), } \\
\%\end{array}$ & NBS & 8.5 & 7.3 & 6.8 & 7.9 & 8.1 & 7.3 \\
\hline in urban areas & NBS & 15.7 & 13.8 & 12.1 & 12.2 & 11.9 & 11.2 \\
\hline in rural areas & NBS & 3.4 & 2.7 & 3.0 & 4.5 & 5.0 & 4.0 \\
\hline $\begin{array}{l}\text { Average nominal monthly salary per } \\
\text { employee in the economy, MDL }\end{array}$ & NBS & 408 & 544 & 692 & 891 & 1103 & 1320 \\
\hline $\begin{array}{l}\text { Real salary index, (year } 2000 \text { is used as } \\
\text { base year) }\end{array}$ & NBS & 100.0 & 129.6 & 146.9 & 169.8 & 187.0 & 199.8 \\
\hline $\begin{array}{l}\text { Average length of unemployment, } \\
\text { months }\end{array}$ & NBS & 25 & 26 & 27 & 23 & 22 & 24 \\
\hline Long-term unemployment rate, ILO, \% & NBS & 60.4 & 58.0 & 59.6 & 48.3 & 44.8 & 48.9 \\
\hline $\begin{array}{l}\text { Economic dependency ratio (inactive and } \\
\text { unemployed population per } 1000 \text { active } \\
\text { employed persons), } \%\end{array}$ & NBS & 1,408 & 1,428 & 1,413 & 1,671 & 1,745 & 1,733 \\
\hline \multicolumn{8}{|l|}{ 18. Youth policy } \\
\hline $\begin{array}{l}\text { Registered youth unemployment, ILO, } \\
\text { thousand persons }\end{array}$ & NBS & 37.8 & 35.5 & 32.1 & 30.5 & 30.8 & 28.5 \\
\hline $\begin{array}{l}\text { Registered youth unemployment (15-24 } \\
\text { years), ILO, \% }\end{array}$ & NBS & 15.8 & 16.3 & 15.2 & 18.1 & 19.7 & 18.7 \\
\hline \multicolumn{8}{|l|}{$\begin{array}{l}\text { Rate of enrolment in education of } 15-24 \\
\text { year-old persons, } \%\end{array}$} \\
\hline & NBS & 34.2 & 35.4 & 37.5 & 38.7 & 40.5 & $\ldots$ \\
\hline
\end{tabular}

${ }^{\mathrm{i}}$ Calculated by JPPM. Ministry of Economy and Trade; NBS will perform calculations after the approval of methodological principals by the Government.

ii January - September.

${ }^{\text {iii }}$ According to data on large enterprises included in monthly statistical study. 


\section{ANNEX C: Guidelines on the process of monitoring, evaluation and reporting of the implementation of the Economic Growth and Poverty Reduction Strategy Paper (EGPRSP) and the Millennium Development Goals (MDGs)}

\section{Background}

1. These guidelines were developed in order to ensure an objective and operational assessment of economic and social processes, create a framework for a continuous improvement of the strategic management tools, establish the informational-analytical base to solve practical problems at central and local level, and to ensure the interaction between central and local public authorities in the process of implementation, monitoring, evaluation and reporting of the main development strategies/programmes (in particular, the Economic Growth and Poverty Reduction Strategy Paper (EGPRSP) and the Millennium Development Goals (MDGs).

2. Monitoring is a continued function of systematic collection of data for the EGPRSP and MDG indicators and of information about the implementation of actions and policies to provide decisionmakers and stakeholders with information on the progress in the achievement of development strategy/programme objectives and the efficient use of allocated resources.

3. Evaluation is systematic and objective analysis of development strategies/programmes, aimed at identifying the relevance and the achievement of their objectives, their efficiency, effectiveness, impact and sustainability.

4. Participants to the monitoring and evaluation process are central and local public authorities, other organizations responsible for the implementation of actions stipulated in the EGPRSP/MDG, and other stakeholders.

5. With a view of institutionalizing the functions of monitoring and evaluation of the main development strategies/programmes, policy and analysis units shall be created within ministries, agencies, and other institutions of the central public administration. At the local level, monitoring shall be conducted by the economic divisions of the municipal/rayon councils.

6. The coordination of the monitoring process at the interministerial and national level will be carried out by the Ministry of Economy and Trade (MET).

7. The outputs of monitoring and evaluation are the reports on the EGPRSP/MDG implementation, which serve as basis for the development and improvement of implementation policies, mechanisms and tools to achieve the objectives of such strategies.

8. The reporting shall be made:

i. Quarterly and annually, for the EGPRSP

ii. Once in two years, for the MDG

9. The components of the monitoring and evaluation process are:

- Monitoring of financial coverage

- Monitoring of trends

- Impact evaluation.

10. Institutions of the central and local public administration shall develop, on the basis of EGPRSP/MDG, annual action plans and present them to the Government Administration and the Ministry of Economy and Trade by 15 January of the reporting year. 


\section{Monitoring of financial coverage}

11. Monitoring of financial coverage of priority actions is carried out by stakeholders, in line with Annex 6 to the EGPRSP:

- Consequently for each year;

- By financial sources:

i. from budgetary resources;

ii. from credits, donations, technical assistance.

12. Analysis of financial coverage of priority actions is carried out on a permanent basis by participants to the process of monitoring and evaluation jointly with the Ministry of Finance. The results of the analysis of financial coverage for the previous year shall be submitted to the Ministry of Economy and Trade by 15 January of the year that follows the reporting year.

13. Analysis of financial coverage of priority actions at the regional level is carried out by the local public authorities within the approved branch programmes and by financial sources.

\section{Monitoring of trends}

14. Monitoring of the implementation process and trends is an activity that consists of (i) collection and analysis of indicators which characterize trends in the field of economic growth and poverty reduction (Annex 5) and (ii) analysis of implementation of the Policy Matrix (Annex 6).

15. Policy and analysis units carry out analysis of trends in the sector/territory in terms of the EGPRSP objectives and, based on this, submit reports to the MET:

- quarterly, by the 15 th day of the month following the reporting month;

- annually, by 15 January of the year following the reporting year.

16. National Bureau of Statistics, Ministry of Finance, Ministry of Health and Social Protection, Ministry of Industry and Infrastructure, Ministry of Ecology and Natural Resources, and NBM submits indicators from Annex 5 to the MET, on a quarterly basis, not later than the 25th day of the month following the reporting period.

17. Ministry of Economy and Trade shall create and maintain a pilot database (DevInfo) which will contain quantitative indicators collected throughout the trends monitoring process.

18. DevInfo ${ }^{1}$ is a database system for the consolidated monitoring of quantitative indicators classified by objectives and targets related to one or more development strategies/programmes.

19. Ministry of Economy and Trade shall update the database with quantitative trends monitoring indicators on a quarterly basis.

\footnotetext{
${ }^{1}$ DevInfo System was developed by UNICEF, adopted by the UN and was implemented for over 80 national databases.
} 


\section{Policy Impact Evaluation}

20. The impact of sector policies on the achievement of EGPRSP objectives shall be evaluated by the stakeholders in the framework of policies and actions stipulated in action plans, taking into account the EGPRSP priorities.

21. The results of policy impact evaluation shall reflect:

- the degree of compliance of policy outputs with strategy priorities;

- policy strengths and weaknesses.

\section{Outputs of monitoring and evaluation}

22. The outputs of monitoring and evaluation are a system of reports on the implementation of EGPRSP/MDG and socio-economic development of the country:

- Biennial MDG Report

- Annual Report on EGPRSP Implementation. The structure of the report shall be specified each year.

- Anual Poverty Report

- Quarterly EGPRSP Reports

- Annual Reports on the socio-economic situation in the sector/territory.

- Database with quantitative trends monitoring indicators, updated on a quarterly basis.

23. Outputs of monitoring and evaluation (reports and database with quantitative trends monitoring indicators) will be made public. 